\title{
The double burden of malnutrition : a study of food security, physical activity and nutritional status among women and children in Narok County, Kenya
}

Citation for published version (APA):

Keino, S. J. (2014). The double burden of malnutrition : a study of food security, physical activity and nutritional status among women and children in Narok County, Kenya. [Doctoral Thesis, Maastricht University]. Universitaire Pers Maastricht. https://doi.org/10.26481/dis.20141001sk

Document status and date:

Published: 01/01/2014

DOI:

10.26481/dis.20141001sk

Document Version:

Publisher's PDF, also known as Version of record

Please check the document version of this publication:

- A submitted manuscript is the version of the article upon submission and before peer-review. There can be important differences between the submitted version and the official published version of record.

People interested in the research are advised to contact the author for the final version of the publication, or visit the DOI to the publisher's website.

- The final author version and the galley proof are versions of the publication after peer review.

- The final published version features the final layout of the paper including the volume, issue and page numbers.

Link to publication

\footnotetext{
General rights rights.

- You may freely distribute the URL identifying the publication in the public portal. please follow below link for the End User Agreement:

www.umlib.nl/taverne-license

Take down policy

If you believe that this document breaches copyright please contact us at:

repository@maastrichtuniversity.nl

providing details and we will investigate your claim.
}

Copyright and moral rights for the publications made accessible in the public portal are retained by the authors and/or other copyright owners and it is a condition of accessing publications that users recognise and abide by the legal requirements associated with these

- Users may download and print one copy of any publication from the public portal for the purpose of private study or research.

- You may not further distribute the material or use it for any profit-making activity or commercial gain

If the publication is distributed under the terms of Article $25 \mathrm{fa}$ of the Dutch Copyright Act, indicated by the "Taverne" license above, 


\section{The Double Burden of Malnutrition:}

A study of food security, physical activity and nutritional status among women and children in Narok County, Kenya 
(C) Susan J. Keino, Maastricht 2014

ISBN 9789461593665

Production: Datawyse | Universitaire Pers Maastricht 


\title{
The Double Burden of Malnutrition: A study of food security, physical activity and nutritional status among women and children in Narok County, Kenya
}

\author{
DISSERTATION \\ to obtain the degree of Doctor at Maastricht University \\ on the authority of the Rector Magnificus, Prof. dr. L.L.G. Soete \\ in accordance with the decision of the Board of Deans, \\ to be defended in public on \\ Wednesday October 1, 2014 at 16.00 hours.
}

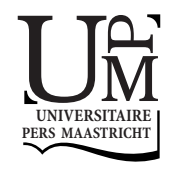




\section{Promotor}

Prof. dr. H.W van den Borne

\section{Co-promoter}

Dr. G. Plasqui

\section{Assessment Committee}

Prof. dr. N.K. de Vries (Chair)

Prof. dr. ir J. Brug (VUMC, EMGO Instituut)

Prof. dr. S. Kremers

Prof. dr. N. Röling (Wageningen University)

Prof. dr. A. Schols

Financial support by the Netherlands Fellowship Programme (NFP) administered by Netherlands organization for international cooperation in higher education (NUFFIC) is greatly acknowledged. 


\section{Table of Contents}

CHAPTER 1 General Introduction 7

CHAPTER 2 Determinants of stunting and overweight among young children 23 and adolescents in Sub-Saharan Africa

CHAPTER 3 Household food insecurity and overweight among women in Kenya 45

CHAPTER 4 Is overweight found among the food insecure? A study of 63 prevalence and risk factors of malnutrition among children in Kenya

CHAPTER 5 Body composition, water turnover and physical activity in women 83 in Narok County

CHAPTER 6 Impact of physical activity and food security on pregnancy outcomes among women in Narok County, Kenya

CHAPTER 7 Body composition, body mass index, waist -hip ratio, waist circumference and overweight among Kenyan women

CHAPTER 8 General discussion

APPENDIX Summary

Valorization

Thank you

List of Publications

Curriculum Vitae 

CHAPTER 1

General introduction 


\section{Global trends in overweight and under-nutrition}

In the twenty first century, food insecurity, hunger and malnutrition remain the most devastating problems among the world's poor (1). The Food and Agricultural Organization (FAO) reports that more than 870 million people were chronically undernourished in 2010-2012 and the vast majority of these are in the developing countries (2). Most of the under-nourished people of the world are in Asia and Africa and most affected are children below the age of five years. Despite gains in food crop productivity and agricultural development in the last fifty years across the globe, under-nutrition has persisted in sub-Saharan Africa (3). According to the United Nations (UN) reports, stunting is preventing at least $\mathbf{2 0 0}$ million children from reaching their full development and growth potential, under-nutrition is the cause for an estimated 35 percent of all deaths among children under five years of age, and maternal and child undernutrition accounts for 11 percent of the global disease burden (4-6). While undernutrition continues to be a problem for policy makers, over-nutrition has been reported among countries that are still battling hunger and under-nutrition. The rising prevalence of overweight and obesity among developing countries has made combating the double burden of malnutrition a pressing challenge and overweight has increased by 100 percent in some countries in the past 30 years (6).

The World Health Organization (WHO) reports that one-third of the 1.5 billion overweight people in the world are obese (7). Overweight and obesity are defined as abnormal or excess weight accumulations that impair health (8). It is estimated that in 2015, 2.3 billion adults will be overweight and 700 million adults will be obese (9). Of the 43 million overweight children in the world, 35 million of them are in the developing countries and the largest numbers are in Asia, however, the fastest growth rates are in Africa (7). Increasing rates of overweight and obesity are being identified in subSaharan Africa (SSA), especially among women and urban populations (10-12). The estimated prevalence of childhood overweight and obesity in Africa in 2010 was $8.5 \%$ and it is expected to reach $12.7 \%$ in 2020 (13)

There is a growing concern over the increasing number of overweight people in developing countries particularly in Africa. Overweight and obesity have always been regarded as diseases of the west and Africa has always struggled with under-nutrition and persistent household food insecurity. The increase in the prevalence of overweight and obesity in the developing countries is largely attributed to lifestyle changes that are consistent with countries in transition. These changes are associated with industrialization, economic development (14), globalization and urbanization(15). Factors characteristic to countries in transition are dietary changes, changes in nutritional status and disease patterns, as well as changes in life expectancy (14). Dietary changes include adopting unhealthy eating behaviors as a result of influx and penetration of 
supermarkets that sell highly processed foods. There is a shift from a traditional food system to modern food distribution and sales. Traditional food systems entailed one growing food and locally processing it (for example using grinding stones to mill grains and fermentation of milk and grains). The shift in the food environment may enhance intake of processed, lower quality foods (16). The concern regarding food processing meshes well with the vast shift away from consumption of legumes, coarse grains high in fiber, fruits and vegetables to consumption of refined grains, total fat, saturated fat, high sugar and high salt intakes (15). Nutritional status has changed from persistent underweight, stunting and wasting to overweight and obesity among children and adults and more so a combination of under-nutrition and over-nutrition among children resulting in the now common phrase of 'double burden of malnutrition.' With the changes in dietary patterns and reduced physical activity, there is an increase in numbers of overweight and obesity particularly among the poor and the urban and rural populations (17). Physical inactivity has been reported in many developing countries, particularly in Africa among the urban populations (18). In addition, there has been a global increase in prevalence of chronic non-communicable diseases (NCDs) such as hypertension, stroke, coronary heart diseases, and Type 2 diabetes and studies have demonstrated a strong association between overweight and chronic NCDs (15) including some types of cancers. With the increase of non-infectious diseases and the high prevalence of chronic and degenerative diseases, there have been increased mortality and morbidity and disability associated with these diseases. Thus, life expectancy has been dramatically shortened in these developing countries undergoing economic and nutrition transition $(14,19)$. In these countries in transition, women work away from home-leaving less time for growing and producing food and therefore rely on ready foods available in the supermarkets and fast food chains (20). There is also an increase in sedentary activities associated with urban jobs and increase in the availability of television and computers (21) and reduced energy expenditure which has pushed the overweight and obesity numbers upwards.

\section{Malnutrition in Kenya and their risk factors among women and children}

The Kenya Demographics Health Survey (KDHS) report of 2008-2009 indicates that 35\% of children under five years of age are stunted, while the proportion of severely stunted children was $14 \%$ (22). Underweight among children under five years of age was $16 \%$ and the proportion of severely underweight children was $4 \%$. Wasted children aged below five were $7 \%$ and $2 \%$ were severely wasted. Regionally, the North Eastern province has the highest proportion of children exhibiting severe wasting (8\%), while the Eastern province has the highest levels of stunting among children (44\%) (23). In 
rural areas higher rates of under-nutrition are reported compared to urban areas, while in poor households also more underweight is observed compared to richer households (22). Underweight and wasting are negatively associated with education level, wealth and nutritional status of the mother (22). Levels of stunting, wasting and underweight are declining across Kenya except in drought prone areas, while overweight is on the increase. Overweight has not been reported very much in Kenya, however, in a government report of 2012, the prevalence of overweight among preschool children was reported to be $18 \%$, while obesity was $4 \%(23)$. Overweight is associated with imbalance between energy intake and expenditure, lack of physical activity and genetic factors $(24,25)$. In children, being overweight has been known to impact on self-esteem, possibility of developing juvenile diabetes and other diseases association to excess weight.

The mean body mass index (BMI) among women aged $15-49$ is 23 and $12 \%$ of the women are considered thin (BMI<18.5) (22). A UNICEF report of 2006 indicates that there was high malnutrition among pregnant women in Kenya and in some regions the prevalence was higher than that of children especially in the drought prone areas (26). The proportion of overweight and obesity among women has increased from $23 \%$ in 2003 to $25 \%$ in 2008-2009 $(22,23)$. Levels of overweight increase with age, education levels and wealth (22). Regional disparities also cannot be ignored, with Nairobi Province reporting the highest number of overweight women at $41 \%$ and $11 \%$ with the lowest reported in North Eastern Province (22).

\section{Linking childhood under-nutrition and infant feeding to overweight later in life}

There is a concern over the association between stunting among children and overweight later in life. Research has shown that rapid growth during infancy as a result of intervention after a period of stunting and underweight may result in overweight later in childhood and into adulthood (27). Concern therefore, has been raised about the promotion of rapid weight gain in children that are malnourished (27). In addition high birth weight also increases the likelihood of childhood overweight and obesity later in life (28). Breastfeeding and late introduction of solid foods is moderately protective against childhood overweight whereas early introduction of solid foods had an impact on childhood overweight by increasing the probability of one becoming overweight (28). Rapid infant weight gain has been associated with increased overweight later in life $(29,30)$. Systematic reviews estimate that rapid growth in the first one to two years is associated with odds ratios of later obesity ranging from 1.4 to $5.7(31,32)$. A study by Druet et al. suggests that regardless of its causal role, rapid weight gain adds 
substantially to the prediction of childhood obesity together with several factors that include birth weight, infant weight gain, mothers' body mass index (BMI) and sex of the child. Rapid weight gain and faster growth during childhood is therefore associated with increased risk of overweight later in life suggesting that interventions aimed at inducing childhood growth at an optimum rate can prevent obesity later in adulthood (31).

\section{Association between food insecurity, physical inactivity and overweight in Africa}

The association between overweight/obesity and food insecurity status is now well supported in the literature and has been identified in developed countries like in the United States of America (33). Some studies indicate that a relationship exists between low income households and obesity, as well as food insecurity and childhood and adolescent overweight/obesity are associated (34-37). In addition, a relationship is also seen in overweight/obesity among women and household food insecurity (38). In developing countries a study in Colombia indicated no association between food insecurity and overweight among women (39), while in Brazil overweight in adolescents and severe food insecurity were found to be associated (40).

Studies relating food insecurity to overweight and obesity among women and children in Africa are limited. A study in Kenya by Steyn (15) links the association between food insecurity to overweight to a theory of behavior proposed by Basiotis which indicates that when low income households are faced with uncertainty about food, they buy less expensive foods and less variety in food products. A further decrease in income leads to reduced purchases of food within the home and therefore food intake especially for children will also reduce (41). Faced with the inability to grow food, or failure of crops and/or inadequate income to purchase food, families will likely opt for the cheapest costs per calorie from the available choices (42). In most cases these are energy dense, sugary and fatty foods that are cheap and easily available and that may predispose one to weight gain.

As a result of the impact of food insecurity, there is a need for strategies aimed at reducing food insufficiency within households. Endorsing strategies directed at reducing food insecurity in these countries could directly reduce the prevalence of stunting and at the same time indirectly reduce the prevalence of overweight and the consequent chronic Non-Communicable Disease (NCDs) (42). Food security will enable households to select foods that are less fatty, not energy dense and therefore do not promote weight gain. 
Research has shown that physical inactivity and overweight are on the increase in Africa (43). Weight gain as a result of physical inactivity and obesity is a risk factor for many chronic diseases such as hypertension, heart diseases, cancer etc. Physical inactivity is increasing due to automation (44), and in Africa more and more people, particularly in the urban areas use cars as means of transport. Many households own television sets and this has promoted inactivity and sitting for a long time. Women and children who stay home the whole day are affected by this. Physical activity in Africa is normally achieved through the usual day-to-day chores and not many people partake in xercise for fitness except professional athletes.

\section{Conceptual and analytical Framework}

This study focuses on two opposite forms of malnutrition: under-nutrition and overnutrition and to understand both, we have applied two conceptual frameworks to develop an analytical framework.

The first framework is the United Nation Children's Education Fund (UNICEF) conceptual framework on child malnutrition (Figure 1) and the second is the conceptual framework on etiology of overweight and obesity in Africa (Figure 2) by Scott et al.(45).

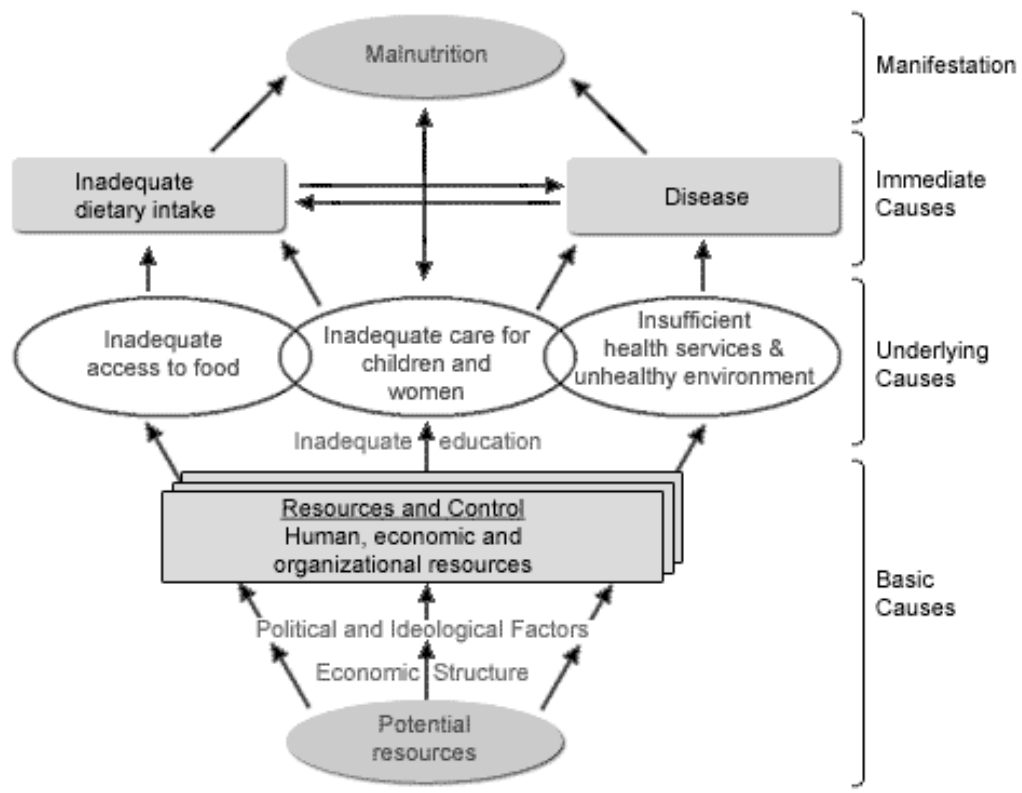

Figure 1: The UNICEF Conceptual framework on causes of malnutrition among children and women The following conceptual framework that explains the etiology of overweight and obesity in Africa is adapted from a study by Scott et al. (45). 


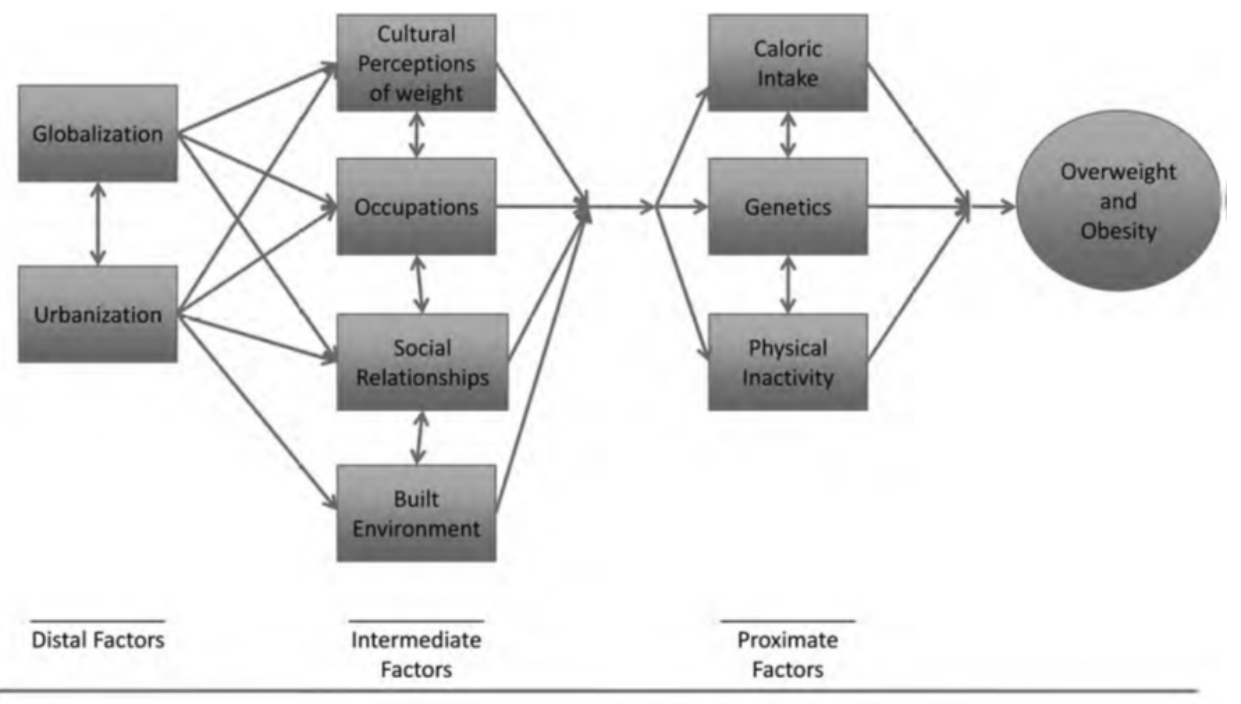

Upstream

Downstream

Figure 2: The Scotts et al. (45) causality continuum model for obesity in sub-Saharan Africa.

The conceptual framework by UNICEF summarizes the causes of malnutrition into immediate causes, underlying causes and basic causes. Immediate causes of undernutrition in this case are inadequate intake of food and diseases. When food is insufficient, children do not get enough to eat and therefore become undernourished. Disease may result in weight loss and wasting due to poor appetite, vomiting, and diarrhea from infections. Fever has also been known to be associated with wasting. To incorporate overweight in this conceptual framework, the immediate causes of malnutrition would include inadequate intake of quality foods. Quality would encompass foods that are balanced nutritionally.

The underlying causes include insufficient health care and unhealthy environment which may include poor screening services at the health facilities and poor intervention measures put in place to deal with under-nutrition and overweight. Whereas overweight may occur if an 'obesogenic' environment is provided to an individual i.e. a cheaply available high fat and high sugar diet which is easily accessible as street food or in the retail and supermarkets. This includes ready to eat packed foods that may not require preparation. Another underlying factor in the UNICEF framework includes inadequate access to food, which in this case is one of the dimensions of food insecurity. Food security has four dimensions: adequate access, availability, utilization, and stability (46). Thus, to explain malnutrition, we would use food insecurity as whole and 
not just one dimensions for our study to explain causes of under-nutrition and overweight/obesity.

In the second conceptual framework by Scott et al. (45) there are distal, intermediate and proximate forces that interact to bring about the increase in overweight and obesity in sub-Saharan Africa. The distant forces include globalization and urbanization, while intermediate forces are sedentary occupations, cultural perceptions of weight, built environments and social relationships. The proximate forces known to cause overweight/obesity include physical inactivity, genetic factors and caloric intake. Genetic factors play a role in the general physical growth and development of an individual (47). In the continuum, globalization forces can impact on occupation, in that with improved economies, occupations may change from labor intensive to high inactivity which may result in overweight, or with globalization also diets may change to promote overweight.

\section{Consequences \& impact of malnutrition (under-nutrition and over-nutrition)}

Consequences of malnutrition are varied and far reaching (1). It is estimated that 200 million children in developing countries fail to achieve their developmental and cognitive potential due to exposure to chronic poverty and its co-factors $(48,49)$. Undernutrition can retard growth and development, reduce physical activity, impair resistance to infection, increase morbidity and disabilities which may lead to death (1). In pregnant women, under-nutrition can lead to increased prevalence of anemia, increased pregnancy and delivery problems, increased intrauterine growth retardation, low birth weight, congenital malformation and other birth defects, perinatal mortality, and poor health. Persistent under-nutrition can lead to reduced productivity, reduced physical activity and reduced intellectual performance (1).

The relationship between early stunting in children and later overweight/obesity raises concerns regarding the rising metabolic diseases (50). Stunting in children has been associated with increased risk of overweight and obesity later in life (51). Another study indicated that stunting during childhood is associated with obesity during adulthood (52). Pediatric obesity and adult short stature are risk factors for metabolic syndrome and metabolic diseases in adulthood (50). Overweight generally is a known risk factor for the development of non-communicable diseases (8). Overweight in children has serious health consequences including early onset of diabetes, high blood pressure, heart disease and certain cancers later in life $(53,54)$. In addition, WHO indicates that childhood obesity is also associated with higher chance of obesity, premature death and disability in adulthood (8). 


\section{Previous studies on under-nutrition and over-nutrition among women and children in Kenya}

Women and children are more vulnerable to under-nutrition due to biological reasons. Women have enormous responsibility of childbirth compounded with household responsibilities of caring for the children and food provision. Children (0-5yrs) have a high growth velocity and consequently have a need for high nutrient intake to keep up with the growth. The percentage of overweight or obese preschoolers had more than doubled in Africa from 4\% in 1990 to $8.5 \%$ in 2010 (13). A study that compared the prevalence of overweight between Kenyan and South African (SA) women found the prevalence of overweight almost the same in the two countries (Kenya 29.1\%; SA: $27.5 \%)$ whereas obesity was higher in SA (27.4\%) than in Kenya (14.2\%).

In a study among women in four regions in Kenya (15), it was found that women were significantly more likely to be overweight or obese if they had a higher level of education, were in the high income group and lived in a household where there was a low room density, tap water, flush toilet, electricity or gas. Underweight women were more likely to come from a female headed household with low level of education, low income and no telephone in the house.

There are a number of studies done in Kenya to assess the prevalence of undernutrition and some studies have been conducted on over-nutrition. Several of these studies have used secondary data from previous Demographic and Health surveys (DHS). A study by Masibo et al (55) reports on the emerging pattern in Kenya of the dual burden of malnutrition within the same household whereby overweight mothers were reported to have stunted children. This confirms the findings from Gewa (56) who also reported on data from DHS. The study by Gewa also reported on overweight/obese children who also had overweight or obese mothers. The prevalence of overweight among pre-school going children in Kenya were reported to be $18 \%$ and $4 \%$ were obese $(22,23,55)$. A significant finding in the study by Gewa was that overweight among children decreased with age and a higher percentage of the overweight were found in urban areas, which was also consistent with other studies that have reported overweight to be high in urban areas in sub-Saharan Africa (SSA). A population based study in Tanzania found higher prevalence of overweight in the urban than rural areas (57) and a study on eight countries in SSA also reports higher urban overweight and more so among the low socio economic status group (58). The study by Gewa and two other studies reported that longer breastfeeding had an inverse relationship with childhood overweight/obesity $(56,59,60)$. These studies show that children that were breastfed for long periods had lower odds of being overweight. Breastfeeding also had a protective effect against under-nutrition such as stunting and underweight. Younger children are more overweight than their older counterparts $(56,61)$. 


\section{Gaps identified in the studies in Kenya}

Studies that showed global trends of overweight have used data gathered from the national surveys; however the studies in developing countries show limitations in that most surveys have shown estimates from a group of countries (East Africa, Asia etc) and these estimates were affected by countries with large populations (13). In addition many countries have not yet conducted their health surveys and thus prevalence may not be known. In Kenya this is done every five years. Another limitation on national surveys is that surveys were not done randomly across geographical regions, but strategic cluster sites were used in some and thus bias may have been introduced. In Kenya, some studies done previously have also reported on data from health surveys (55, 62) done nationally, which were subject to the limitations explained above. None of the studies on overweight in women and children were conducted in an arid and semiarid area. Most studies that report on overweight were conducted in urban areas for example Nairobi (63). In addition many studies on overweight in Kenya and other parts of the world may not be easily comparable due to the different cut-off points and reference standards for malnutrition used. Many countries now have their own national reference centile charts for BMI for age (64)

\section{Study objectives 2}

- To determine the prevalence and risk factors of malnutrition(overweight, stunting, wasting and underweight) among children in Narok County- Kenya.

- To assess food insecurity and its effects on maternal and child malnutrition.

- To assess physical activity, water turnover and body composition.

- To assess physical activity and food insecurity among pregnant women and their impact on pregnancy outcomes.

\section{Study area}

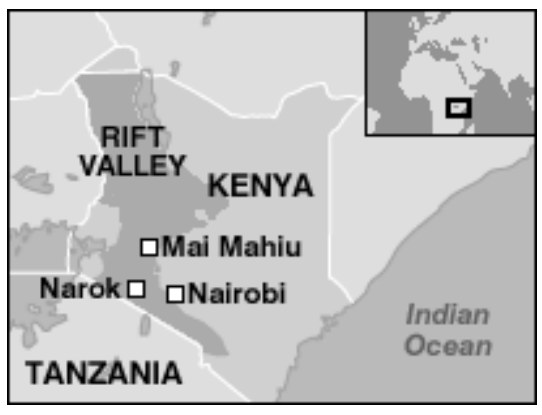

The study was carried out in Narok County, Kenya. Narok County is located on the South Rift Valley to the north of Tanzania, it borders six counties with Nakuru to the North, Bomet, Nyamira and Kisii to the North West, Kajiado to the East and Migori to the West. The area is $17,944\left(\mathrm{Km}^{2}\right)$ 
Temperatures range from minimum of 8 to a maximum of 28 degrees centigrade. It has two rainy seasons with average rainfall ranging from 500 to $1,800 \mathrm{~mm}$ per annum. The road network within the county has improved over the years. Bitumen Surface covers $172 \mathrm{Km}$, Gravel Surface covers $162 \mathrm{Km}$ and Earth Surface covers a total of 205.5 $\mathrm{Km}$. The population of Narok is approximately 850,920. Population density is approximately 47 people per $\mathrm{Km}^{2}$ and with a population growth rate of $3.3 \%$. The population distribution according to age group is $0-14$ years is $53 \%, 15-64$ years are $45 \%$ and over 65 years are $2 \%$. Narok town is the county administrative and economic capital. The constituencies within Narok county are Narok North, Narok south and Kilgoris, while the districts are Narok North, Narok South, Transmara East, Transmara West/Dikirr.

The poverty level in the district is high compared to other counties in Kenya, 12\% of the population lives below the poverty line. The main agricultural products are Wheat, Barley, Maize, and Livestock.

In education, the teacher ratio for public primary schools is 33 to 1 with a total enrollment of 175,409 at the rate of $83 \%$ of the boys and $73 \%$ of the girls are enrolled. In secondary schools total enrollment is 13,852 , at an enrollment rate of $20 \%$ for boys and $15 \%$ for girls and tertiary institutions are 8 youth polytechnics and 1 university.

Narok County has 84 health dispensaries, 16 health centers, 1 Sub district and 3 district hospitals. The doctor to patient ratio is $1: 100,953$, the infant mortality rates and under-five mortality rates are not known in the district but the provincial data shows Rift valley to an infant mortality rate of 60 per 1,000 live births and under-five mortality of 12 per 1000 live births. The most prevalent diseases affecting people in the county include malaria and HIV/AIDs.

\section{Outline of the thesis}

Chapter 1: The general introduction gives an overview of trends of malnutrition among women and children in Kenya and emphasizes on the 'double burden of malnutrition' brought about by the emergence of overweight among food insecure and undernourished populations. We discuss the etiology and trends of overweight in developing countries more so in sub-Saharan Africa and specifically in Kenya. This chapter also discusses studies on overweight in Kenya and outlines the gaps in these studies and our major objectives for this study. Chapter 1 also gives a general introduction to the study area; its topography and general characteristics as well as the study settings and methods. Chapter $\mathbf{2}$ is a review of determinants of stunting and overweight among children. Chapter 3 describes the status of food insecurity using household food insecurity access score (HFIAS) as a measure of food insecurity and its relationship with overweight and underweight among women in Kenya. Chapter 4 discusses the preva- 
lence of malnutrition among children (0-5yrs) in Narok County and it emphasizes on predictors of overweight, underweight, stunting and wasting among these children. It also looks at how these factors are associated with food insecurity. Chapter $\mathbf{5}$ and $\mathbf{6}$ focuses on how physical activity relates with body composition and water turnover among women. It also discusses how physical activity and food security influence pregnancy outcomes. Chapter 7: Describes the measures of adiposity in women. There is no standard measurement of adiposity among women therefore our study focuses on how some of these measures relate with each other and the consequences of using them. Chapter 8: The general discussion gives a summary of important findings reported in this thesis and it also highlights practical implications and recommendations for future research. 


\section{References}

1. FAO. Nutrition and develoment: a global challenge Food, Nutrition and Agriculture [Internet]. 1992 Accessed on 17th June 2013. Available from: http://www.fao.org/docrep/u9920t/u9920t07.htm.

2. FAO. Undernourishments around the world 2012. Available from: http://www.fao.org/docrep/016/i3027e/i3027e02.pdf.

3. Pingali P, Ricketts K, sahn D. Agriculture for Nutrition: Getting policies right Nutrition challenges and changing food systems: Global and national perspectives [Internet]. 2013. Available from: http://www.fao.org/docrep/meeting/029/mi896e.pdf.

4. United Nations Children's Fund (UNICEF). Tracking progress on child and maternal nutrition 2009. Available from: http://www.childinfo.org/files/Tracking_Progress_on_Child_and_Maternal_Nutrition_EN.pdf.

5. United Nation's Inter-Agency Group for Child Mortality Estimation. Report levels and trends in child mortality 2011. Available from: http://www.childinfo.org/files/Child_Mortality_Report_2013.pdf.

6. Food and Agricultural Organization (FAO), International Fund for Agriculture and Development (IFAD), World Food Program (WFP). UN System task team on the post-2015 UN development agenda Imagining a world free from hunger: Ending hunger and malnutrition and ensuring food and nutrition security [Internet]. 2012. Available from: http://www.un.org/millenniumgoals/pdf/Think\%20Pieces/6_food_nutrition.pdf.

7. WHO. Epidemics of underweight and overweight growing 29th May 2013. Available from: http://www.voanews.com/content/epidemics-of-underweight-and-overweight-growing118113289/171407.html.

8. Obesity and overweight [Internet]. 2013. Available from: http://www.who.int/mediacentre/factsheets/fs311/en/.

9. WHO. Global strategy on diet, physical activity and health: obesity and overweight 2010 3rd June 2013 Available from: http://www.who.int/dietphysicalactivity/strategy/eb11344/strategy_english_web.pdf.

10. Kimani-Murage EW, Kahn K, Pettifor J, Tollman S, Kipstein-Grubusch K, Norris S. Predictors of adolescent weight status adn central obesity in rural South Africa Public Health Nutrition. 2011;14:1114-22. Epub 2011 Feb 28.

11. Abubakari A, Lauder W, Agyemang C, Jones M, Kirk A, Bobhal R. Prevalence and time trends in obesity among adults West Africa populations: meta-analysis Obesity Reviews 2008;9:297-311.

12. Kruger SH, Puoane T, Senekal M, van der Merwe M. Obesity in South Africa: chalenges for government and health professionals Public Health Nutrition. 2005;8:491-500.

13. de Onis $\mathrm{M}$, Blossner $\mathrm{M}$, Borghi E. Global prevalence and trends of overweight and obesity among preschool children The American Journal of Clinical Nutrition 2010 August;92:1257-64.

14. WHO. Nutrition in transition, globalization and its impact on nutrition 2003.

15. Steyn NP, Nel JH, Parker W, Ayah R, Mbithe D. Dietary, social and environmental determinants of obesity in Kenyan women. Scandinavian Journal of Public Health 2011 August 39:88-97.

16. Asfaw A. Does consumption of processed foods explain the disparities in the body weight of individuals Health Economics 2011;20(2):184-95.

17. Popkin B. Global nutrition dynamics: the world is shifting rapidly towards a diet linked with noncommunicable diseases American Journal of Clinical Nutrition. 2006;84(2):289-98.

18. Lambert EV, Bohlmann I, Kolbe-Alexander T. 'Be active '- Physical activity for health in South Africa South African Journal of Clinical Nutrition 2001;14(3).

19. P S, Schmidhuber J. Nutrition, lifestyle, obesity and chronic disease. New York United Nations, 2011 Contract No.: 2011/3.

20. Kenned G, Nantel G, Shetty P. Globalization of food systems in developing countries: impact on food security and nutrition. FAO Food and Nutrition Papers. 2004;83:1-300.

21. Abrahams Z, Mchiza Z, Steyn NP. Diet and mortality rates in sub-Saharan Africa: stages in the nutrition transition BMC Public Health 2011;11(801).

22. Kenya National Bureau of Statistics and ICF Macro. Kenya Demographic and Health Survey 2008092010. Available from: http://dhsprogram.com/pubs/pdf/FR229/FR229.pdf.

23. GOK Ministry of Public Health and Sanitation. National nutrition action plan 2012-20172012. Available from: http://scalingupnutrition.org/wp-content/uploads/2013/02/Kenya_KNN_Action-Plan_2012_2017.pdf. 
24. Galgani J, Ravussin E. Energy metabolism, fuel selection and body weight regulation. International Journal of Obesity 2008 Dec;32(Suppl 7):109-19.

25. Hill JO, Wyatt HR, Peters JC. Energy balance and obesity Circulation. 2012;126:126-32.

26. UNICEF. Survey reveals high malnutrition among pregnant women in Kenya 2006. Available from: http://www.unicef.org/infobycountry/kenya_33782.html.

27. Ong KK, Loos RJ. Rapid infancy weight gain and subsequent obesity: systematic reviews and hopeful suggestions. Acta Paediatrica. 2006;95(8):904-8.

28. Weng SF, Redsell SA, Swift JA, Yang M, Glazebrook CP. Systematic review and meta-analyses of risk factors for childhood overweight identifiable during infancy Archieves of Diseases in Chilhood 2012;0:1-8.

29. Young BE, Johnson SL, Krebs NF. Biological determinants linking infant weight gain and child obesity: Current knowledge and future directions. Advances in Nutrition 2012;3:675-86.

30. Parsons TJ, Power C, Logan S, Summerbell CD. Childhood predictors of adult obesity: a sytematic review International Journal of Obesity and Relate Metabolic Disorders 1999;23(S1-S107).

31. Baird J, Fisher D, Lucas P, Kleijnen J, Roberts H, Law C. Being big or growing fast: systematic review of size and growth in infancy and later obesity BMJ. 2005;331(929).

32. Druet C, Stettler N, Sharp S, Simmons RK, Cooper C, Smith GD, et al. Prediction of childhood obesity by infancy weight gain: an individual-level meta-analysis Paediatric and Perinatal Epidemiology. 2011;26(1):19-26.

33. Crawford PB, Webb KL. Unraveling the paradox of concurrent food insecurity and obesity. American Journal of Preventive Medicine. 2011;40(2):274-5.

34. Eisenmann JC, Gundersen C, Lohman BJ, Garasky S, SD. S. Is food insecurity related to overweight and obesity in children and adolescents? A summary of studies, 1995-2009. Obesity Reviews. 2011;12(5):e73-83. Epub March 8th 2011.

35. Rose D, JN. B. Household food insecurity and overweight status in young school children: results from the Early Childhood Longitudinal Study. Paediatrics. 2006;117(2):464-73.

36. Gundersen C, Lohman BJ, Garasky S, Stewart S, Eisenmann JC. Food Security, Maternal Stressors, and Overweight Among Low-Income US Children: Results From the National Health and Nutrition Examination Survey (1999-2002) Paediatrics. 2008;122(3):e529-e40.

37. Crawford PB, Lamp CL, Nicholson Y, Krathwohl S, Hudes M, Townsend MS. Food insecurity may be linked to childhood obesity in low-income Mexican-American families. California Agriculture 2007 September 61(3):106-11.

38. Townsend MS, Peerson J, Love B, Achterberg C, SP. M. Food insecurity is positively related to overweight in women. Journal of Nutrition 2001 March 2001;131(6):1738-45.

39. Isanaka S, Mora-Plazas M, Lopez-Arana S, Baylin A, Villamor E. Food insecurity is highly prevalent and predicts underweight but not overweight in adults and school children from Bogotá, Colombia. Journal of Nutrition. 2007;137(12):2747-55.

40. Kac G, Velásquez-Melendeza G, Schlüssel MM, Segall-Côrrea AM, Silvaa AAM, Pérez-Escamilla R. Severe food insecurity is associated with obesity among Brazilian adolescent females. Public Health Nutrition. 2012 October 2012;15(10):1854-60.

41. Basiotis PP, Lino M. Food insufficiency and prevalence of overweight among adult women Nutrition Insights 2002;26:1-2.

42. Popkin BM, Adair LS, Ng SW. Global nutrition transition and the pandemic of obesity in developing countries Nutrition Reviews 2012;70(1):3-21.

43. Onywera V. Childhood obesity and physical inactivity threat in Africa: strategies for a healthy future. Global Health Promotion. 2010;17(45).

44. WHO. Global strategy on diet, physical activity and health 2003. Available from: http://www.who.int/dietphysicalactivity/media/en/gsfs_obesity.pdf.

45. Scott A, Ejikeme CS, Clottey EN, Thomas JG. Obesity in sub-Saharan Africa: development of an ecological theoretical framework Health Promotion International 2012 August;28(1).

46. Gross R, Schoeneberger H, Preuss HA. The four dimensions of food, nutrition and security: Definitions and concepts Nutrition and Food Security [Internet]. 2000; (April ). Available from: http://www.foodsec.org/DL/course/shortcourseFA/en/pdf/P-01_RG_Concept.pdf.

47. Rogol AD, Clark PA, JN R. Growth and pubertal development in children and adolecents: effects of diet and physical activity American Journal of Clinical Nurition. 2000;72(2):521s-8s. 
48. Abubakari A, Holding P, Van de Vigver, Newton C, Van Baar A. Child at risk for developmental delay can be recognized by stunting, being underweight, ill health, little maternal schooling or high gravidity Journal of Child Psychology and Psychiatry 2010;51(6):652-9.

49. Grantham-McGregor S, Cheung YB, Cueto S, Richter L, Strupp B. Developmental potential in the first 5 years for children in developing countries -. The Lancet 2007;369(9555):60-70.

50. Kimani-Murage EW. Exploring the paradox: double burden of malnutrition in rural South Africa. Global Health Action 2013;6(19249).

51. Fernald LC, Neufeld LM. Overweight with concurrent stunting in very young children in rural mexico: prevalence and associated factors European Journal of Clinical Nutrition 2007;61(5):623-32. Epub 29th Nov 2006.

52. Chopra M, Darnton-Hill I. Responding to the crisis in sub-Saharan Africa: the role of nutrition Public Health Nutrition 2006;9(5):544-50.

53. Walley AJ, Blakemore AIF, Froguel P. Genetics of obesity and prediction of risk for health Human Molecular Genetics 2006;15(2):124-30.

54. Daniels SR. The consequences of childhood overweight and obesity Future Child 2006;16(1). Epub 4767.

55. Masibo P, Makoka D. Trends and determinants of undernutrition among young Kenyan children: Kenya Demographic and Health Survey; 1993,1998, 2003 and 2008-2009. Public Health Nutrition. 2012;15(9):1715-27.

56. Gewa C. Childhood overweight and obesity among Kenyan pre-school children: association with maternal and early child nutritional factors Public Health Nutrition. 2010 November;13(4):496-503.

57. Aspray TJ, Mugusi F, Rashid S, Whitin D, Edwards R, Alberti KG, et al. Rural and urban differences in diabetes prevalence in Tanzania: the role of obesity, physical inactivity and urban living. Transactions of the Royal Society of Tropical Medicine and Hygience 2000;94(6):637-44.

58. Ziraba AK, Fotso JC, Ochako R. Overweight and obesity in urban Africa: A problem of the rich or the poor? BMC pUblic Health 2009;9(465).

59. Owen GG, Martin RM, Whincup PH, Smith GD, DG. C. Effects of infant feeding on risk of obesity Pediatrics 2005;115(5):1367-77.

60. Horta BL, Bahl R, Martenes J, Victoria CG, editors. Evidence on the long-term effects of breastfeeding: systematic reviews and meta-analysis Geneva: World Health Organization; 2007.

61. Semproli S, Gualdi-Russo E. Childhood Malnutrition and Growth In a Rural Area of Western Kenya American Journal of Physical Anthropology 2007;132:463-9.

62. Wamani H, Åstrøm AN, Peterson S, Tumwine JK, Tylleskär T. Boys are more stunted than girls in subSaharan Africa: a meta-analysis of 16 demographic and health surveys BMC Pediatrics 2007;7(17).

63. Mbochi RW, Kuria E, Kimiywe J, Ochola S, Steyn NP. Predictors of overweight and obesity in adult women in Nairobi Province, Kenya Public Health Nutrition. 2012;12(823).

64. Cole TJ, Flegal KM, Jackson AA. Body mass index cut offs to define thinnes in children and adolescents: international survey BMJ. 2007;335(194). 


\section{CHAPTER 2}

\section{Determinants of stunting and overweight among young children and adolescents in sub-Saharan Africa}

Susan Keino, Guy Plasqui, Grace Ettyang, and Bart van den Borne Accepted for publication in Food and Nutrition Bulletin (June 2014) 


\begin{abstract}
Background: Stunting and overweight are nutritional problems affecting most of sub-Saharan Africa. The region now has the world's highest rate of stunting among children-43 percent, whereas overweight and obesity is becoming a global epidemic and Africa is not spared. The past two decades has seen a dramatic increase in obesity in sub-Saharan Africa. The purpose of this systematic review is to explore the determinants of stunting and overweight in sub-Saharan Africa.

Methods: A Literature search was conducted in PubMed using the key words stunting, overweight, obesity, Africa, sub-Saharan Africa, determinants and prevalence. Limits were set to include articles published within the period of 1990-2012. The systematic review resulted in 38 studies and after selection based on title; content and the country of study, 18 studies were eligible for this review. Chi square was used in data analysis.
\end{abstract}

Results: Prevalence of stunting and overweight were dependent on socioeconomic, demographic and environmental factors. Many studies indicate that being male and living in a rural setting one is likely to be stunted, whereas overweight among children depended more on age, household composition, occupation of the mother and the mother's body mass index. Being both stunted and overweight occurred across gender and ages 1-5 y. Stunting was more prevalent among males compared to females. Socio-economic status such as mothers' education, occupation, household income were some of the determinants directly linked to stunting, whereas, environmental factors such as rural and urban settings and sanitation influenced both stunting and overweight. Concurrent stunting and overweight is influenced by maternal and household factors such as maternal height, age and education as well as large household size and lower socioeconomic status respectively.

Conclusion: Although socio-economic, demographics and environment factors were significant in determining stunting and overweight, other factors such as nutritional and lifestyles were important risk factors. Stunting in childhood is a risk factor that may results in overweight and obesity later in adolescence and adulthood indicating the need to screen children below 1 y to identify stunting early in life. Promoting exclusive breastfeeding is reported to be important in preventing both stunting and overweight among children. More research is needed to explore the relationship between stunting and overweight and explore policy guidelines to address the phenomenon.

Key Words: stunting, overweight, sub-Saharan Africa, determinants 


\section{Introduction}

Chronic malnutrition is a persistent problem for young children in sub-Saharan Africa (1). It is worth noting that malnutrition is a term that has often been used interchangeably with under-nutrition in explaining nutritional problems particularly in developing countries. A high percentage of malnourished children fail to reach the normal international standard of height for their age that is they are stunted (1). In the recent past, studies have shown different trends; increasing over-nutrition in different countries and persistent under-nutrition in other countries particularly in sub-Saharan Africa (2). According to Hoffman, the prevalence of obesity is increasing worldwide, including in some developing countries with previously a very low prevalence (3). The World Health Organization (WHO) defines overweight and obesity as a condition of abnormal or excessive fat accumulation (4). A chronic positive energy balance normally precipitates the accumulation of excess adipose tissue. This positive energy balance is believed to be influenced by a number of environmental, socioeconomic and physiological factors such as high fat diets and/or decreased physical activity. How these factors are manifested in developing countries is critical to the recent increase of obesity in countries undergoing transition, i.e. increasing urbanization (3).

The WHO indicates that globally in 2005, there were more than 1 billion overweight adults, at least 300 million of them obese (5) and up to 20 million children under five who were overweight (6). There are no reliable statistics on obesity in Africa, however, more than one-third of African women and a quarter of African men are estimated to be overweight and according to the WHO this will rise to 41 percent and 30 percent respectively in the next 10 years (7). On the other hand, the region now has the world's highest rate of stunting among children i.e. 43 percent and has shown little improvement over the past 15 years (1). Childhood obesity continues to be a serious health problem across the globe (8) and has become a global epidemic both in children and in adults, and is still increasing in both industrialized and developing countries (9). However, some studies have indicated that in developing countries there is an increase in prevalence of overweight and obesity among children who are stunted (10-12). More specifically, stunting has also been associated with obesity later in life (13). The coexistence of both stunting and overweight/obesity among populations in developing countries poses a major challenge to policy makers. Mainly because these countries in the past have been struggling with problems of under-nutrition and are now faced with the challenges that come with overweight and obesity. Therefore they may lack the infrastructure to treat and manage chronic diseases associated with obesity. 


\section{Emerging trends and their effects on nutrition in sub-Saharan Africa}

Africa is gradually moving from a continent of food deficit and under-nutrition to a continent with both under-nutrition and over-nutrition. According to Schmidhuber et al. way back in the 60 's, the entire developing world was suffering from substantive calorie deficits, chronic undernourishment and in some cases outright famine, except in a few countries (14). They further indicate that, by the end of the 90s, the rather homogenous picture of low supply of food and hunger of the 60s had changed completely and the prevalence of undernourishment had fallen to levels below $10 \%$ in all regions except for sub-Saharan Africa as well as a few countries in South Asia. The more rapidly growing developing countries, in particular, are beginning to suffer from an oversupply of food energy such that hunger and obesity now often co-exist in the same country or region (14).

WHO indicates that changes in diets and lifestyles resulting from industrialization, urbanization, economic development and market globalization are having a significant impact on the nutritional status of populations (15). Further, WHO reiterates that the processes of modernization and economic transition have led to industrialization in many countries and the development of economies that are dependent on trade in the global market. Even though this resulted in improved standards of living and greater access to services, there have also been significant negative consequences in terms of inappropriate dietary patterns and decreased physical activities as well as a corresponding increase in related diseases (15). The nutrition transition that has been witnessed in many parts of the world especially in the developing countries with fast growing economies, has led to changes in dietary patterns (16-18).

Rapid urbanization and changing consumption patterns mean greater demand for agricultural products by people who often do not produce them (1). Due to increased economic development and urbanization, populations in many developing countries are now consuming more energy, more processed foods including more refined grains, and more foods higher in saturated fat, sugar and salt (19-21). National food and nutrition policies, as well as trade policies that affect the relative price of food, may also encourage such changes. Low prices and increased income mean that people now access food that they could normally not afford and in most cases these are the fried, sugary and salty foods in place of traditional whole grain and leafy vegetables. As income grows, consumers want to diversify away from cereals and other starchy foods (22). These are foods that are normally ready to eat, highly processed, high in salt and fat, which people find convenient; this is as opposed to healthy foods which require further preparation and processing like cooking.

Nutrition transition is a contributing factor towards increased obesity. Das (23) indicates that societal changes and worldwide nutrition transition are driving the obe- 
sity epidemic. As incomes rise and populations become more urban, diets high in complex carbohydrates give way to diets with a higher proportion of fats, saturated fats, and sugar. At the same time, large shifts toward less physical activity are also found in the increasing use of automated transport, technology in the home and more passive leisure pursuits. As a result, if energy intake exceeds expenditure for a long time period, the surplus of energy is stored as fat mass and if energy imbalance continues, the result is overweight and obesity (24).

\section{Association between stunting and overweight}

Stunting and overweight/obesity are both forms of malnutrition. Stunting represents under-nutrition, whereas overweight represents over-nutrition. The trend now in developing countries is the coexistence of both stunting and overweight among individuals, households, within communities. The existence of stunted children-overweight mother pairs has been reported in some studies (20,25-27), and other studies show a correlation between nutritional stunting (growth retardation attributed to undernutrition during childhood) and later obesity in developing countries $(3,13,28,29)$. A recent study in Mexico reveals that overweight with concurrent stunting occurs in young children: $5 \%$ in indigenous and over $10 \%$ in non-indigenous children $24-60$ months (30).

Having a stunted child and an overweight mother is more prevalent in Latin America than in Africa and it is linked to economic development in both regions as well as to urbanization in Latin America (31). Some developing countries that have higher numbers of overweight mothers also have higher numbers of stunted children, further, since overweight is higher in urban areas and now increasing in the rural areas in Africa, stunted child-overweight mother pairs exists more in the urban areas (31). This double burden phenomenon brings into light factors related to intra-household food distribution and gestational weight gain that may lead to overweight mothers and stunted children. A study by Dieffenbach and Stein (25) indicate that the increasing stunted children and overweight mother pairs is due to the increasing prevalence of overweight mothers and decreasing prevalence of childhood stunting and that the underlying factors remain the same. Thus intervention on the double burden of malnutrition does not need to change from the already existing interventions targeting overweight mothers and stunted children.

Stunting has been found to be associated with both metabolic and psychological risk factors for obesity; furthermore, nutritionally stunted children have impaired fat oxidation compared with non-stunted children from the same environment (3). Stunted children from poor backgrounds are at risk of obesity and may gain weight over 
time when food supplies become sufficient to allow an ad libitum consumption (3). In urbanized developing countries with higher a Gross National Product (GNP), food scarcity may no longer be the driving factor behind energy intake (32). Instead the availability of cheap, energy-dense food (including those from the street vendors and fastfood restaurants) may facilitate the consumption of more calories. Therefore, families moving from rural to urban areas face the possible risk of overweight and obesity particularly among previously stunted children

A study among children in Brazil revealed that childhood nutritional stunting was associated with impaired fat oxidation, a factor that predicted obesity in other at-risk populations(12). A longitudinal study also in Brazil indicated that girls recovering from under-nutrition tend to have a high ratio of fat to protein accretion and the cause is not known (28). In the same study, a higher increase in weight-for-height was shown among the stunted than the non-stunted when higher fat diets were consumed (28). A study among young children in Mexico also showed that mild stunting was a risk factor for accumulation of excess body fat (30).

Overweight and stunting have been explained differently in the studies above, particularly in the different continents that represent the developing countries and more so in countries experiencing a nutrition transition. However, Africa is a unique continent in that it is the only continent where under-nutrition is still increasing in absolute numbers in spite of the progress made in terms of poverty reduction. The increasing under-nutrition is accompanied by increasing overweight and obesity. What remains unknown is the magnitude of the problem of stunting and overweight in Africa although the problem has been discussed in many publications. In addition, there is need to know implications of having both overweight/obesity occurring concurrently with stunting among individuals and in the same household and community. This is a gap that needs to be filled as it is important to both researchers and policy makers. Thus there is need for more studies on stunting and overweight in Africa as a whole. Thus the main focus of this systematic review is an analysis of the co-existence of and the association between stunting and overweight/obesity among children in subSaharan Africa.

\section{Research Methods}

A literature search of the PubMed central database was conducted for relevant articles on April $5^{\text {th }}, 2011$. First we searched for review article on the same topic to ensure the study had not been conducted before. Two searches were performed with the search terms 'stunting AND underweight AND overweight AND sub-Saharan Africa' or 'stunting AND overweight AND Africa' respectively. The first search resulted in 13 articles 
and the second search resulted in 37 articles. When comparing the two search results, some articles were included twice. Thus after elimination a total of 38 titles were identified to include only those studies done in sub-Saharan Africa. The inclusion criteria were that articles needed to be published within the time period of 1990 to 2012 and studies must contain relevant data of children 0-18 years from sub-Saharan African countries. A total of 19 studies were eliminated by year of publication and one was in Norwegian and a total 18 studies were selected for this review. A descriptive analysis was done of the data obtained from the reviewed papers to include the prevalence of stunting and overweight, their causative factors and the country where the study took place. The associations reported by the studies reviewed were compared and the significance of the associations found was tested by using Chi square. Our hypothesis was that stunting and overweight are independent of demographic, socioeconomic, environmental, lifestyle and nutritional status in the 18 studies.

\section{Results}

The results from the literature search are summarized in Table $1(10,33-49)$ and Table 2. Table 1 shows data on the prevalence and determinants of stunting, overweight and stunted-overweight in sub-Saharan Africa from the 18 studies identified:-53\% were performed in South Africa, 11\% in Cameroon, 11\% in Nigeria, 5\% in Equatorial Guinea and $5 \%$ in Kenya. Three (16\%) studies involved multiple countries in Africa. The determining factors of stunting, overweight, and stunted-overweight were scored using the symbol asterisk $(*)$ to represent the risk factors. The number of stars in a column represents the number of factors in that category that influenced the nutritional status. Demographic factors included age, gender and ethnicity; Social Economic Status included income, parental education, parental occupation etc; Environmental factors included region (urban and rural) and household size and composition; lifestyle factors included physical activity, food choices and dietary habits; nutritional factors included mother's body mass index (BMI), dietary intake, infant feeding, among others. Table 2 shows the summary statistics from Table 1 . The results indicate demographic, socioeconomic and environmental factors were significant while lifestyle and nutritional factors were not significant.

The prevalence of undernutrition in both preschool and adolescents showed significant sex differences with stunting and underweight being more pronounced in males than females $(10,33-36)$. Adolescent girls were more overweight than boys (33, 34); however, among preschool children, males were more overweight than females (18.3\% and $17.2 \%$, respectively), whereas $8 \%$ were both stunted and overweight (10). The prevalence of stunted and obese increased from 0.59\% in 1997 to $3.59 \%$ in 2004 in 
Equatorial Guinea (37). When considering obesity, no statistically significant difference across gender and age groups were found among adolescents as reported in as study in South Africa (33). In a study in Equatorial Guinea between 1997 and 2004, the prevalence of overweight children increased from $21.8 \%$ to $31.7 \%$, especially in urban areas (from $18.2 \%$ to $29.4 \%, p=0.01$ ) (37), meaning that the rural areas also saw and increase of the prevalence of overweight in this country. The prevalence of overweight was also reported as high among 1 to $3 y(23.8 \%)$ in a study in South Africa (38).

\section{Demographic factors associated with stunting and overweight}

In the 18 studies sampled, demographic factors were significant in contributing to prevalence of overweight and stunting $\chi^{2}(3, n=18)=18.84, p<0.05$ (Table 2). However, a study in Nigeria indicated that although males were taller than females, stunting was more pronounced in males, who were $7.5 \mathrm{~cm}$ shorter than the 2006 WHO reference compared with females who were $3.5 \mathrm{~cm}$ shorter than the standard (34). However, a study among adolescents in Cameron showed more girls to be stunted than boys (39). In Cameron, girls might be more stunted as a result of cultural preferences whereby the males have access to food, education and other social economic facilities as compared to the females. In explaining overweight using demographic factors such as gender, girls tend to be more overweight compared to boys $(33,34,36,40,41)$. Regarding age as a determining factor, in a South African study, stunting was already present in children during the first year of life; this brings into focus the importance of assessment of length at birth or during the first year of life to identify stunted children for intervention. (50). Since stunting occurs as a result of chronic malnutrition, maternal nutrition before and at pregnancy becomes important if stunting at the first year of life is to be prevented. Mothers' age is also a determinant in the nutritional status of a child. A study in Kenya indicated that a mother's age is a positive and significant determinant of children's height and the reverse is observed for stunting risk suggesting that children's nutritional status improves with age of the mother at the time of delivery (51).

\section{Socioeconomic factors associated with stunting and overweight}

In the sampled 18 studies, stunting and overweight were dependent on socioeconomic factors, $\chi^{2}(3, n=19)=8.5, p<0.05$ (Table 2). Out of 19 studies, 14 indicated that socio-economic factor were associated with stunting, underweight and overweight. Some maternal factors (occupation and education) and household factors (income and lower socio-economic status) were associated with concurrent stunting 
and overweight. Household factors such as size and composition also have an impact in that large household size may suggest that there is more competition for available food. Maternal education was cited as important in improving nutritional status of children $(10,38,42-44,49)$. Maternal education is also often associated with maternal employment and higher income (10). Having a mother as a student increased the risk of stunting at 3 years, whereas having a working mother increased the risk of overweight (50). A working mother in most cases would mean increased income for the household and consequently more access to food.

\section{Environmental factors associated with stunting and overweight}

Our study found that in the stunting and overweight were dependent of environmental factors, $\chi^{2}(\mathrm{df}=3, \mathrm{n}=18)=8.88, p<0.05$ (Table 2). Rural and urban differentials were the most common factors among the reviewed studies to affect stunting and overweight $(10,34,36,38,45,47,49)$. In a study in Nigeria, adolescents in rural schools were much more likely to be stunted than those in urban private schools (34). Stunting and underweight were most severe in the rural adolescents, where they were 16 times more likely to be stunted and 4 times more likely to be underweight than adolescents in urban private schools (34). Rural and urban settlements vary in terms of poverty levels and socio-economic status. A study in South Africa by Kruger (35) reported no significant association between stunting and overweight; however, there was a tendency to gain subcutaneous fat after the age of $14 \mathrm{y}$, especially in urban girls. Living conditions such as housing, sanitation etc. were also cited in some studies as important factors in determining malnutrition $(35,38,39,47)$. Sanitation and access to health care was reported as a factor in the differences in nutritional status between urban and rural children(51). In as much as there was an increase in overweight in the urban settlements as reported in many studies, the rural areas are also not spared, as seen in Equatorial Guinea (37) and South Africa (36).

\section{Lifestyle and its effects on stunting and overweight among children}

Our study found out that stunting and overweight of children were independent of lifestyle factors, $\chi^{2}(\mathrm{df}=3, \mathrm{n}=18)=4.08$, (Table 2). Although, lifestyle factors such as physical activity is crucial in determining nutritional status of young children, only 3 studies reviewed reported that physically inactive children were more likely to be overweight $(36,39,41)$, two other studies indicated its importance in proper growth and development. Smoking was also reported among some young children, its link to 
stunting and overweight was not reported, although studies have linked smoking among pregnant women to low birth weight $(52,53)$.

\section{Nutritional factors and their effects on stunting and overweight among children}

Our study found out that stunting and overweight of children were independent of nutritional factors, $\chi^{2}(\mathrm{df}=3, \mathrm{n}=18)=3.10$, (Table 2$)$. In a study by Oliveria et al the association between parental and children's dietary practices was shown to be stronger for the mother-child comparison than that for the father-child comparison (54). Studies have reported maternal nutritional status to be positively associated with child nutritional 5status $(10,55)$. In a study in Kenya it was found that maternal nutritional status was significantly associated with overweight as well as with obesity among pre-school children (10). Therefore the health and wellbeing of the mother is necessary to ensure healthy children. However this is not always the case as seen in some studies that report stunting as well as underweight in households with overweight mothers (31, 56). Inadequate dietary intake was reported to contribute to stunting and underweight among children in many studies $(10,43,44,47)$, while formula feeding and early weaning contributed to overweight (42).

\section{Discussion}

This review investigated the prevalence and determinants of stunting and overweight among young children and adolescence and the findings were that demographic, socio-economic and environmental factors were significant in determining stunting and overweight in the 18 studies reviewed, and although lifestyle and maternal nutritional factors were important factors, we did not find them significant. This agrees with a study by Frongillo et al (57) that indicates that socio-economic and demographic factors are associated with worldwide stunting and wasting. However, in our study we did not look at wasting, which has been known to be closely associated with stunting as described in the study Victoria (58), but we looked at underweight, overweight and stunted-overweight. In our study, we found males had higher prevalence of stunting than females, whereas overweight was more prevalent in females. Overweight among children depended more on demographic factors such as age, household composition, occupation of the mother and the mother's BMI. Being both stunted and overweight occurred across gender and ages 1-5 y. Stunting was more prevalent among males compared to females. Socio-economic status such as mothers' education, occupation, household income were some of the determinants directly linked to stunting, whereas, 
environmental factors such as rural and urban settings, and sanitation influenced both stunting and overweight. Thus the high prevalence of stunting among male children, the role of socio-economic factors particularly maternal levels of education, occupation and income as well as the maternal nutritional status formed the highlight of the discussion in this review.

This study has shown that in developing countries, socio-economic factors contribute significantly to the prevalence of stunting, underweight and overweight among $0-20$ years $(10,34,36,39,42)$. Another study reveals that some maternal factors (lower height, age and education) and household factors (large size and lower socioeconomic status) were associated with concurrent stunting and overweight (59). However, male children were more prone to undernutrition than the female, and this agrees with a study by Kabubo-Mariara, which indicated that boys are more likely to suffer chronic and acute undernutrition as well as underweight than girls (51). The rise in the numbers of stunted and overweight may be as a result of rapid economic growth that has resulted in nutrition transition as well as economic transition. Economic growth affects sections of a population differently (60). The poor who are food insecure may suddenly be able to access foods that are cheap but lacking in nutrients and thus over-consumption of energy-dense foods may occur resulting in overweight and obesity. This therefore may explain the presence of stunting and overweight among households and the concurrent occurrence of the same among individuals.

Co-existence of stunting and overweight in the same child was found to be common in children less than five years but was uncommon in older children 5-9 years and adolescents aged $10-20$ years (36). Children under five years of age have to be weaned and therefore, feeding practices and underlying hygiene and sanitation within the home may influence the nutritional status of a child. This may also depend on whether the child was exclusively breastfed or otherwise. According to a study in South Africa many infants were underweight at birth but fewer were stunted, however in the first 12 months, growth patterns change with infants gradually becoming more stunted and more overweight because exclusive breastfeeding for longer periods was uncommon in the study area (43). Promotion of exclusive breastfeeding is therefore important in the prevention of overweight and stunting amongst new born babies for a period of 6 months and continued breastfeeding alongside complementary feeding for a period of 24 months as outlined in the UNICEF programming guide (61). There is need for a mother to know the importance of breastfeeding and the need for proper hygienic practices during weaning. A South African Study points out that a child's Human Immunodeficiency Virus (HIV) status is a significant predictor of underweight and this is important regarding the mothers' choice to breastfeed or not breastfeed depending also on her HIV status (62). 
Poor hygiene may occur as a result of lack of clean water, poor drainage, contaminated water sources and lack of knowledge on importance of practicing proper hygiene and sanitation. A South African study also indicated that having an informal housing structure and fewer rooms in the house, poor or inadequate water and sanitation, low income and unemployment contribute towards undernutrition (38). Other than poor hygienic practices, mother's level of education was a major determinants for development of under-nutrition in Africa (63). Cultural practices may contribute to low education among women, in that many cultures particularly in Africa still see education of the girl-child as not as important as educating the male-child.

With the persistent high prevalence of stunting and overweight among African children there is need for an urgent intervention. Martorell et al. indicate that the challenge for developing countries is eliminating malnutrition and growth faltering while preventing obesity from rising (41). Socio-economic disparities are widening with the poor remaining poor or worsening and the rich becoming richer, the major challenge for countries in transition is the reduction of poverty and also to the reduction of socioeconomic and health disparities particularly in the urban areas (32).

The coexistence of under- and over-nutrition in the same household and among individuals has implications for food and nutrition programming. Targeting intervention programs to both stunted and overweight individuals is a challenge since the desired outcome is contradictory:-ensuring there is no stunting, underweight and wasting and preventing overweight. However, some important interventions for reducing the rate of under nutrition may also be beneficial in terms of reducing the burden of obesity i.e. promoting breastfeeding, improving the nutritional status of women of reproductive age, reducing the rates of fetal growth retardation and low birth weight. In addition, intervention programs for the male children have to be put in place as they were most vulnerable as seen in the high prevalence of stunting and underweight in the reviewed studies.

\section{Conclusion}

In this review, we found demographic, socio-economic and environmental factors as significant in determining stunting and overweight. Being male and living in a rural setting, one is likely to be stunted, whereas overweight among children depended more on age, household composition, occupation of the mother and the mother's BMI. Also noted was that mother's age was a positive and significant determinant of children's height, indicating that women need to delay their child bearing in order to lower the chances of having stunted children. The co-existence of both stunting and overweight was common among children under-five. Therefore, there is a need to promote 
pre-pregnancy and pregnancy nutrition in order to prevent overweight in later childhood and adulthood. More studies are needed in other parts of sub-Saharan Africa to be able to make a conclusive report regarding prevalence of stunting and overweight in order to come up with policy frameworks for addressing both stunting and overweight since in this review most of the studies were from the southern region of subSaharan Africa. 


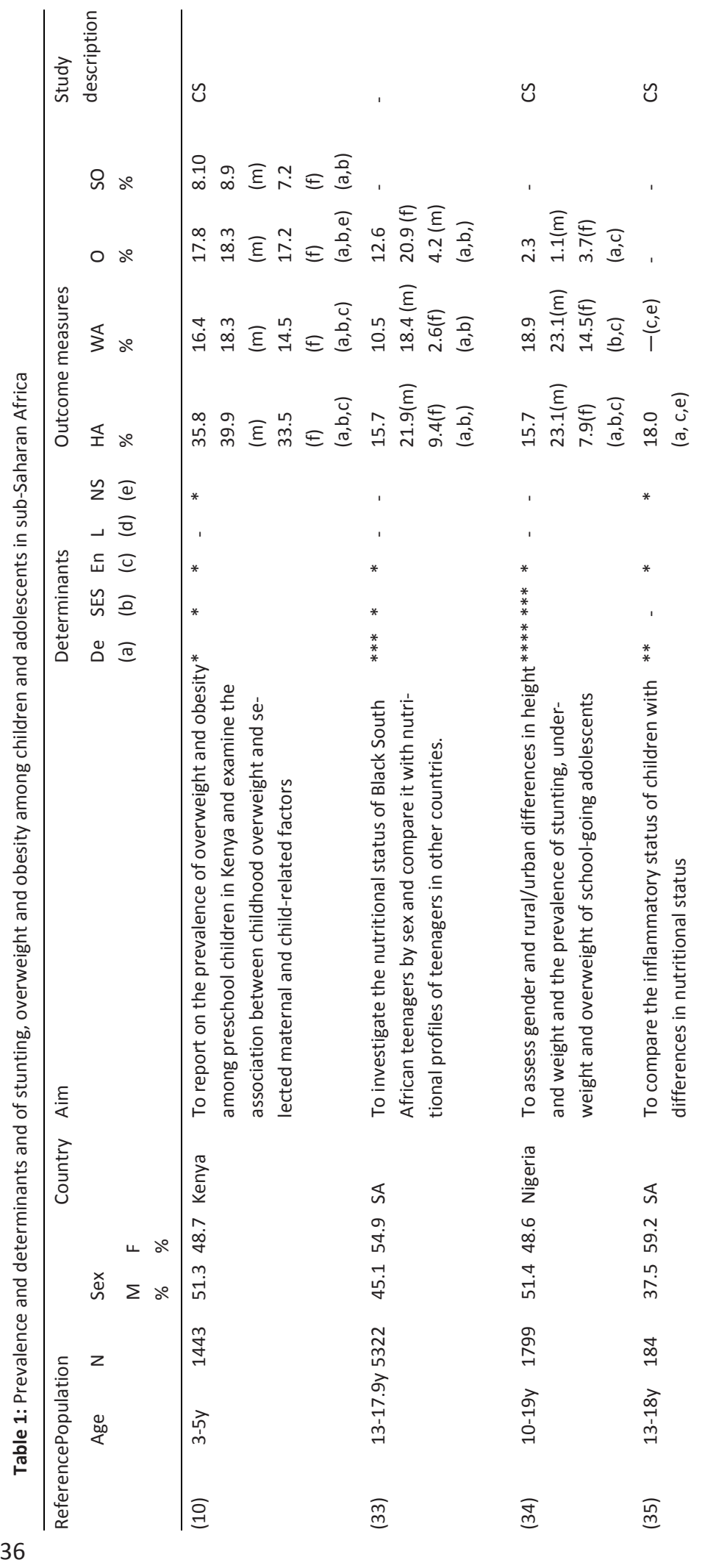




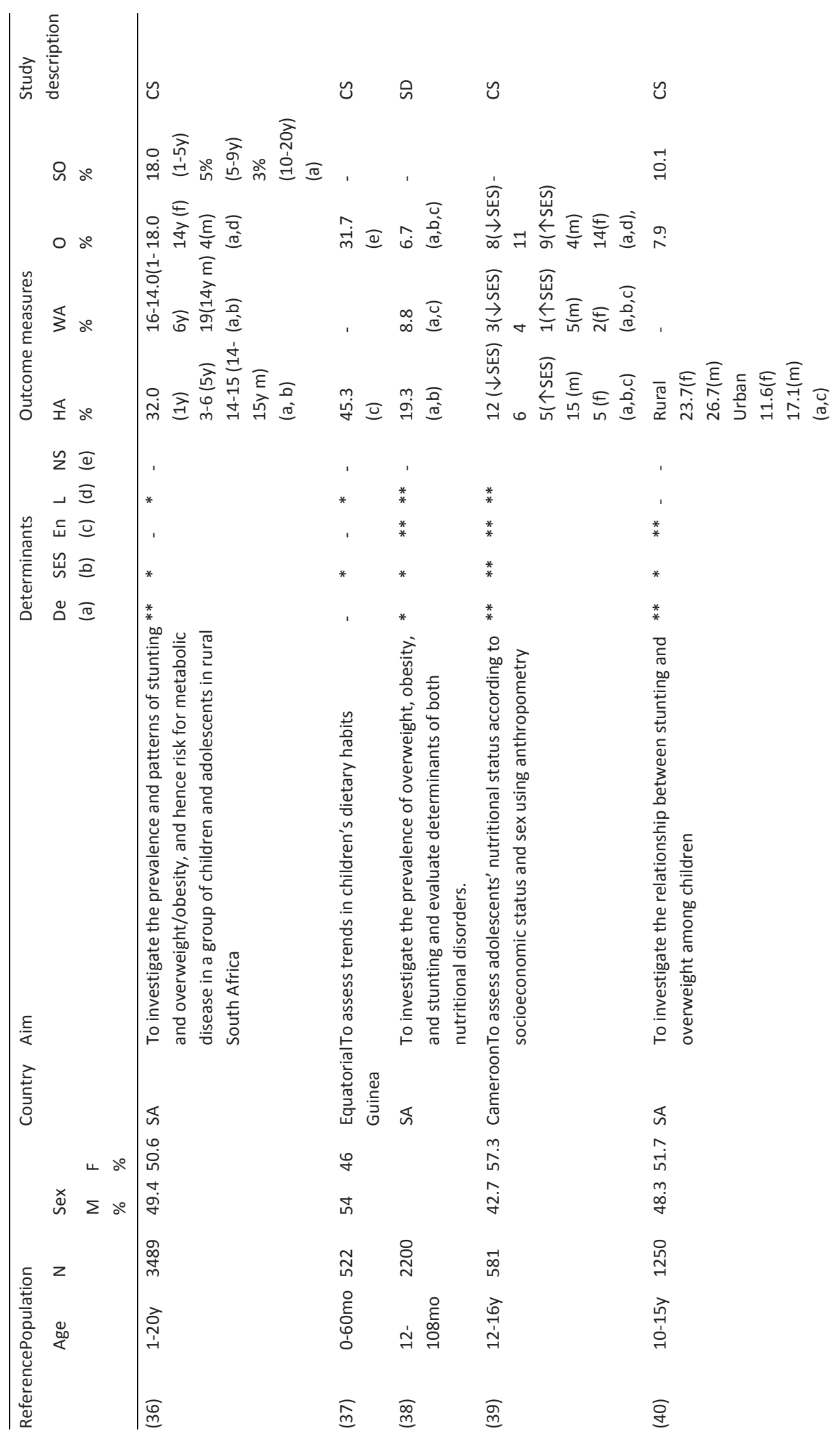




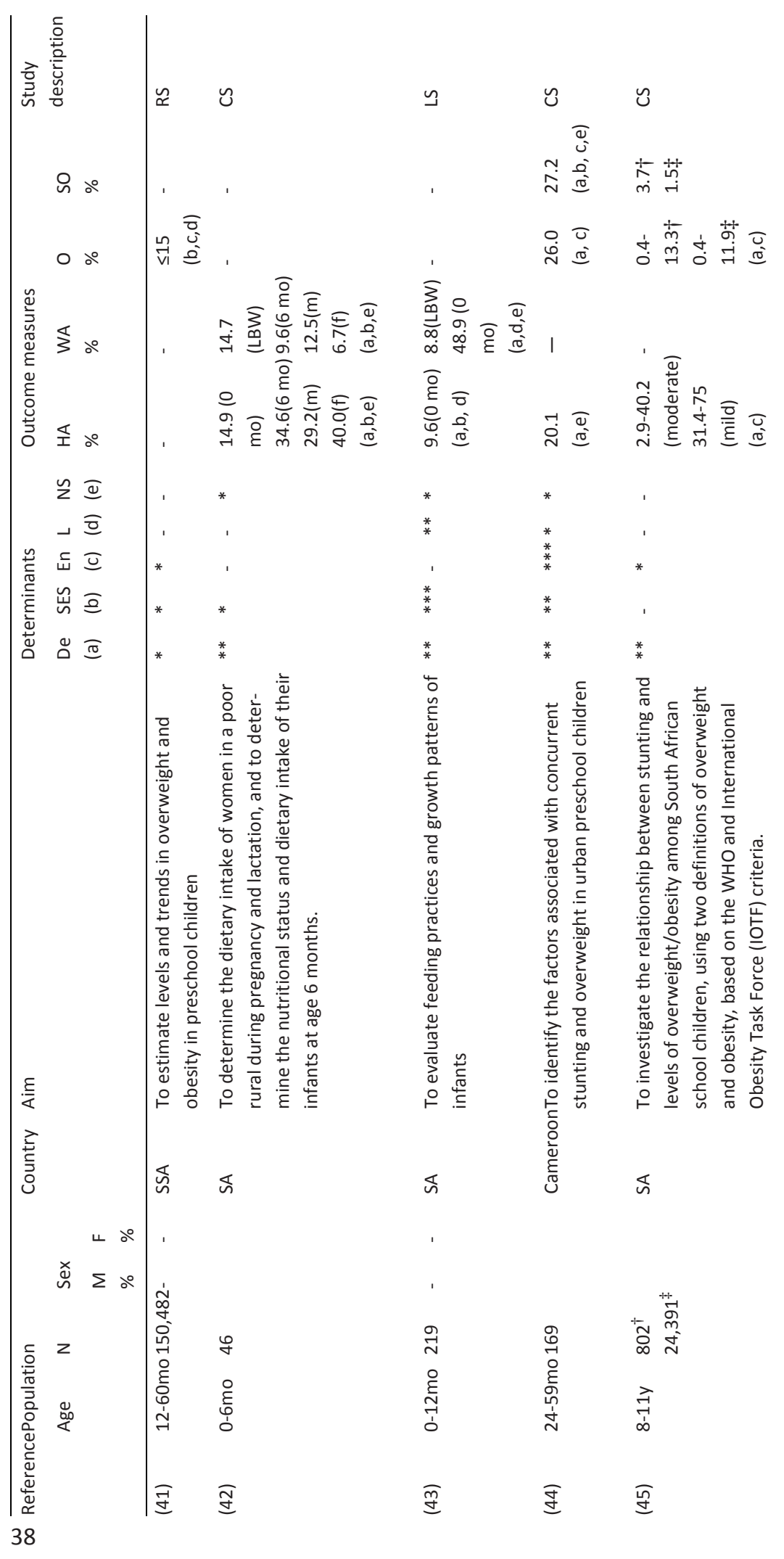




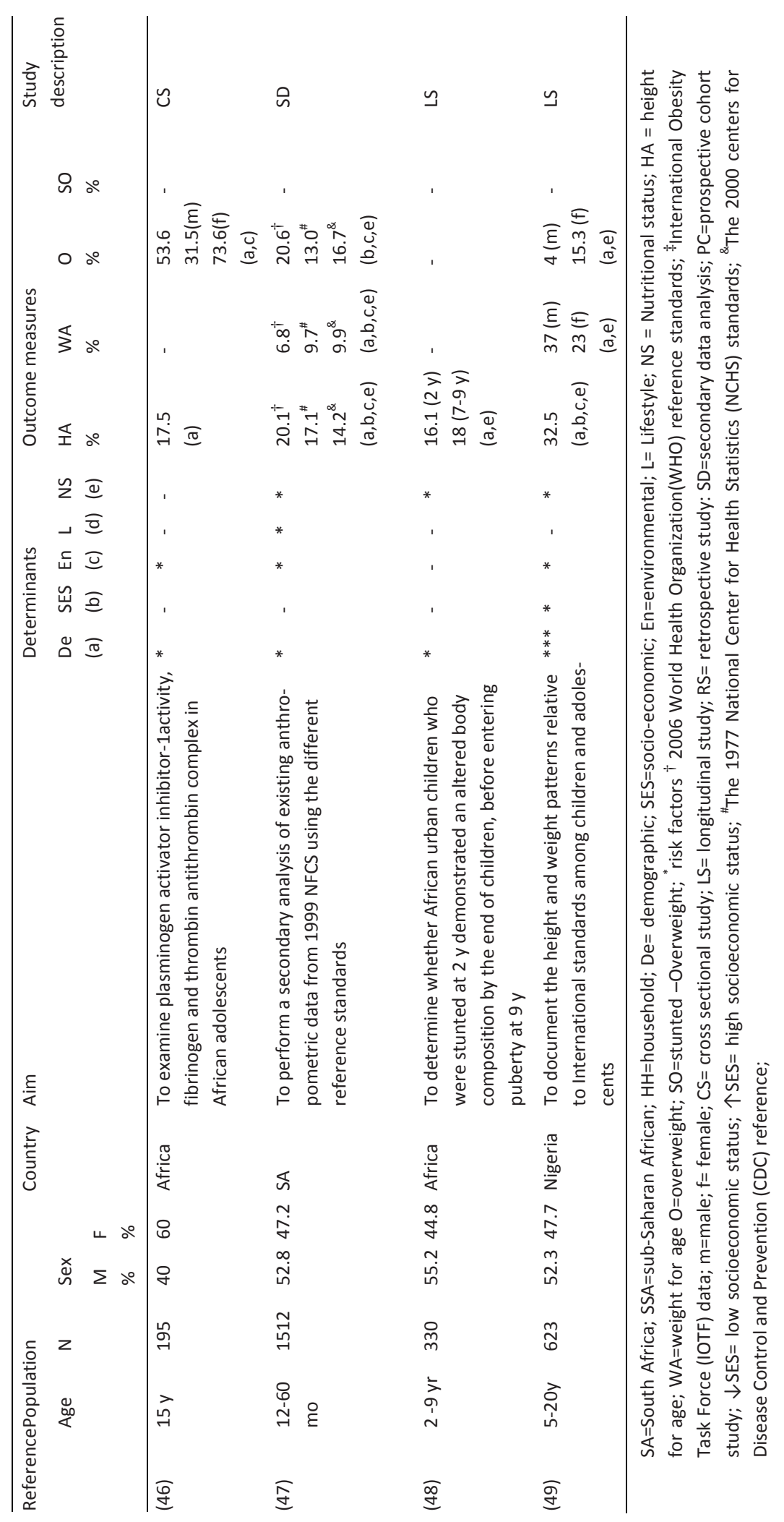




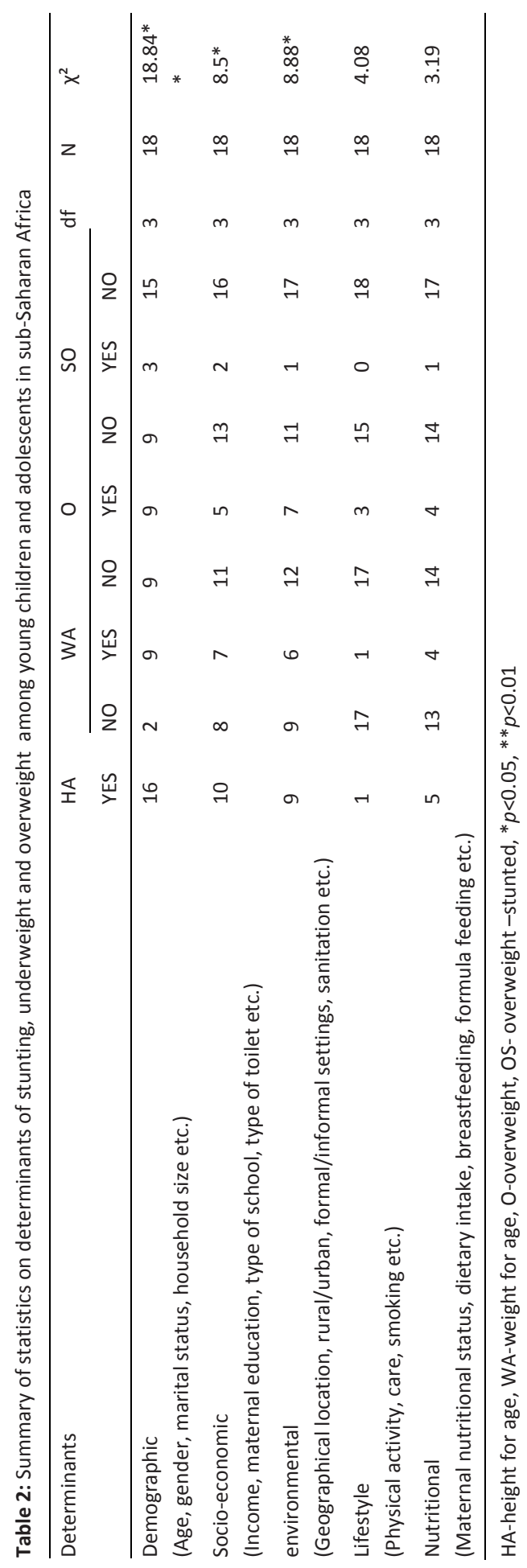




\section{References}

1. Teller CH \& Alva S. Reducing Child Malnutrition in Sub-Saharan Africa: Surveys Find Mixed Progress. Population Reference Bureau 2008.

2. Jehn MB, A. Paradoxical malnutrition in mother-child pairs: Untangling the phenomenon of over- and under-nutrition in underdeveloped economies. Economics \& Human Biology. 2009 March 2009;7(1):28-35.

3. Hoffman D. Obesity in developing countries: causes and implications. Food, Nutrition and Agriculture Review, FAO [Internet]. 2001; 28. Available from: http://www.fao.org/docrep/003/y0600m/y0600m05.htm\#PO_0.

4. WHO. Obesity: preventing and managing the global epidemic. Working Group on Obesity. Geneva, World Health Organization.1998. Available from: http://www.who.int/nutrition/publications/obesity/WHO_TRS_894/en/.

5. WHO. Fact Sheet: Obesity and Overweight. WHO Global Strategy on Diet, Physical Activity and Health [Internet]. 2003. Available from: <http://www.who.int/hpr/gs.fs.obesity.shtml>

6. WHO. Obesity and Overweight fact sheet2006. Available from: http://www.who.int/mediacentre/factsheets/fs311/en/print.html.

7. Johnson D. Africa sees growing obesity rates 2009. Available from: http://www.classesandcareers.com/education/2009/09/09/africa-sees-growing-obesity-rates/.

8. Onywera V. Childhood obesity and physical inactivity threat in Africa: strategies for a healthy future. Gobal Health Promotion. 2010;17(2 suppl):45-6.

9. Wang Y, Lobstein T. Worldwide trends in childhood obesity. International Journal of Pediatric Obesity. 2006;1(1):11-25.

10. Gewa C. Childhood overweight and obesity among Kenyan pre-school children: association with maternal and early child nutritional factors. Public Health Nutrition 2010 April;13(4):496-503. English

11. Semproli S, Gualdi-Russo E. Childhood malnutrition and growth in a rural area of Western Kenya. American Journal of Physical Anthropology. 2007 January 132(3):463-9.

12. Hoffman D, Sawaya AL, Verreschi I, Tucker KL, Roberts SB. Why are nutritionally stunted children at increased risk of obesity? Studies of metabolic rate and fat oxidation in shantytown children from São Paulo, Brazil. American Journal of Clinical Nutrition 2000;72(3):702-7.

13. Popkin BM, Richards MK, Monteiro CA. Stunting is associated with overweight in children of four nations that are undergoing the nutrition transition. Journal of Nutrition. 1996;26:3009-16.

14. Schmidhuber J, and Shetty, P. Nutrition Transition, Obesity \& Noncommunicable Diseases: Drivers, Outlook and Concerns. SCN. 2005;29(1564-3743):13-9.

15. WHO. Nutrition in Transition: globalization and its impact on nutrition patterns and diet-related diseases. 2003b.

16. Frenk DJ. Globalization: Obesity prevention source 2012 11th October 2012 Available from: http://www.hsph.harvard.edu/obesity-prevention-source/obesity-and-urbanization/.

17. Prentice AM. The emerging epidemic of obesity in developing countries International Journal of Epidemiology 2006;35(1):93-9.

18. Drewnowski A, Bopkin B. The nutrition transition: new trends in the global diet. Nutrition Reviews. 1997 Feb 55(2):31-43.

19. Tokunaga M, Takahashi T, Singh RB, Rupini D, Toda E, Nakamuka T, et al. Diet, nutrients and noncommunicable diseases The Open Nutraceutical Journal 2012;5:14-159.

20. Garrett JL, Ruel MT. Stunted child-overweight mother pairs: prevalence and association with economic development and urbanization. Food and Nutrition Bulletin 2005;26(2):209-21.

21. Shetty P, Schmidhuber J. Nutrition, lifestyle, obesity and chronic diseases 2011; 2011(2011/3). Available from: http://www.un.org/esa/population/publications/expertpapers/2011-3-shetty.pdf.

22. Haddad L. What can food policy do to redirect the diet transition? International Food Policy Institute Discussion Paper 165 (December 2003). Food and Nutrition Bulletin. 2005;26(2):238-40.

23. Das Undurti N. Metabolic Syndrome Pathophysiology: The role of essential fatty acids lowa, USA: Wiley-Blackwell Publishers 2010. 
24. Bergstrom E, Hernell O. Obesity \& Insulin Resistence in Childhood and Adolescence 2001. Available from: http://link.springer.com/chapter/10.1007\%2F978-1-59259-039-1_10.

25. Dieffenbach $S$, Stein AD. Stunted child/overweight mother pairs represent a statistical artifact, not a distinct entity Journal of Nutrition 2012 April 142(4):771-3. Epub Feb.

26. Lee $Y$, Houser RF, Must A, Palma de Fulladolsa P, Bermudez OI. Socioeconomic disparities and the familial coexistence of child stunting \& maternal overweight in Guatamala Economics \& Human Biology 2012 Aug 16;10 (3):232-41. Epub 2011.

27. Masibo PK, Makhoha D. Trends and determinants of undernutrition among young Kenyan children: Kenya Demographic and Health Survey; 1993,1998,2003 and 2008-2009. . Public Health Nutrition 2012;15(9):1-13. Epub Jan 14: .

28. Sawaya AL, Roberts S. Stunting and Future Risk of Obesity: principle physiological mechanims. Cadernos de Saude Publica 2003;19:S21-S8.

29. Sawaya AL, Sesso R, Florencio TM, Fernandez M, Martins PA. Association between chronic undernutrition \& hypertension Maternal \& Child Nutrition 2005;1(3):155-65.

30. Fernald LC, Neufeld LM. Overweight with concurrent stunting in very young children from rural mexico: prevalence and associated factors. European Journal of Clinical Nutrition 2007;61:623-32.

31. Garrett JL, Ruel MT. Stunted child-overweight mother pairs: An emerging policy concern? . Washington DC: International Food Policy Research Institute 2003. Available from: http://citeseerx.ist.psu.edu/viewdoc/download?doi=10.1.1.58.3600\&rep=rep1\&type=pdf.

32. Caballero B. A Nutrition Paradox-Underweight and Obesity in Developing Countries. New England Journal of Medicine. 2005;352(15):1514-6.

33. Jinabhai CC, Reddy P, Taylor M, Monyeki D, Kamabaran N, Omardien R, et al. Sex differences in under and over nutrition among school-going black teenagers in South Africa: an uneven nutrition trajectory Tropical Medicine and International Health 2007 Aug;12(8):944-52.

34. Omigbodun $\mathrm{OO}$, Adediran KI, Akinyemi JO, Omigbodun AO, Adedokun BO, O E. Gender and rural-urban differences in the nutritional status of in-school adolescents in south-werstern Nigeria Journal of Biosocial Sciences 2010 Sept;42(5):653-76.

35. Kruger SH, Pretorius R, Schutte AE. Stunting, adiposity, and low-grade inflammation in African adolescents from a township high school. Nutrition 2010;26(1):90-9.

36. Kimani-Murage EW, Kahn K, Pettifor JM, Tollman SM, Dunger DB, Gomez-Olive XF, et al. The prevalence of stunting, overweight, and obesity, and metabolic disease risk in rural South African children. Biomed Central Public Health 2010;10(158).

37. Custodio E, Descalzo MA, Roche J, Molina L, Sanchez I, Lwanga M, et al. The economic and nutrition transition in Equitorial Guinea coincided with a double burden of over- and under nutrition. Economics and Human Biology 2010 March;8(1):80-7.

38. Steyn NP, Labadarios D, Maunder E, Nel J, Lombard C. Secondary anthropometric data analysis of the National Food Consumption Survey in South Africa: the double burden Nutrition. 2005 Jan;21(1):4-13.

39. Dapi LN, Janlert U, Nouedoui C, Stenlund H, Haglin L. Socioeconomic and gender differences in adolescents' nutritional status in urban, Cameroon, Africa. Nutrition Research. 2009 May 29(5):313-9.

40. Mukkudem-Petersen J, Kruger HS. Association between stunting and overweight among 10-15 y old children in the North West Province of South Africa : The THUSA BANA study International Journal of Obesity Related Metabolic Disorder. 2004 July;28(7):842-51.

41. Martorell R, Kettel Khan L, Hughes ML, LM G-S. Overweight and Obesity in Preschool children from Developing countries International Journal of Obesity. 2000;24:959-67.

42. Mostert D, Steyn NP, Temple NJ, Olwagen R. Dietary Intake of pregnant women and their infants in a poor black South African Community Curationis 2005 Nov;28(4):12-9.

43. Mamabolo RL, Alberts M, Mbenyane GX, Steyn NP, Nthangeni NG, Delemarre-Van De Waal HA, et al. Feeding practices and growth of infants from birth to 12 months in the central region of the Limpopo Province of South Africa Nutrition. 2004 March;20(3):327-33.

44. Said-Mohamed R, Allirot X, Sobgui M, Pasquet P. Determinants of overweight associated with stunting in preschool children of Yaounde, Cameroon. Annals of Human Biology. 2009 March-April 36(2):14661.

45. Jinabhai CC, Taylor M, Sullivan KR. Implications of the prevalence of stunting, overweight and obesity amongst South African primary school children: a possible nutritional transition? . European Journal of Clinical Nutrition 2003 Feb;57(2):358-65. 
46. Nienaber C, Pieters M KS, Stonehouse W, HH V. Overfatness, stunting and physical inactivity are determinants of plasminogen activator inhibitor-1activity, fibrinogen and thrombin antithrombin complex in African adolescents Blood Coagulation and Fibrinolysis Journal. 2008;19(5):361-8.

47. Bosman L, Herselman MG, Kruger HS, Labadarios D. Secondary Analysis of Anthropometric Data from South Africa National Food Consumption Survey, Using Different Growth References Standards Maternal Child Health Journal 2011 Sept;15(8):1372-80.

48. Cameron N, Wright MM, Griffiths PL, Norris SA, Pettifor JM. Stunting at 2 years in relation to body composition at 9 years in African Urban children. Obesity Research 2005;13(1):131-6.

49. Ayoola O, Ebersole K, Omatode OO, Tayo BO, Brieger WR, Salaami K, et al. Relative height and weight among children and adolescents of rural southwestern Nigeria Annals of Human Biology 2009 JulAug;36(4):388-99.

50. Mamabolo RL, Alberts M, Steyn NP, Delemarre-Van De Waal HA, Levitt NS. Prevalence and determinants of stunting and overweight in 3-year-old black South African children residing in the Central Region of Limpopo Province, South Africa Public Health Nutrition 2005 Aug;8(5):501-8.

51. Kabubo-Mariara J, Ndenge GK, Mwabu D K. Determinants of Children's Nutritional Status in Kenya: Evidence from Demographic and Health Surveys. Journal of African Economies. 2008;18(3):363-87.

52. Steyn K, de Wet T, Saloojee $Y$, Nel H, Yach D. The influence of maternal cigarrete smoking, snuff use and passive smoking on pregancy outcome: the Birth to Ten Study Paediatric and Perinatal Epidemiology 2006;20:90-9.

53. Chiolero A, Bovet P, Paccand F. Association between maternal smoking and low birth weith in Switzerland: the Eden study. Swiss Medical Weekly 2005;135:525-30.

54. Oliveria SA, Ellison RC, Moore LL, Gillman MW, Garrahie EJ, Singer MR. Parent-child relationships in nutrient intake: the Framingham Children's study. American Journal of Clinical Nutrition. 1992;56:5938.

55. Thuita FM, Mwadime RK, JK W. Child Nutritional Status and Maternal factors in an urban slum in Nairobi, Kenya. East Africa Medical Journal 2005 April 82(4):209-15.

56. Jehn M, Brewis A. Paradoxical malnutrition in mother-child pairs: Untangling the phenomenon of overand under-nutrition in underdeveloped economies. Economics \& Human Biology. 2009 March 2009;7(1):28-35.

57. Frongillo Jnr EA, de Onis M, Hanson KMP. Socioeconomic and Demographic Factors Are Associated with Worldwide Patterns of Stunting and Wasting of Children. Journal of Nutrition. 1997 December;127(12).

58. Victoria CG. The association between wasting and stunting: An International Perspective Journal of Nutrition. 1992;122:1105-10.

59. Fernald LC, Neufeld LM. Overweight with concurrent stunting in very young children from rural mexico: Prevalence \& associated factors. European Journal of Clinical Nutrition. 2007;61(5):623-32. Epub 29th Nov 2006.

60. Lobstein T. Prevalence and trends in Childhood obesity.

61. UNICEF. Programming Guide: Infant and Young Child Feeding Programmes [Internet]. 2011. Available from: http://www.unicef.org/nutrition/files/Final_IYCF_programming_guide_2011.pdf.

62. Kimani-Murage E. Exploring the paradox: double burden of malnutrition in rural South Africa. Global Health Action. 2013 Jan 2013;6(19249).

63. Tlandinyane $P$. The Difference in factors influencing childcare between mother/caregivers of undernourished and well nourished children aged 1-4 years in Oukasie (Brits), North West Province MEDUNSA. 2003. 



\section{CHAPTER 3}

Household Food Insecurity Access:

a predictor of overweight and underweight among Kenyan Women

Susan Keino, Guy Plasqui and Bart van den Borne

Agriculture \& Food Security 2014, 3:2 


\begin{abstract}
Objective: There has been a rise in the number of overweight women across the globe and sub-Saharan Africa has not been spared. Our objective was to describe the performance of household food security as a factor in determining overweight and underweight among Kenyan women of child-bearing age.

Design: A cross sectional survey using a structured questionnaire was carried out among 656 households with women of child-bearing age from both rural and urban settings in the Rift Valley, Kenya.

Results: Of all households involved $70.1 \%$ were categorized as severely food insecure, $21.9 \%$ were moderately food insecure, $3.7 \%$ were mildly food insecure whereas $4.3 \%$ were food secure. Urban women had higher mean $B M I(M=24.53, S D=4.36)$, compared to rural women $(\mathrm{M}=22.52, \mathrm{SD}=3.71, p<.000)$. Households with more children had decreased dietary diversity $(r=-.154: p<0.01)$. Logistical regression indicated that more food secure households (OR=0.97, $\mathrm{Cl} 9.4,1.0,95 \%)$, urban residence (OR=1.82, $\mathrm{Cl}$ 1.1, 3.0, 95\%) being older (OR=1.10, $\mathrm{Cl} 1.1,1.5,95 \%)$ and high standard of living $(\mathrm{OR}=1.79, \mathrm{Cl} 1.2,1.5,95 \%)$ were strong predictors of overweight while being underweight was predicted by younger age $(\mathrm{OR}=.91, \mathrm{Cl} .83,1.0,95 \%)$.

Conclusion: A food secure household does not predict underweight but predicts overweight among women.
\end{abstract}

Key words: food insecurity access, overweight, underweight, dietary diversity and women 


\section{Introduction}

Overweight and obesity and its risk factors are in the increase in sub-Saharan Africa with higher increase among the urban-poor dwellers (1-4). The current estimates are that as much as $20-50 \%$ of urban populations in Africa are classified as either overweight or obese $(5,6)$ and that by 2025 three quarters of the obese population worldwide will be in non-industrialized countries (7). Reasons for the increase in overweight and obesity are not fully understood although physical inactivity and increased consumption of high fat and refined carbohydrates are thought to be contributing factors (8-10). However, it has also been suggested that overweight and obesity may occur due to limited availability of food and this occurs if food insecurity leads to consumption of obesity promoting foods (11) or overeating when food becomes available or metabolic change that permits efficient use of energy (12). Food security exists when all people at all times have access to sufficient, safe, nutritious food for a healthy and active life (13). Food insecurity is defined as limited or uncertain availability of nutritionally, adequate and safe foods, or limited or uncertain ability to acquire acceptable foods in socially acceptable ways(14). Food insecurity and malnutrition result in serious health problem and loss of human potential in developing countries (15). Increasing food insecurity in the developing world paradoxically has resulted in increasing numbers of overweight. Past studies cite increased availability of high sugar and energy, low fibre foods as a major cause for overweight and obesity $(16,17)$. However some studies conducted in developed countries have consistently shown that mild but not severe food insecurity is associated with obesity among women (18-20). This association between food insecurity and obesity has not been confirmed in studies performed in developing countries, where poverty rates are much higher (21). In spite of the increasing numbers of overweight, underweight still persists in these food insecure groups, and both may coexist within the same households or neighborhood $(22,23)$. Although the prevalence of overweight exceeds that of underweight in most developing countries (24), the consequence of both are damaging to health. A study among adults and children from low-and middle-income families in Bogota, Columbia, indicated that food insecurity was related to maternal underweight but not to maternal overweight(25). The association of food insecurity and overweight is not consistent as found by two studies $(26,27)$. The adverse health effects resulting from overweight and underweight are far reaching and are sometimes permanent and may result in death $(28,29)$. Women and children are vulnerable to malnutrition and food insecurity. Further women globally have higher rates of obesity than men (9). Therefore this study targets women of child bearing age in Kenya to identify the relationship between food insecurity, overweight and underweight among this group of women and to highlight the predictors of overweight and underweight. 


\section{Methods}

\section{Study, setting, design and sampling}

This was a cross-sectional study that took place in Narok County, Kenya. The Narok County is made up of an agricultural and agro-pastrolists community in the South Rift Valley. The study was carried out in the Narok District Hospital where we randomly selected women of child bearing age (15-45 y) to participate in this prevalence study. The women were randomly selected from the Mother and Child Health (MCH) clinics where they were bringing their children for immunization and weighing. The women were approached and assigned a number between 1 and 2 and all the women assigned number 1 were asked if they were willing to participate. A total of 649 participants from rural and urban areas agreed to the study protocol and gave an informed consent. The inclusion criterion was that the women must have one child below five years of age at the time of the study.

All study procedures were approved by the Institute for Research and Ethics Committee (IREC) of Moi Teaching and Referral Hospital, Eldoret, Kenya. The subjects gave written and verbal consent to both study procedure and participation. The data were collected by the principal author and three trained research assistants in July and August 2011.

\section{Measurements}

Data were collected through interviews and anthropometric measurements. The interview consisted of a structured questionnaire and included questions on household socio-economic and demographic characteristics, 24 hour dietary recall, and a Household Food Insecurity measurement. After the interview, the respondents presented themselves for the anthropometric measurements. Data on standard of living (SOL), age, household size, marital status and number of children were collected.

To measure SOL, we considered assets ownership as well as income and expenditure. Income and expenditure were categorize into 1 for high and 0 for low income as well as 1 for high expenditure and 0 for low expenditure. The assets included owning a radio, cell phone, refrigerator, mode of cooking (gas, firewood or electricity) and type of house as well as having access to a toilet facility. We recorded the type of energy used for cooking into advanced and old methods of cooking: Gas and electricity were included in the advanced list whereas charcoal and firewood among other energy sources were in the old methods of cooking. The type of house was the last factor, where type of house was defined by the roofing and the building materials. Iron sheets and tiled roofing as well as stone were categorized into 1 for higher levels whereas 
grass-thatched and mud/iron-sheet roofing were categorized into 0 for the lower level. Principle component analysis and calculation of Cronbach's Alpha resulted in an 8 item standard of living scale.

Food Insecurity was measured by the Household Food Insecurity Access Scale (HFIAS) which is a nine-items scale consisting of two types of questions; an occurrence question followed by a frequency of occurrence question which asked the participant how often the condition reported in the previous occurrences question happened during the previous month (30). The occurrence questions asked whether the respondent or other household members either felt a certain way or performed a particular behavior over the previous one month. Before inclusion in the questionnaire, the questions were reviewed with Key Informants as suggested in the protocol. A standard scoring procedure was used with 1 point for occurrence and 0 for non-occurrence. The frequency scores ranged from 0 to 3, where 0 was the score for non-occurrence, 1 for rarely (once or twice in the past four weeks), 2 for sometimes (three to ten times in the past four weeks) and 3 for often (more than ten times in the past month). For the purpose of this paper we used the total score (9-items based on the frequency score). A total score of 27 represents a food insecure household whereas a lower score represents a more food secure household.

Data on household dietary diversity was collected with the Household Dietary Diversity Score (HDDS) (13). The HDDS captures dietary diversity in a normal 24 hour period by the household as a whole and not a single member. Food consumed outside the home that was not prepared in the home was not included. A set of 12 food groups was used to guide the scoring as per the food items consumed, with 1 being the minimum score and 12 as the maximum (13).

Anthropometric measurements of weight and height were taken from the woman who was interviewed. Weight was measured to the nearest $0.5 \mathrm{~kg}$ using a mechanical scale (SECA 762). Height was measure to the nearest millimeter also using a transportable stadiometer (SECA 214). The scales were calibrated after each session of measurements. Waist and hip measurements were measured using a tape. The waist was measured around the narrowest point between the navel and the ribcage. The hip was measured around the widest part of the hip to the nearest $\mathrm{cm}$. All measurements were taken with light clothing on and without shoes. A total of two measurements were taken and an average calculated.

\section{Data management and analysis}

The data were entered using Microsoft Excel 2003 and rechecked for accuracy to minimize errors. Analysis was done using Statistical Package for Social Sciences (SPPS) Version 17.1. Frequency distribution of all the data was done for descriptive purposes. 
Internal consistency of the measurements (Cronbach Alpha) was calculated for the Household Food Insecurity Access (HFIAS) and SOL. Pearson's correlation analysis was performed to compare relationship between variables. Logistic regression analysis was used to examine factors related to underweight (BMI $\leq 18.5)$ and overweight $(\mathrm{BMI} \geq 25)$ and linear regression analysis for predicting the total BMI score.

Tables 1: General characteristics of women in rural and urban in Narok County, Kenya

\begin{tabular}{lllll}
\hline & $\begin{array}{l}\text { Population } \\
\text { Mean (SD) } \\
\mathrm{n}=649\end{array}$ & $\begin{array}{l}\text { Rural } \\
\text { Mean } \\
\mathrm{n}=162\end{array}$ & $\begin{array}{l}\text { Urban } \\
\text { Mean } \\
\mathrm{n}=487\end{array}$ & p-value \\
\hline Weight $(\mathrm{kg})$ & $61.8(12.3)$ & $58.2(10.6)$ & $63.0(12.6)$ & .000 \\
Height $(\mathrm{m})$ & $1.6(0.07)$ & $1.61(0.07)$ & $1.60(0.06)$ & $\mathrm{NS}$ \\
Hip circumference $(\mathrm{cm})$ & $96.9(10.0)$ & $94.2(9.4)$ & $98.0(9.9)$ & .000 \\
Waist Circumference $(\mathrm{cm})$ & $79.0(10.5)$ & $77.3(11.2)$ & $79.3(11.1)$ & 0.05 \\
SOL & $4.97(1.92)$ & $3.62(1.82)$ & $5.42(1.73)$ & .000 \\
Household size & 4 & 5 & 4 & $\mathrm{NS}$ \\
Age (years) & 26 & 26 & 26 & $\mathrm{NS}$ \\
Post Primary education \% & 49.2 & 12.3 & 36.9 & .000 \\
Marital status (\%) & & & & \\
Single & 9.5 & 6.2 & 87.5 & $\mathrm{NS}$ \\
Married & 88.6 & 92.0 & 1.8 & $\mathrm{NS}$ \\
Other\# & 1.8 & 1.9 & $\mathrm{NS}$ \\
\hline
\end{tabular}

Note: SD- standard deviation, cm- centimeters, NS-not significant, \#separated/widowed/divorced

\section{Results}

\section{Anthropometrics measurements and general characteristics}

Table 1 presents data on age, marital status, education and anthropometric measurements of the women. Among the participants, $88.6 \%$ were married. At least $5.5 \%$ of the women had no formal or informal education and $49.2 \%$ had post primary level of education in the study group and primary education was reported by $45.3 \%$ of the women. Education beyond primary level was reported by $54.4 \%$ and $33.3 \%$ of the urban and rural participants respectively. Main source of income, according to $38.6 \%$ of the respondents was from formal employment.

Running of a small holdings business such as small shops or kiosks as the main source of income was reported by $24.5 \%$, whereas farming was the main source of income for $19.6 \%$ participants. Crop production (28\%) was the main agricultural activity followed by mixed farming at $11.6 \%$ (livestock and crop). 
The women who had more than one child less than five years of age were $40 \%$. The average household size was 5 and 4 in the rural and urban areas respectively. At the interview date, $73.7 \%$ of the women had not moved residence within the past six months and $66.6 \%$ lived in rental houses. A total of $33.5 \%$ of women had access to their own tapped water, while $25.5 \%$ of the women used communal tapped-water points, $16 \%$ bought water from vendors and $25 \%$ got the water from a borehole, a stream/river or harvested rain water. Women who had no access to a toilet facility were $7.9 \%$. Relief food which is common in the arid and semi-arid areas has not been accessed by $88.6 \%$ of the women in the community. Meals were shared at the same time by all family members in $66.3 \%$ of the households whereas $16.9 \%$ served children first whereas $16.2 \%$ served husband or male figures in the households first.

\section{Nutritional status and Household food security}

Body Mass Index (BMI) of women was higher in the urban (24.5) compared to the rural (22.5) areas. Combined overweight and obesity was higher in the urban $39.6 \%$ compared to that of rural participants (21\%). However, underweight was $11.2 \%$ and $3.7 \%$ among the rural and urban women respectively. The percentage of the population that had waist-to-hip ratio (WHR) $\geq 0.85$ was $26.2 \%$, whereas those who had waist circumference $\geq 80 \mathrm{~cm}$ were $38.9 \%$ (Table 2). The Household Dietary Diversity Score (HDDS) had a mean score of 6.56 for the total population and did not significantly differ between urban and rural settings.

However, the Household food insecurity access differed slightly with rural settings being more insecure $(12.61 \pm 6.8)$ than the urban $(11.20 \pm 6.03)$. A total of $4.3 \%$ of the population were food secure whereas $70.1 \%$ reported severe food insecure access. Affirmative responses to the 9 items in the scale ranged from $53.5 \%$ to $88.0 \%$. The item least frequently receiving an affirmative response was question 8 , 'Did you or any household member go to sleep at night hungry?' Whereas the item receiving the highest number of affirmative responses was question 1, 'Did you worry that your household would not have enough food?' 
Table 2: Descriptive statistics of Nutritional status, Dietary diversity and Household food security among rural and urban women in Narok County, Kenya ( $\mathrm{N}=649)$

\begin{tabular}{lllll}
\hline Variables & $\begin{array}{l}\text { Population } \\
\text { Mean (SD) } \\
n(649)\end{array}$ & $\begin{array}{l}\text { Rural } \\
\text { Mean (SD) } \\
n(162)\end{array}$ & $\begin{array}{l}\text { Urban } \\
\text { Mean (SD) } \\
n(487)\end{array}$ & p-value \\
\hline Average meals per day & $3.0(0.51)$ & $2.97(0.47)$ & $3.03(0.52)$ & 0.15 \\
HDDS & $6.56(1.3)$ & $6.41(1.27)$ & $6.61(1.30)$ & 0.093 \\
HFIAS score & $11.5(6.26)$ & $12.61(6.80)$ & $11.20(6.03)$ & 0.013 \\
BMI (kg/m²) & $24.0(4.3)$ & $22.4(3.6)$ & $24.5(4.4)$ & 0.000 \\
- Underweight (\%) & 5.6 & 11.2 & 3.7 & 0.000 \\
- Normal (\%) & 59.4 & 67.7 & 56.6 & 0.000 \\
- Overweight (\%) & 26.0 & 18.6 & 28.4 & 0.000 \\
- Obese (\%) & 9.1 & 2.5 & 11.3 & 0.000 \\
Waist circumference cm (\%) & 38.9 & 41.2 & 32.1 & 0.04 \\
WHR (\%) & 26.2 & 29.0 & 25.3 & 0.34 \\
\hline
\end{tabular}

Note: Body mass index $\left(\mathrm{kg} / \mathrm{m}^{2}\right)$, WHR- waist to hip ratio, HFIAS-Household food insecurity access scale, HDDS- household Dietary Diversity

Table 3: Inter-correlation of variables associated with nutritional status among women in Narok County, Kenya $(\mathrm{N}=649)$

\begin{tabular}{|c|c|c|c|c|c|c|c|c|c|}
\hline Variables & 1 & 2 & 3 & 4 & 5 & 6 & 7 & 8 & 9 \\
\hline 1 marital status & - & & & & & & & & \\
\hline 2. Education & -.054 & - & & & & & & & \\
\hline 3. HFIAS & -.004 & .022 & - & & & & & & \\
\hline 4.SOL & .004 & -.002 & $-.280 * *$ & - & & & & & \\
\hline 5. HDDS & -.020 & .048 & $-.127^{* *}$ & $.266^{* *}$ & - & & & & \\
\hline 6. Residence & .047 & $.137^{* *}$ & $.098 *$ & $-.408^{*}$ & -.068 & - & & & \\
\hline 7. BMI_Underweight & .044 & $.146^{* *}$ & $.078^{*}$ & $-.162 * *$ & -.037 & $.140 * *$ & - & & \\
\hline 8. BMI_Overweight & .038 & -.052 & $-.133^{* *}$ & $.257^{* *}$ & .042 & $-.169 * *$ & $-.178 * *$ & - & \\
\hline 9. No of children & $.12 * *$ & $.138 * *$ & $.167^{*}$ & $-.305^{* *}$ & $-.154 * *$ & $.253^{* *}$ & -.055 & $.082 *$ & - \\
\hline
\end{tabular}

Note: ${ }^{*} p<0.05 ;{ }^{*} p<0.01$, HFIAS-household food insecurity score, SOL- Standard of living HDDS- Household dietary diversity score, BMI_underweight =1, BMI_overweight=1

Pearson product-moment correlations were computed to assess the relation between SOL, HDDS, education, residence and number of children (Table 3 ). There was a positive association between HDDS and SOL $(r=.27, p<0.01)$ and negative association between HDDS and number of children ( $r=-.15, p<0.01$, whereas SOL was negatively associated with number of children $(r=-.31, p<0.01)$. When comparing education and $\mathrm{BMI}$, there was a significant positive relationship between education and underweight 
$(r=.15, p<0.01)$, and a positive relationship between education and overweight $(r=-$ $.052, p=0.184)$. Looking at the numbers of those with no education and underweight, the numbers were higher in the rural $(66.7 \%)$ areas compared to the urban $(45.6 \%)$ areas. Overweight had a positive association with number of children ( $r=.082, p<0.05)$.

Logistic regression analyses were performed on overweight and underweight as separate outcomes and eight predictor variables: marital status, education, SOL, number of children, household food insecurity score, household dietary diversity score, age and residence.

Table 4: Logistic Regression analysis of predictors of overweight among women in Narok County, Kenya $(n=648, B M I \geq 25)$

\begin{tabular}{lllll}
\hline & & \multicolumn{2}{l}{$95 \% \mathrm{Cl}$ for Odds } & \\
\cline { 5 - 5 } & $\mathrm{B}(\mathrm{SE})$ & Lower & Odds & \\
\hline Overweight & & .32 & .60 & 1.12 \\
Marital status & $-.510(0.32)$ & .81 & 1.22 & 1.86 \\
Education & $.202(0.21)$ & 1.19 & 1.79 & 1.53 \\
SOL & $.298^{*}(0.07)$ & .92 & 1.13 & 1.38 \\
No of children & $.117^{*}(0.11)$ & .94 & .97 & 1.00 \\
HFIAS & $-.029 *(0.016)$ & .86 & .99 & 1.15 \\
Dietary Diversity & $-.009(0.075)$ & 1.10 & 1.82 & 3.00 \\
Residence (urban) & $.597 *(.255)$ & 1.05 & 1.10 & 1.15 \\
Age & $.093^{*} *(0.023)$ & & & \\
Constant & $-4.977(.831)$ & & .96 & \\
\hline
\end{tabular}

Model $x^{2}(1)=94.00,{ }^{*} p<.05,{ }^{*} p<.001 ;$ SOL- standard of living; HFIAS- household food insecurity access scores; SE-standard error.

Table 4 and Table 5 show the regression coefficients, odds ratios and 95\% confidence intervals for each of the eight predictor variables. Predictors of overweight that were significant were SOL, age, number of children in the household, residing in the urban and lower household food insecurity access score as indicated in Table 4. Women who had higher SOL had higher odds of being overweight (OR=1.79, $\mathrm{Cl} 1.19,1.53,95 \%)$, and older women had higher odds of being overweight (OR=1.10, $\mathrm{Cl}, 1.05,1.15,95 \%)$. A negative association was reported between overweight and HFIAS (OR=.97, Cl .94, 1.0, 95\%), indicating that the lower the food insecurity score the higher overweight and vice versa. Regarding the prediction of underweight, younger women had higher odds of being underweight ( $\mathrm{OR}=.91, \mathrm{Cl} .83,1.0,95 \%)$ (Table 5). Although not significant, being underweight reduced with increased SOL. 
Table 5: Logistic Regression analysis of predictors of underweight among women (BMI $\leq 18.5, \mathrm{n}=649$ )

\begin{tabular}{lllll}
\hline & & \multicolumn{2}{l}{$95 \% \mathrm{Cl}$ for Odds Ratio } \\
\cline { 4 - 5 } & $\mathrm{B}(\mathrm{SE})$ & Lower & Odds & Upper \\
\hline Underweight & $.249(0.53)$ & .45 & 1.28 & 3.64 \\
Marital status & $.343(0.46)$ & .57 & 1.41 & 3.50 \\
Education & $-.186(0.13)$ & .65 & .83 & 1.07 \\
SOL & $.198(0.19)$ & .84 & 1.22 & 1.78 \\
No of children & $.013(0.03)$ & .96 & 1.01 & 1.07 \\
HFIAS & $-.020(0.15)$ & .73 & .98 & 1.32 \\
Dietary Diversity & $-.093 *(.05)$ & .83 & .91 & 1.004 \\
Age & $-.568(0.42)$ & .25 & .57 & 1.295 \\
Residence (urban) & $-.093(1.67)$ & & & \\
Constant & & & & \\
\hline
\end{tabular}

Model $x^{2}(1)=21.59$ : HDDS-Household dietary diversity score, SOL- standard of living, No- number, SE-

standard error

Linear regression analysis was computed to assess the association between $\mathrm{BMI}$ and all 8 predictor variables. There was a positive significant relation between $\mathrm{BMI}$ and the predictor variables $\left(\mathrm{R}^{2}=.17, \mathrm{p}<.001\right)$ as seen in Table 6. Only age (Beta $\left.=.28, \mathrm{P}<.001\right)$ and SOL (Beta=.29, $\mathrm{p}<.001$ ) were positively associated with BMI.

Table 6: Linear Regression analysis of BMI and standardized beta of predictors variables among women in Narok County, Kenya ( $n=649)$

\begin{tabular}{llll}
\hline & B & SE B & B \\
\hline Marital status & .19 & .50 & .01 \\
Education & -.08 & .38 & -.01 \\
SOL & .63 & .10 & $.28^{*}$ \\
No of children & .07 & .18 & .02 \\
HFIAS & -.02 & .03 & -.04 \\
HDDS & -.02 & .13 & -.01 \\
Age & .23 & .04 & $.29 *$ \\
Residence (urban) & .08 & .41 & .01 \\
Constant & 14.95 & 1.46 & \\
\hline
\end{tabular}

Note: $\mathrm{R}^{2}=.17(p<.001)$. ${ }^{*} p<.001$, SOL-standard of living, HFIAS-household food insecurity access score, HDDShousehold dietary diversity 


\section{Discussion}

In this study, urban women had higher numbers of overweight compared to their rural counterparts, and although underweight existed in both groups, the prevalence was lower compared to overweight in the study group. This is in agreement with many studies in developing countries that report that urban dwellers are frequently better nourished than their rural counterparts (31-33). However, the fact that the urban areas in our study mainly consisted of peri-urban dwellers with a poor infrastructure and low economic status may explain that the prevalence of underweight persisting among both the rural and urban dwellers although the prevalence was high among rural dwellers. In addition, overweight is an emerging problem among the rural dwellers as observed in our study. The predictors of overweight among our participants were SOL, age, HFIAS score, residence and number of children while age was a significant predictor of underweight.

In our study the urban dwellers reported a high number of overweight and underweight respectively and that overweight was related to high standard of living. This was the case in a study by Ziraba et al. that indicated that urban dwellers had the highest cases of obesity (2). High standard of living using wealth index may be translated to mean wealthy households thus our study agrees with the findings from a study among Ghanian women which indicated that obesity was common among wealthy households as opposed to the poor (34) and a study by Shayo (35) which indicated that participants with a high socio-economic status had a statistically significant increased risk for obesity compared to participants with low socio-economic status. It is worth noting that the study by Ziraba (2), reports an increase in obesity among higher socioeconomic groups as well as an increase in the number of obese among the lower socioeconomic group. In our study SOL was a measure of income, expenditure, access to toilet facility, advanced cooking method, owning a cell phone as well as type of housing material thus it cannot be used interchangeably with socioeconomic status in the reported studies.

Education levels within the study area were still low compared to other counties in Kenya (36). Education is important in terms of making choices when it comes to resource allocation. Studies indicated that women who receive even a minimal education are generally more aware than those who have no education of how to utilize available resources for the improvement of their own nutritional status and that of their families (37-39). A cultural practice that is common among the study population is that of marrying-off girls at a young age, thus within this community one is likely to find young married women. The youngest participant among the study population was 15 years of age. According to a government document released in 2008 secondary education enrolment rate for girls in the study area was $15 \%$ and that of boys was 
$20 \%$, while primary education enrollment rate was $73 \%$ and $83 \%$ for girls and boys respectively (36). Using education as a proxy for socioeconomic status the study by Ziraba et al. which included data from Kenya, indicated that the prevalence of obesity was higher among the non-educated than educated group (2), however in our study, it is worth noting that the percentage number of women who had attained post-primary education was higher among rural dwellers compared to urban dweller. Thus the noneducated and the primary level educated women were mainly found in the urban areas, where overweight was higher. In addition, overweight women were low among households where the respondent had no education but the numbers increased among the primary and secondary level of education respondents. This may relate to income or job opportunities whereby the no education women had lower chances of getting higher paying employment while those with primary or secondary level of education had opportunities of increasing income and thus increased in food access, however this may not always be the case.

Age was an important predictor of BMI among women in that the older the women the higher the chances of them being overweight and the younger the women the higher the probability of underweight and thinness (40). Women tend to gain weight with increasing age and parity (41-44). However some studies indicate greatest weight gain among young adults (20-29y) particularly women (45). During pregnancy women gain weight and they may not lose this weight after pregnancy and in the event that they become pregnant again additional weight is gained. This concurs with other studies that indicated that if excessive pregnancy weight is not lost soon after breastfeeding, overweight and obesity may occur (46). However, younger age was an important predictor of underweight as also reported by Griffiths et al (40). Underweight prevalence was also higher among rural women compared to urban women in our study; this may be explained by the longer distances women traveled to access social amenities such as shops, health centers, searching for water etc. Thus, activity levels may be high among this group leading to underweight and thinness. However, this is beyond the scope of this paper and will be discussed elsewhere.

Most households were predominantly male-headed households as indicated by the larger percentage of married women among the participants. According to a study done in Ethiopia, marital status of women is associated with household headship and other social and economic status of the women that affects their nutritional status (37). When women control resources, children and household members become better nourished (47). However, when it comes to nutritional status of children, conflicting results have also been reported in studies that show children of working mothers to have a lower nutritional status compared to children of mothers who work at home (48). This brings into focus the issue of care, whereby women who leave their children in the care of others may compromise the nutritional status of their children as op- 
posed to the mothers who work at home and care for their children themselves. In our study, the married participants had higher prevalence of overweight compared to the single, divorced or separated; however, underweight was more prevalence among the younger group (ages 15-24).

Household food insecurity arises when families do not have enough to eat, in that food is neither available nor accessible. In our study area, food insecurity was predominant in many households as reported in government documents (49). Seasonal hunger per se is the most common during planting seasons and just before harvest are the times the people go hungry. According to a study by Vaitla et al. most of the world's hunger and under-nutrition occurs during the pre-harvest season (50). However, as much as this is the case in this population, overweight is still reported among some of the participants in our study, indicating that overweight is not only a disease of the rich but also of the poor. The results from this study indicated that household food insecurity access is a predictor of overweight and this is also reported in other studies $(2,19$, $21,35)$. In this study, household food insecurity access is not a statistically significant predictor of underweight. This is in contradiction with a study which showed that food insecurity predicted underweight but not overweight among adults and children (25). With increasing overweight and underweight among respondents within food insecure household brings into question the quality of the food consumed and maybe also the quantity, particularly fried foods which are cheap and easily available particularly in the urban areas.

Number of children being a predictor of overweight in this study seems related to parity. As a woman gives birth to many children without losing pregnancy weight between births, their weight progressively increases. Parity, according to a study done in Ghana, was significant in predicting obesity (34). In our study women who had one or two children were more likely to be underweight and overweight. Increased number of children per household would mean scarcer resources and increased physical activity for the mother in providing and caring for the children thus the lower BMI among those with many children. Sanitation is equally important in determining nutrition and in this study most of the households used communal water points and in the rural area women traveled long distances to get water whereas within the urban area water was sold at the communal water-points by water vendors. Several studies have looked at the relationship between source of water and availability of toilet facility in that inadequate water and sanitation increase the probability of infectious disease and indirectly cause some types of malnutrition $(38,39)$. The relationship between sanitation and nutritional status of women was reported in another unpublished article (51).

Our study had some limitations; i) we did not study cultural diversity. Different cultures have different food consumption patterns and dietary habits and thus nutritional status of the different communities (tribes) would differ as a result of varied 
dietary habits, ii) Nutrient security is also important in explaining the overall nutritional status of an individual, our study did not look at the different nutrients in the diet, which would predispose one to either overweight or underweight, iii) Our study did not take into consideration physical activity to explain overweight and underweight among women but included in another ongoing study.

\section{Conclusion}

Overweight is a major nutritional problem among women in the study area although food insecurity is also a problem confirming the paradox of over-nutrition occurring where food insecurity exists. In our study food secure household have higher odds of being overweight and not underweight. Other predictors of overweight included being in an urban settlement, high SOL, increasing number of children and age whereas, dietary diversity reduced with increasing household food insecurity. 


\section{References}

1. Villamor E, Msamanga G, Urassa W, Petraro P, Spiegelman D, Hunter DJ, et al. Trends in obesity, underweight and wasting among women attending prenatal clinics in urban Tanzania 1995-2004. American Journal of Clinical Nutrition 2006 83(6):1387-94.

2. Ziraba AK, Fotso JC, Ochako R. Overweight and obesity in urban Africa: A problem of the rich or the poor? BMC Public Health 2009;9.

3. Abubakari AR, Lauder W, Agyemang C, Jones M, Kirk A, Bhobal RS. Prevalence and time trends in obesity among adult West African populations: a meta-analysis Obesity Reviews 2008;9(4):297-311.

4. Martorell R, Khan LK, Hughes ML, Grummer-Strawn LM. Obesity in women in developing countries European Journal of Clinical Nutrition 2000;54(3):247-52.

5. Kamadjeu R, Edwards R, Atanga JS, Kiawi EC, Unwin N, Mbanya JC. Anthropometry measures and prevalence of obesity in the urban adult population of Cameroon: an update from Cameroon Burden of Diabetes Baseline Survey BMC Public Health. 2006;6:228.

6. Sodjinou R, Agueh V, Fayomi B, Delisle H. Obesity and cardio-metabolic risk factors in urban adult of Benin: relationship with socio-economic status, urbanization, and lifestyle patterns BMC Public Health. 2008;8:84.

7. WHO. Preventing chronic diseases, a vital investment. 2005.

8. Gulliford MC, Mahabir D, Rocke B. Food Insecurity, food choices, and body mass index in adults: Nutrition transition in Trinidad and Tobago International Journal of Epidemiology 2003;32:508-16.

9. WHO. Obesity: Preventing and Managing global epidemic Report of a WHO consultation WHO Technical Report [Internet]. 2000. Available from: http://www.ncbi.nlm.nih.gov/pubmed/11234459.

10. Harnack LJ, Jeffrey RW, Boutelle KN. Temporal trends in energy intake in the US: an ecological perspective American Journal of Clinical Nutrition. 2002;71(1478-84).

11. Dietz WH. Does hunger cause obesity? . Pediatrics 1995;95:766-7.

12. Alaimo K, Olson CM, Frongilo EA Jr. Low family income \& food insufficiency in relationhip to overweight in US children: Is there a paradox Arch Pediatrics Adolescents Med. 2001;155:1161-67.

13. Swindale A, Bilinsky P. Household Dietary Diversity Score (HDDS) for Measurement of Household Food Access: Indicator Guide v. 2. Food and Nutrition Technical Assistance Project, Academy for Educational Development [Internet]. 2006. Available from: http://www.unscn.org/layout/modules/resources/files/HDDS_for_measurement_of_household_food_access.pdf.

14. Carlson SJ, Andrews MS, Biekel GW. Measuring food insecurity and hunger in the United Stats: Development of a national benchmark measure and prevalence estimate. Journal of Nutrition. 1999;129(510S-06S).

15. Pinstrup-Andersen P, Cohen MJ. Modern Biotechnology for Food Agriculture: Risks and opportunity for the poor 2000. Available from: http://cgiar.bio-mirror.cn/biotech/rep0100/Ppanders.pdf.

16. Popkin BM. An overview on the nutrition transition and its health implications: the Bellagio meeting. Public Health Nutrition. 2002;5(1A):93-103.

17. Clugston GA, Smith TE. Global nutrition problems and novel foods Asia pacific journal of clinical nutrition 2002;11(S6):S100-S11.

18. Sarlio-Lahteenkorva S LE. Food insecurity is associated with past and present economic disadvantage and body mass index Journal of Nutrition. 2001;131:2880-4.

19. Adams EJ, Grummer-Strawn L, Chavez G. Food insecurity is associated with increased risk of obesity in California women Journal of Nutrition. 2003;133:1070-4.

20. Townsend MS, Peerson J, Love B, Achterberg C, Murphy SP. Food insecurity is positively related to overweight in women journal of Nutrition. 2001;131:1738-45.

21. Velasquez-Melendez G, Schlussel MM, Brito AS, Silva AAM, Lopes-Filho JD, Kac G. Mild but not light or severe food insecurity is associated with obesity among Brazilian women The journal of nutrition 2011 May;141(5):898-902.

22. Doak CM, Adair IS, Monteiro C, Popkin BM. Overweight and underweight coexist within households in Brazil, China and Russia. Journal of Nutrition 2000;130:2965-71.

23. Caballero B. A Nutrition Paradox-underweight and obesity in Developing Countries The New England Journal of Medicine. 2005;352(15):1514-6.

24. Mendez MA, Monteiro CA, Popkin MB. Overweight exceeds underweight among women in most developing countries American Journal of Clinical Nutrition. 2005;81:714-21. 
25. Isanaka S, Mora-Plazas M, Lopez-Arana S, Baylin A, Villamor E. Food insecurity is highly prevalent and predicts underweight but not overweight in adults and school children from Bogota, Columbia. Journal of Nutrition. 2007 Dec;137(12):2747-55.

26. Whitaker RC, Sarin A. Change in food security status and change in weight are not associated in urban women with preschool children Journal of Nutrition. 2007;137:2134-9.

27. Jones SJ, Frongillo EA. Food insecurity and subsequent weight gain in women Public Health Nutrition. 2007;10:145-51.

28. Krause RM, Winston M, Fletcher BJ, Grundy SM. Obesity: impact on cardiovascular disease. Circulation 1998;98:1472-6.

29. WHO. Obesity: preventing and managing the global epidemic Report of WHO consultation on obesity 3-5 June 1997 [Internet]. 1997. Available from: http://whqlibdoc.who.int/hq/1998/WHO_NUT_NCD_98.1_(p1-158).pdf.

30. Coates J, Swindale A, Bilinsky P. Household Food Insecurity Access Scale (HFIAS) for Measurement of Food Access: Indicator Guide v. 3. Food and Nutrition Technical Assistance Project, Academy for Educational Development [Internet]. 2007. Available from: http://www.fao.org/fileadmin/. user_upload/eufao-fsi4dm/doc-training/hfias.pdf.

31. Smith LC, Ruel MT, Ndiaye A. Why is child malnutrition lower in urban than in rural areas? Evidence from 36 developing countries World Development 2005;33(8):1285-305.

32. Ruel MT, Garret JL, Morris SS, Maxwell DS, Oshaug A, Engle P, et al. Urban challenges to food and nutrition security: a review of food security, health and Caregiving in the cities. FCND Discussion Paper [Internet]. 1998; 51. Available from: http://citeseerx.ist.psu.edu/viewdoc/summary?doi=10.1.1.31.791.

33. Ruel MT, Garrett JL. Features of urban food and nutrition security and considerations for successful urban programming Paper prepared for FAO Technical Workshop [Internet]. 2003. Available from: ftp://ftp.fao.org/es/esn/food_systems/RuelF.pdf.

34. Dake FA, Tawiah EO, Badasu DM. Sociodemographic correlates of obesity among Ghanaian women Public Health Nutrition. 2010;14(7):1285-91.

35. Shayo GA, Mugusi FM. Prevalence of obesity and associated risk factors among adults in Kinondoni municipal district, Dar es salam Tanzania. BMC Public Health. 2011;11:365.

36. GOK. Narok District Development Plan2008. Available from: http://books.google.co.ke/books/about/District_Development_Plan_2008_2012_Naro.html?id=JxAZnQEACAAJ\&redir_esc=y.

37. Girma W, Genebo T. Determinants of nutritional stuat of women and children in Ethiopia2002 November Available from: http://dhsprogram.com/pubs/pdf/FA39/02-nutrition.pdf.

38. UNICEF. Strategies of improving nutritional status of children and women in developing countries Indian Journal of Pediatrics 1990 Jan-Feb;58(1):13-24.

39. Engle PL. Care and child nutrition: Theme paper for the international conference on nutrition (ICN)1992 March.

40. Griffiths PL, Bentley ME. The Nutrition Transition is Underway in India Journal of Nutrition. 2001;131(10):2692-700.

41. Cohen SS, Larson CO, Mathews CE, Buchowski MS, Signorello LB, Hargreaves MK, et al. Parity and Breastfeeding in relation to obesity among black and white women in the southern commmunity cohort study Journal of women's Health 2009;18(9):1323-32.

42. Harris HE, Elisson GT, M. H. Is there an independent association between parity and maternal weight gain? Annals of Human Biology. 1997 Nov-Dec;24(6):507-19.

43. Cohen A, Pieper CF, Brown AJ, Bastian LA. Number of children and risk of metabolic syndrome in women Journal of women's Health. 2006;15:763-73.

44. Buschur E, Kim C. Guidelines \& Interventions for obesity during pregnancy International journal of gynaecology and obstetrics 2012 July;119(1):6-10.

45. Kimokoti RW, Newby P, Gona P, Zhu L, Mckeon-O'malley C, Guzman JP, et al. Patterns of weight change and progression to overweight and obesity differ in men and women: Implications for research and Interventions. Public Health Nutrition 2012 August 1-13.

46. Rooney BL, Schauberger C.W. Excessive pregnancy weight gain and long-term obesity: one decade later. Obstetrics and Gynecology 2002 August 100(2):245-52.

47. Kelkar G. Rural women's work and capabilities: information for Gener-Responsibilities Development Policies. High-Level consultation on rural women \& information [Internet]. 1999. Available from: <http://www.fao.org/docrep/X3803E/X3803E00.htm>. 
48. Bennet L. The role of women in income, production and intra-household allocation of resources as a determinant of child nutrition and health Food and Nutrition Bulletin 1988;10(3).

49. GOK. Arid Lands Resource Management Project Drought Monthly Bulletin [Internet]. 2011. Available from: http://www.aridland.go.ke/bullentins/2011/september/narok.pdf.

50. Vaitla B, Devereux S, Swan HS. Seasonal hunger: A neglected problem with proven solutions. PLoS Medicine 2009 June 6(6).

51. Keino S, Plasqui G, van den Borne B. Is overweight found among the food insecure? - A study on prevalence and risk factors of malnutrition among children in Narok, Kenya 2013. 



\section{CHAPTER 4}

Is overweight found among the food insecure?

a study on prevalence and risk factors of malnutrition among children in Narok

County, Kenya

Susan Keino, Guy Plasqui and Bart van den Borne

Submitted for publication 


\begin{abstract}
Background: Overweight is on the increase in sub-Saharan Africa, where food insecurity is prevalent. The overall objective of this study was to investigate food insecurity and the prevalence and risk factors of overweight and under-nutrition among children in Narok County, in Kenya.
\end{abstract}

Methods: From a random sample of 649 children under-five attending the Mother and Child Clinic (MCH) in Narok County, anthropometric measurements were taken and a structured questionnaire was completed by the mothers.

Results: Mild, moderate and severe stunting were $12.3 \%, 4.8 \%$ and $2.6 \%$ respectively, $15.7 \%, 6.0 \%$ and $2.2 \%$ for underweight and $16.6 \%, 5.2 \%$ and $4.3 \%$ for wasting respectively. Overweight was $6.9 \%$. Logistic regression showed that having a married mother (Odds ratio $(O R)=.4$, confidence interval $(\mathrm{Cl}) 95 \%, 1.2-6.5$ ) and drinking boiled water $(\mathrm{OR}=0.3, \mathrm{Cl} 95 \%, .11-.83)$ as significant predictors of overweight. Significant predictors of stunting included being a younger child $(\mathrm{OR}=1.1, \mathrm{Cl}, 95 \%, 1.0-1.1)$, high number of children in a household $(\mathrm{OR}=1.7, \mathrm{Cl} 95 \%, 1.2-2.5)$, and high maternal $\mathrm{BMI}$ (OR=1.1, $\mathrm{Cl} 95 \%, 1.0-1.2)$. While significant predictors of wasting included high number of children (OR=.67, $\mathrm{Cl} 95 \%, .46-.98)$, having a married mother (OR=.13, Cl 95\%, .02$.96)$ and recently suffered from fever (OR=1.8, Cl95\%, 1.2-2.5). Significant predictors of underweight were being a younger child's (OR=1.1, CI95\%, 1.0-1.1) and young mother (OR=.90, Cl95\%, .82-.98).

Conclusion: Household food insecurity was not a predictor of overweight; however maternal factors play a crucial role in under- nutrition of children and also overweight. Tailor-made programs are needed to curb the raising overweight and persistent under-nutrition in Kenya. Key words: Household food insecurity access, overweight, underweight, stunting, children (0-5yrs) 


\section{Introduction}

Food insecurity is the inability to consistently acquire enough calories and nutrients for a healthy and productive life (1). Food insecurity affects dietary intake and, ultimately, nutritional status and physical well-being of children (2). In some developed countries, studies report a link between food insecurity and overweight and obesity $(3,4)$, while in developing countries food insecurity has always been associated with hunger and under-nutrition, until recently when the 'double burden' of malnutrition was reported showing under-nutrition along with an increase in overweight and obesity in the same population (5).

Globally, approximately $30 \%$ of children under 5 years old are stunted and $18 \%$ are underweight (6). In 2010, 35 million children in developing countries were estimated to be overweight and obese and it is projected that in 2015, 4.5 million children (0-5 y) will be overweight and obese in Eastern Africa (7). The Kenya demographic Health Survey (KDHS) of 2008-2009 indicated that the proportion of stunted children declined from $35 \%$ in 2000 to $30 \%$ in 2008-09 (8). Overweight among children (< 5 yr.) in Kenya is reported in some studies (9-11) and the prevalence was 5\% in 2008 (10). Stunting and overweight have been reported to coexist in the same population and sometimes an individual can be stunted and overweight at the same time (9). A recent study on trends and determinants of under-nutrition in Kenya indicates an emerging pattern of this double burden of malnutrition in the same households (12). However, the study by Masibo et al. does not report on the magnitude of overweight as a health problem in Kenya and its determinants. Childhood overweight and obesity are known to have serious adverse psychological, social and health consequences in childhood and later in life, particularly cardiovascular diseases (13). Stunting has also been known to increase the likelihood of one being overweight later in life (14). While studies conducted previously have highlighted the prevalence and determinants of under-nutrition $(12,15)$ few studies have examined the element of over-nutrition and its determinants in Kenya, particularly its coexistence with under-nutrition and food insecurity (9). The studies by Gewa (9) and that of Pawloski et al. (11) were based on the data from the Demographic Health Survey (8). Gewa reported overweight among pre-school children to be approximately $18 \%$ and obesity was $4 \%$ while factors associated with overweight among children were higher maternal level of education, maternal overweight, high birth weight and being stunted. Whereas Pawloski et al. indicated that there were geographic factors influencing the nutritional status of children for example the high prevalence of overweight and obesity in the urban areas and possibility of cultural factors impacting on nutrition. Both studies do not report on the role of food security or the lack of it on overweight among children. The relationship between disease and nutritional status among children has been documented $(16,17)$. Child malnutrition may 
cause infections while infections may result in under-nutrition. Wamani et al. indicate that stunting was predicted by factors such as socio-economic, health-care and environmental factors (18), while Masibo and Makoka reiterate that wasting is associated with availability and type of toilet facility (12). The emphasis of this paper was to highlight the importance of stunting and overweight among children in Africa and how food insecurity and other factors plays a role in determining nutritional status. Therefore the specific objectives of the study were to document prevalence of malnutrition, to determine the association between household food security and malnutrition and to identify the predictors of malnutrition among children in Kenya.

\section{Methods}

\section{Study setting}

This study was conducted in Narok County, Kenya. Narok County is located on the South West part of Kenya within the Rift Valley region. It borders Nakuru, Bomet, Bureti, Nyamira and Kisii Counties to the North West, Kajiado to the East and Migori to the West. Narok County also shares a border to the South West with Tanzania. The estimated total population in Narok by the year 2009 was 850,920 with a density of 47 people per $\mathrm{Km}^{2}$ (19) The study took place in the former Narok North before it merged with Narok South to form the Narok County. Narok has a varied topography with altitudes ranging from 3,098 metres above sea level in the highlands to 1,000 meters in the lowlands. Although, the potential for farming in the highlands is high, the lowlands have made the County be classified as among the Arid and semi-arid lands, which are dry and prone to drought and food insecurity (20).

\section{Recruitment and Sampling}

This study was part of a longitudinal study that included women 15- 45 years of age with their youngest child below the age of $5 \mathrm{yr}$. Data collection took place between March 2011 and March 2012 at the Narok District Hospital which serves the entire Narok County. A total of 670 women were recruited through random sampling. A total of 21 women were excluded from the study for either not completing the questionnaire or declining to be interviewed. The final sample interviewed for this study was 649 women and 649 children were also presented for measurements. Interviews and measurements were conducted after the women had gone through routine clinic check-up and if for any reasons this was not completed follow-ups were made to the respondent's residence or during the next clinical visit. Research assistants were trained for two days on how to carry out the measurements and to familiarize them- 
selves with the tools. A pilot study took place prior to the main study to test the instruments (21).

\section{Measures}

\section{a. Household food insecurity}

Food Insecurity was measured by the Household Food Insecurity Access Scale (HFIAS) which is a nine-items scale consisting of two types of questions; an occurrence question followed by a frequency of occurrence question which asks the participant how often the condition reported in the previous occurrences question happened during the previous month (22). The occurrence questions ask whether the respondent or other household members either felt a certain way or performed a particular behavior over the previous one month. Before inclusion in the questionnaire, the questions were reviewed with Key Informants as suggested in the protocol. A standard scoring procedure as detailed in the protocol (22) was applied to arrive at the categories of food insecurity access (food secure, mild, moderate and severe food insecurity) and the Household food insecurity score (HFIAS Score) based on the frequency of occurrence scores. A household food insecure score of 27 is deemed as food insecure and 0 for food secure.

\section{b. Dietary Diversity}

Data on household dietary diversity was collected with the Household Dietary Diversity Score (HDDS). The HDDS captures dietary diversity in a normal 24 hour period by the household as a whole and not for a single member. Food consumed outside the home that was not prepared in the home was not included. A set of 12 food groups was used to guide the scoring as per the food items consumed, with 1 being the minimum score and 12 as the maximum for dietary diversity (23).

\section{c. Anthropometric measurements}

Weight and height/length were measured to assess the nutritional status of the children. Height/length was measured using a SECA 416 measurement board whereas weight was measured using a SECA 725/834 digital baby weight scale. For Children < 2 years the recumbent length was measured with the child lying down on its with legs stretched. Two measurements were obtained for both and the average was calculated and recorded. Both measurements were obtained with minimal clothing on the child and without shoes.

The weight and height of the mother was also measured to calculate BMI. A SECA 762 mechanical scale was used to measure weight to the nearest $0.1 \mathrm{~kg}$ and a SECA $217 / 214$ height board was used to measure height to the nearest $0.1 \mathrm{~cm}$. Both measurements were taken with minimal clothing on and without shoes. 


\section{d. Interview Schedule}

A structured questionnaire was used to obtain data on socio-economic and demographic characteristics and was administered to the mother. The questionnaire was divided into 3 main sections: i) Socio-economic and demographic ii) food, nutrition and health iii) $a$. Household food insecurity access scale-the measurement tool and $b$. Household Dietary Diversity Indicator-Measurement of Household food access.

\section{Data processing and analysis}

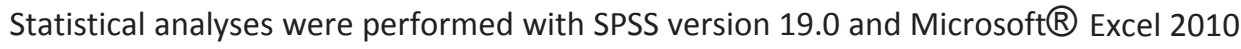
for Windows 7. Anthropometric measurements of all the sampled children and $z$ scores were determined using EPI Info ${ }^{\mathrm{TM}} 7$ using WHO reference standards (24) and the indices (Height-for-age, weight-for-height and weight-for-age) analyzed in SPSS. Children who were below minus 1 standard deviations (-1SD) were considered mildly undernourished, while below minus 2 (-2SD) were considered, moderately undernourished, while those below minus 3 standard deviation (-3SD) were severely undernourished. Overweight was above 2 standard deviation (+2SD) weight-for-height. Nutritional status of the mothers was determined using BMI (Weight in kilograms divided by height in meters square). The BMI for mothers was categorized according to WHO (25) classifications; underweight (BMI<18.5), normal weight (BMI=18.5-24.9), overweight $(B M I=25-29.5)$ and obese $(B M I \geq 30)$. Binary logistic regression analysis was used to identify the significant predictors of malnutrition among children. The independent variables were all entered in one model with the outcome variables coded as 0 and 1 , 1 to indicate if the outcome of interest is present and 0 for when it is absent. Independent t-test was used to compare rural and urban affirmative response scores in food insecurity access.

\section{Ethical Approval}

The study procedures and protocol was approved by the Moi University and the Moi Teaching and Referral Hospital ethics committee in Eldoret, Kenya. It was also approved by the Narok District Hospital Medical Officer who gave permission for the research team. Written informed consent was obtained from the mother for the interview to take place and the measurements of the child to be taken.

Results 
Socio-demographics characteristics, food security status and nutritional status of children

The male and female children were $51.8 \%$ and $49.2 \%$ respectively, while those from urban area were $75 \%$ and the rural area 25\% (Table 1). The participant's ages ranged from 1 month to 59 months (Mean: 8.7, SD: 8.4) whereas $88.6 \%$ of the children were from households with a married mother. The mean household size was $4.3(S D=1.7)$. There was no significant difference in mean height between male and female children $(69.2 \pm 10.6,67.9 \pm 9.3)$, except for weight which was significantly higher among males $(8.16 \pm 2.4,7.65 \pm 2.3 ; p<0.001)$. The prevalence of stunting was $12.3 \%$ mildly stunted, $4.8 \%$ moderately stunted and $2.6 \%$ were severely stunted. Mildly wasted was reported among $16.6 \%$ of the children, $5.2 \%$ were moderately wasted and $4.3 \%$ were severely wasted. Mildly underweight was reported among $15.7 \%$ of the children, $6.0 \%$ were moderately underweight and $2.2 \%$ were severely underweight. Overweight prevalence was at $6.9 \%$ among the study group and stunted-overweight children were $2.5 \%$. Male and more male (4.2\%) children and more male (4.2\%) children than females $(2.8 \%)$ were overweight.

TABLE 1: Household socio-demographic characteristics in percentages, Narok County, Kenya

\begin{tabular}{|c|c|c|}
\hline Socio-demographics & $\mathrm{N}$ & $\%$ \\
\hline \multicolumn{3}{|l|}{ Residence } \\
\hline Urban & 487 & 75 \\
\hline Rural & 162 & 25 \\
\hline \multicolumn{3}{|l|}{ Gender } \\
\hline Male & 336 & 51.8 \\
\hline Female & 313 & 48.2 \\
\hline \multicolumn{3}{|l|}{ Age of children in months } \\
\hline $0-6$ & 315 & 48.5 \\
\hline $7-12$ & 224 & 34.5 \\
\hline $13-24$ & 74 & 11.5 \\
\hline $25-60$ & 36 & 5.5 \\
\hline \multicolumn{3}{|l|}{ Age of mother } \\
\hline $15-24$ & 302 & 46.6 \\
\hline $25-50$ & 347 & 53.4 \\
\hline \multicolumn{3}{|l|}{ Maternal Marital status } \\
\hline Single/divorced/separated & 75 & 11.5 \\
\hline Married & 575 & 88. \\
\hline \multicolumn{3}{|l|}{ Maternal level of education } \\
\hline Primary & 294 & 45.3 \\
\hline
\end{tabular}




\begin{tabular}{|c|c|c|}
\hline Socio-demographics & $\mathrm{N}$ & $\%$ \\
\hline Post primary & 319 & 49.2 \\
\hline No formal education & 36 & 5.5 \\
\hline \multicolumn{3}{|l|}{ Household size } \\
\hline $2-3$ & 246 & 37.8 \\
\hline $4-7$ & 367 & 56.6 \\
\hline$>7$ & 36 & 5.6 \\
\hline \multicolumn{3}{|l|}{ No of children } \\
\hline $1-2$ & 447 & 68.9 \\
\hline$>3$ & 202 & 31.1 \\
\hline \multicolumn{3}{|l|}{ No of meals } \\
\hline $1-2$ & 54 & 8.3 \\
\hline$>3$ & 596 & 91.7 \\
\hline \multicolumn{3}{|l|}{ Hired domestic help } \\
\hline Yes & 192 & 29.5 \\
\hline No & 457 & 70.5 \\
\hline \multicolumn{3}{|l|}{ Fever } \\
\hline Yes & 398 & 61.1 \\
\hline No & 251 & 38.9 \\
\hline \multicolumn{3}{|l|}{ Malaria } \\
\hline Yes & 299 & 45.8 \\
\hline No & 350 & 54.2 \\
\hline \multicolumn{3}{|l|}{ Flu } \\
\hline Yes & 501 & 77.1 \\
\hline No & 148 & 22.9 \\
\hline \multicolumn{3}{|l|}{ Diarrhoea } \\
\hline Yes & 321 & 49.4 \\
\hline No & 329 & 50.6 \\
\hline \multicolumn{3}{|l|}{ Access to Toilet facility } \\
\hline Yes & 593 & 91.2 \\
\hline No & 57 & 8.8 \\
\hline
\end{tabular}

Overweight was $5.1 \%$ for children in urban dwellings and $1.8 \%$ for those in rural dwelling. Overweight prevalence was highest at 3.7\% $(p<0.05)$ among children 0-6 months. A total of $88 \%$ of the households reported anxiety and uncertainty about food supply (Q1-4), 65\% positively responded to the questions on insufficient food and its physical consequences (Q5-9) (Table 2). Whereas 70\% of the households were severely food insecure and $4.5 \%$ were food secure (Table 3). On average, rural households expressed greater anxiety about sleeping hungry $(M=0.61, S E=0.04)$ compared to the urban 
households ( $M=0.51, S E=0.02)$ and the difference was significant $(t=-2.10 p<0.05)$ (Table 2).

\section{Predictors of stunting, wasting and underweight among children $(<5 y)$}

Logistic regression results (Table 4 ) indicated that child's age was a significant positive predictor of stunting (OR=1.1, CI95\%, 1.0-1.1) and underweight (OR=1.1, CI95\% 1.01.1) indicating that children between 0-12 months were more likely to be wasted and stunted (Figure 1). Younger mothers were more likely to have children who were stunted (OR=.85, Cl95\% .78-.94) and underweight (OR=.90, Cl95\% .82-.98). However older mothers had higher odds of having wasted children (OR=1.1, CI95\% 1.0-1.2).

Table 2: Percentage distribution of affirmative response to the 9-items in the Household Food Insecurity Access Scale and $t$-test among rural and urban residence, Narok County, Kenya $(n=649)$

\begin{tabular}{|c|c|c|c|c|c|c|c|c|}
\hline & & Overall & & Rural & & Urban & & t-test \\
\hline & Indicator & $\mathrm{n}$ & $\%$ & $\mathrm{n}$ & $\%$ & $\mathrm{n}$ & $\%$ & \\
\hline 1 & Worry about food & 571 & 88.0 & 424 & 65.3 & 147 & 22.7 & -1.25 \\
\hline 2 & Inability to eat preferred food & 522 & 80.4 & 393 & 60.6 & 129 & 19.9 & .30 \\
\hline 3 & Limited variety of food & 521 & 80.3 & 390 & 60.1 & 131 & 20.2 & -.22 \\
\hline 4 & Inability to access to preferred food & 517 & 79.7 & 386 & 59.5 & 131 & 20.2 & -.44 \\
\hline 5 & Smaller amounts of foods & 529 & 81.5 & 398 & 61.3 & 131 & 20.2 & .24 \\
\hline 6 & Reduced number of meals & 512 & 78.9 & 385 & 59.3 & 127 & 19.6 & .18 \\
\hline 7 & Ever no enough food & 384 & 59.2 & 280 & 43.1 & 104 & 16.0 & -1.5 \\
\hline 8 & Sleep hungry & 347 & 53.5 & 249 & 38.4 & 98 & 15.1 & $-2.10^{*}$ \\
\hline 9 & Go whole day without food & 351 & 54.1 & 255 & 39.3 & 96 & 14.8 & -1.53 \\
\hline
\end{tabular}

Whereas households with fewer children were more likely to have wasted children (OR=.67, $\mathrm{Cl} 95 \% .46-.98)$, those with a higher number of children were more likely to have a stunted child (OR=1.7, $\mathrm{Cl} 95 \%, 1.2-2.5)$. Children in this case were the number of the children in the household regardless of age. Mothers who reported to boil drinking water had higher odds of having a stunted child (OR=.42, Cl95\%, .18-.96). Mother's with higher $\mathrm{BMI}(\mathrm{OR}=1.1, \mathrm{Cl} 95 \%$ 1.0-1.2) were more likely to have a stunted child than those with low BMI. Having access to a toilet facility was negatively associated with 
having a child who was wasted (OR=.21, CI95\% .10-.92) and having had a fever recently was a positive predictor of wasting (OR=1.8, Cl95\% 1.2-2.5).

Table 3: Distribution of Household food insecurity access among rural ( $n=162)$ and urban $(n=487)$ settlements in Narok County, Kenya

\begin{tabular}{lllllll}
\hline & Urban & & Rural & \multicolumn{2}{l}{ Overall } \\
& $\mathrm{N}$ & $\%$ & $\mathrm{n}$ & $\%$ & $\mathrm{n}$ & $\%$ \\
\hline Food secure & 17 & 2.6 & 11 & 1.7 & 28 & 4.3 \\
Mildly food insecure & 20 & 3.1 & 4 & 0.6 & 24 & 3.7 \\
Moderately food insecure & 120 & 18.5 & 22 & 3.4 & 142 & 21.9 \\
Severe food insecure & 330 & 50.8 & 125 & 19.3 & 455 & 70.1 \\
\hline
\end{tabular}

\section{Predictors of overweight among children $(<5 y)$}

Logistic regression results (Table 5) showed that marital status $(O R=2.795 \% \mathrm{Cl} 1.2$ $6.5)$ and drinking boiled water (OR=.30, Cl95\%, .11- .83) significantly predicted overweight. Households in which the mother was married had higher odds of having an overweight child and households that drank boiled water had higher odds of having an overweight child. Food insecurity access score and dietary diversity were not significantly associated with overweight.

Table 4: Socio-demographic, Household and maternal factors associated under-nutrition among young children $(<5$ y) in Narok County, Kenya

\begin{tabular}{|c|c|c|c|c|c|c|c|c|c|}
\hline \multirow[t]{2}{*}{$\begin{array}{l}\text { Socio-demographic } \\
\text { characteristics }\end{array}$} & \multicolumn{3}{|c|}{$\begin{array}{l}\text { Stunting } \\
\text { (height-for-age) }\end{array}$} & \multicolumn{3}{|c|}{$\begin{array}{l}\text { Underweight } \\
\text { (weight-for-age) }\end{array}$} & \multicolumn{3}{|c|}{$\begin{array}{l}\text { Wasting } \\
\text { (weight-for-height) }\end{array}$} \\
\hline & OR & \multicolumn{2}{|l|}{$95 \% \mathrm{Cl}$} & OR & \multicolumn{2}{|c|}{$95 \% \mathrm{Cl}$} & OR & \multicolumn{2}{|c|}{$95 \% \mathrm{Cl}$} \\
\hline \multicolumn{10}{|l|}{ Residence } \\
\hline Urban (1) & 1.4 & 0.7 & 3.0 & 1.2 & 0.6 & 2.4 & 1.4 & 0.7 & 2.8 \\
\hline Rural & - & - & - & - & - & - & - & - & - \\
\hline \multicolumn{10}{|l|}{ Sex } \\
\hline Male (1) & 0.8 & 0.4 & 1.5 & 0.6 & 0.3 & 1.2 & 1.0 & 0.6 & 1.8 \\
\hline Female & - & - & - & - & - & - & - & - & - \\
\hline Child's age & $1.1^{* * *}$ & 1.0 & 1.1 & $1.1 * * *$ & 1.0 & 1.1 & 1.0 & 1.0 & 1.0 \\
\hline Size of Household & 1.0 & 0.8 & 1.3 & 0.9 & 0.6 & 1.2 & 1.2 & 0.9 & 1.6 \\
\hline No of children & $1.7^{* *}$ & 1.2 & 2.5 & 1.4 & 0.9 & 2.0 & $0.7 * *$ & 0.5 & 0.9 \\
\hline Maternal BMI & $1.1^{* *}$ & 1.0 & 1.2 & 1.0 & 0.9 & 4.3 & 1.0 & 0.9 & 1.0 \\
\hline \multicolumn{10}{|l|}{ Marital status } \\
\hline Married (1) & 1.9 & 0.8 & 4.7 & 1.0 & 0.4 & 2.7 & $0.1 * *$ & 0.02 & 1.0 \\
\hline
\end{tabular}




\begin{tabular}{|c|c|c|c|c|c|c|c|c|c|}
\hline \multirow{3}{*}{$\begin{array}{l}\text { Socio-demographic } \\
\text { characteristics } \\
\text { Single/divorced }\end{array}$} & \multicolumn{3}{|c|}{$\begin{array}{l}\text { Stunting } \\
\text { (height-for-age) }\end{array}$} & \multicolumn{3}{|c|}{$\begin{array}{l}\text { Underweight } \\
\text { (weight-for-age) }\end{array}$} & \multicolumn{3}{|c|}{$\begin{array}{l}\text { Wasting } \\
\text { (weight-for-height) }\end{array}$} \\
\hline & \multirow{2}{*}{$\frac{\mathrm{OR}}{-}$} & \multicolumn{2}{|l|}{$95 \% \mathrm{Cl}$} & \multirow{2}{*}{$\frac{\mathrm{OR}}{-}$} & \multicolumn{2}{|c|}{$95 \% \mathrm{Cl}$} & \multirow{2}{*}{$\frac{\mathrm{OR}}{-}$} & \multicolumn{2}{|c|}{$95 \% \mathrm{Cl}$} \\
\hline & & - & - & & - & - & & - & - \\
\hline \multicolumn{10}{|l|}{ Maternal Education } \\
\hline Post Primary level (1) & 1.1 & 0.5 & 2.3 & 0.6 & 0.3 & 1.3 & 0.8 & 0.4 & 1.5 \\
\hline Primary and lower level & - & - & - & - & - & - & - & - & - \\
\hline Mother's age & $0.9 * * *$ & 0.8 & 0.9 & $0.9 * *$ & 0.8 & 1.0 & $1.1 * * *$ & 1.1 & 1.2 \\
\hline \multicolumn{10}{|l|}{$\begin{array}{l}\text { Household food security } \\
\text { status }\end{array}$} \\
\hline HDDS & 0.9 & 0.7 & 1.1 & 0.9 & 0.7 & 1.1 & 1.0 & 0.8 & 1.3 \\
\hline HFIAS_score & 1.0 & 1.0 & 1.1 & 1.0 & 1.0 & 1.1 & 1.0 & 1.0 & 1.1 \\
\hline No of meals per day & 0.9 & 0.5 & 1.8 & 1.0 & 0.5 & 1.9 & 1.2 & 0.7 & 2.1 \\
\hline Hired domestic worker & 2.3 & 0.9 & 5.6 & 0.5 & 0.2 & 1.2 & 1.4 & 0.7 & 2.8 \\
\hline Boil drinking water & $0.4^{* *}$ & 0.2 & 1.0 & 0.7 & 0.3 & 1.6 & 1.1 & 0.6 & 2.1 \\
\hline Malaria & 1.0 & 0.6 & 1.5 & 1.0 & 0.7 & 1.6 & 1.0 & 0.6 & 1.4 \\
\hline Fever & 1.0 & 0.6 & 1.5 & 0.6 & 0.3 & 1.4 & $1.8^{* * *}$ & 1.2 & 2.5 \\
\hline Flu & 0.9 & 0.6 & 1.4 & 1.1 & 0.8 & 1.8 & 1.0 & 0.7 & 1.5 \\
\hline Diarrhea & 1.0 & 0.6 & 1.5 & 1.1 & 0.8 & 1.8 & 1.2 & 0.8 & 1.6 \\
\hline Access to toilet & 1.1 & 0.3 & 3.6 & 0.6 & 0.1 & 2.1 & $0.2^{* *}$ & 0.1 & 0.9 \\
\hline
\end{tabular}

${ }^{*} p<0.01, * * p<0.05, * * * p<0.005,1$ - reference category

Table 5: Socio-demographic, Household and maternal factors associated with overweight among young children $(<5$ y) in Narok County, Kenya

\begin{tabular}{llll}
\hline & Overweight & \\
\hline Socio-demographic characteristics & OR & $95 \% \mathrm{Cl}$ & \\
\cline { 2 - 3 } & & Lower & Upper \\
\hline Residence & & & 2.2 \\
Urban (1) & 0.9 & 0.4 & - \\
Rural & - & - & \\
Sex & & & 1.4 \\
Male (1) & 0.7 & 0.4 & - \\
Female & - & - & 1.1 \\
Child's age & 1.0 & 0.9 & 1.7 \\
Size of Household & 1.2 & 0.8 & 3.1 \\
No of children & 1.5 & 0.8 & \\
Mother's nutritional status & & & 1.1 \\
BMI & 0.9 & 0.8 & \\
Marital status & & &
\end{tabular}




\begin{tabular}{llll}
\hline & Overweight & & \\
\hline Socio-demographic characteristics & OR & $95 \% \mathrm{Cl}$ & \\
\cline { 3 - 4 } & & Lower & Upper \\
\hline Married (1) & $0.4^{*}$ & 1.2 & 6.5 \\
Mother's education level & & & \\
Post Primary level & 1.0 & 0.5 & 2.0 \\
Primary and Lower level & - & - & - \\
Household food security status & & & \\
HDDS & 1.1 & 0.8 & 1.4 \\
HFIAS_score & 0.9 & 0.9 & 1.0 \\
No of meals per day & 0.6 & 0.3 & 1.2 \\
Hired domestic worker & 1.0 & 0.5 & 1.2 \\
Boil drinking water & $0.3 *$ & 0.1 & 0.8 \\
Malaria & 1.3 & 0.8 & 1.9 \\
Fever & 0.9 & 0.6 & 1.4 \\
Flu & 1.3 & 0.8 & 2.1 \\
Diarrhoea & 1.1 & 0.7 & 1.5 \\
Access to toilet facility & 2.0 & 0.6 & 7.2 \\
\hline HDDS-household dietary diversity & score, HFIAS-household food insecurity access score, ${ }^{*} p<0.05,1$ - \\
reference category & & &
\end{tabular}

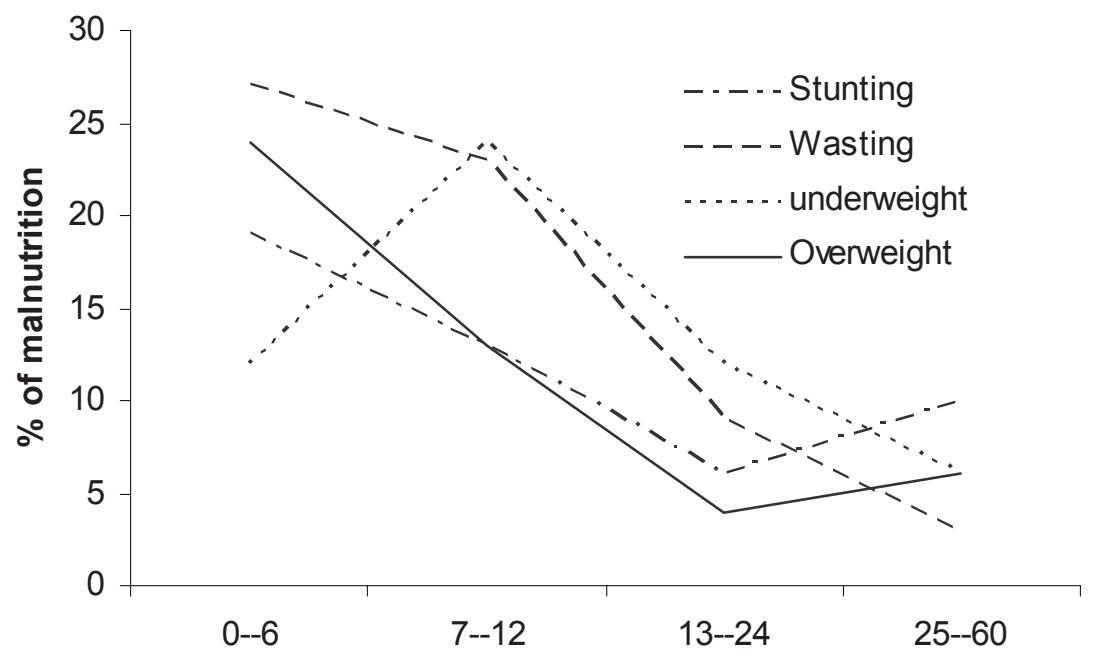

Age in months

Figure 1: Distribution of malnutrition by age-group among children, Narok County, Kenya 


\section{Discussion}

Our study examined the prevalence of malnutrition among children and assessed possible determinants of stunting, wasting, underweight and overweight and their association with household food insecurity in Kenya. Mild, moderate and severe stunting were $12.3 \%, 4.8 \%$ and $2.6 \%$ respectively, while mild moderate and severe underweight were $15.7 \%, 6.0 \%$, and $2.2 \%$ respectively. Mild, moderate and severe wasted were $16.6 \%, 5.2 \%$ and $4.3 \%$ respectively, while overweight was $6.9 \%$ and stuntedoverweight was $2.5 \%$. The findings in this study indicate that prevalence of malnutrition among children was generally lower compared with that reported in other studies in Kenya $(9,15)$. Predictors of overweight among children in our study were having a married mother and providing boiled drinking water in the home. While factors which were significant in predicting wasting included lower number of children in a household, being a younger child, having older mothers and married mothers, having access to a toilet facility and having had fever in the month before the study. In our study being a younger child and having a younger mother were significant predictors of underweight. Being stunted was associated with older age of the child, having a younger mother, and having a mother with higher BMI, and living with a higher number of children in the household.

In as much as the prevalence of stunting, wasting and underweight have declined over the years, overweight and obesity are on the rise (26). Overweight and obesity are indicators of underlying public health problems. Overweight among children is associated with a wide range of serious health complications and an increased risk of premature illness and death later in life (27). Male children were generally more malnourished than girls, a finding which was consistent with other studies $(15,18,28-30)$. It's indicated that girls have an anthropometric advantage which may be as a result of a historic pattern of preferential treatment of females due to the high value placed on women as a source of labor and bride-wealth in this county (31). However, in our study it is worth noting that male children were also more overweight than the females, a fact which was not consistent with other studies in Africa which found female children more overweight than male counterparts (32-34). Overweight has been seen to increase with age among female children due to the fact that women have a higher proportion of fat relative to total body weight as reported in other studies $(35,36)$. However, in our study group the male children may have been overfed due to the local cultures that emphasize that male children need more food than females to be able to grow up strong and healthy.

Stunting and underweight were common among younger children in our study and this finding has been reported in several studies in Africa and several factors come into play to determine the nutritional status at this age for example rapid growth and 
development rate that characterize infancy (37) and also inadequate food intake that may have not been met adequately by the nutrients provided through breast feeding or other complementary feeding during this period. In our study, the prevalence of under-nutrition was high among ages 7 to 12 months, while under-nutrition decreased among children over 1yr. Studies report that the immediate cause of under-nutrition is either inadequate intake of food or poor health status $(38,39)$, however timing of feeding and quality and quantity of food are also crucial particularly at this young age. Infrequent feeding and not enough food may lead to under-nutrition but too frequent feeding with a lot of food may lead to overweight. In our study overweight was high among children 0-6 months of age, low among 13-24 months and higher again after 2 years bringing into question infant feeding practices and the introduction of other foods during weaning which may lead to poor eating habits and infections. Studies have also shown that a shortened period of breastfeeding increases risk of childhood obesity (40-42), however this study did not look at the breastfeeding patterns of these children. Research has also shown that ages between 0-24 months creates a window of opportunity at which malnutrition can be averted if proper intervention is taken and a child is able to catch up in terms of growth and development $(43,44)$. The mother or the caregiver should be the target in any intervention to improve the nutritional status of the child because the overall nutritional status of a child is a reflection of the child's environment as well as social and economic opportunities of the care giver (45). Thus, of importance are the feeding habits which contribute to both overweight and undernutrition though under-feeding or over-feeding. Proper feeding schedule and weighing of the child's food may be important especially when the mother opts not to breastfeed.

Food insecurity has been reported to be associated with overweight which has been reported previously but mainly in the developed countries $(3,46)$ and more so among women than men and children $(4,47)$. Household food insecurity can be defined differently by different people depending on the prevailing circumstances. For example in some cases lack of staple foods or not being able to access preferred food would be defined as food insecurity. However, the same households could have access to foods that are not staple such as fried foods like potato chips, doughnuts and other street foods which may predispose them to overweight. In addition, the coping strategies that the household employs to feed the children during hunger seasons may also predispose them to overweight like force feeding the children with porridge. Force feeding is used by many ethnic groups in Kenya, a technique where the mother uses her left palm curved under the mouth then porridge is poured, while using the thumb to block the nostrils, the child is slowly fed with the porridge, taking breaks in between to allow the child to breath. 
In our study, overweight among children occurred across households of the married and not married women although the prevalence was higher among children born to mothers who were married. Marriage could mean improved livelihoods for women because the husband may provide the food resources they need which may mean more than sufficient food that may lead to overweight. The opposite can also be true, where under-nutrition flourishes in households where the mother is married. For example in our study, wasting, stunting and underweight occurred mostly in households were the mother was married. In the households, the females are generally responsible for food management (46) particularly in African culture and therefore if they have no access to resources, then they may not be able to provide adequately for their children. In most African communities women carry the burden of other household chores and outside the home for instance on the farms and thus may have no time to care for their children which may explain the prevalence of under-nutrition among children from married mothers. Culturally, these obligations may be reduced for a single, divorced or separated mother. Although households with the head of the household being male (married women) were culturally required to provide food for the male figure in the home before the children which may also explain the high number of undernourished children in households with a married mother. In addition, the mother has to divide her time for caring for children and household chores with caring for the husband. However more studies are needed to ascertain reasons for the high malnutrition among children in households with a married mother. Access to safe drinking water in a household would also mean improved livelihoods, and that could be the reason why in our study, we found that a household that had access to boiled drinking water had higher odds of having an overweight child. Access to safe water and improved sanitation can also means reduced incidences of diseases and water borne infections causing the child to remain healthy as reported in a study by Cheng et al. (48). In addition, improved sanitation by accessing clean drinking water and access to a toilet have been emphasized as one of the Millennium Development Goals whose target is the be achieved by halving the number of people without accesses to clean water and basic sanitation by 2015 (49).

The relationship between maternal education and nutritional status of the children has been discussed in many studies whereby the higher the educational attainment, the better the nutritional status of children $(9,50)$. In our study, although the education was found not to be a significant predictor of under-nutrition nor overweight, the importance of maternal education cannot be underestimated. In our study, mothers with post primary education had fewer children who were underweight, wasted, and stunted. However the numbers of overweight were almost the same for mother with lower levels of education compared to those with post primary level of 
education. This suggests that overweight is not only a problem of the educated, rich individuals but also occurs across poor households with low literacy levels.

Fever was associated with wasting, a finding which was consistent with other studies which found high fever to lead to growth faltering $(17,51)$. Wasting is sometimes referred to as acute malnutrition and occurs as a result of most recent effects of lack of food, hunger or illness particularly malaria which is endemic in this region. Therefore, fever results in loss of fluids through dehydration or lack of appetite and it could be an indicator of underlying infection, thus explaining the low weight for height. Preventing frequent bacterial and parasitic infections through improved sanitation, using mosquito nets, boiling drinking water and eating fresh food are important health behaviors contributing to the general welfare of a child and to prevent malnutrition. In addition, having access to a toilet facility is also crucial in improving sanitation within the homestead as it was also found to significantly predict wasting in children in our study, a finding which was consistent with many other studies in Kenya and Africa.

If not reversed, the increasing rates of overweight among children will have enormous implications not only for future health care expenditures but also for the overall development of the nation $(52,53)$. There is urgency in reversing the trends of increasing overweight and obesity in developing countries which are still battling with effects of under-nutrition, food insecurity and hunger. In our study, household food insecurity was negatively associated with overweight among children, and although overweight is in the rise in Narok County, Kenya, under-nutrition still flourishes. Therefore interventions are needed to curb the rising overweight and also tame the prevailing under-nutrition among children to avoid the overwhelming negative consequences that the two will have on the health sector.

\section{Limitations, strengths and recommendations}

The strength of our study is that we were able to analyze the nutritional status of children and determine overweight cases as well as under-nutrition together with food insecurity which has not been reported in many studies in Kenya. The limitation of the study is that the household food insecurity access was assessed based on how the participant answered the questions. Hunger and anxiety of not having sufficient food is perceived differently by different people. Some people consider hunger as not being able to access staple food although other foods may be available. According to the FAO, food security has four dimensions, access, availability, and stability and utilization (54). In our study, we assessed food access using the HFIAS food access tool and utilization was measured using anthropometric measurement, while dimensions of stability and availability were not covered. It is a suggestion for future research that all the dimensions of food security be studied in this area to provide an opportunity for a 
more holistic analysis. Our study also did not measure the actual food taken but relied on recall to assess dietary diversity. Relying on recall can lead to misreporting on the actual events that took place. The participants may not have recalled actual intake due to poor memory or by false reporting. Future research is needed to look at food security's dimensions of stability and availability as well as psychosocial factors surrounding food intake, and how these factors impact on overweight and stunting among children. Further, more studies on dietary intake of the children may highlight the importance of feeding patterns on nutritional status, particularly feeding schedules and weighing the child's food in a situation where the child is not breastfeeding and also the technique of forced feeding needs to be studied further to understand its underlying nutritional effects on children. In addition, an intervention is recommended to curb the raising prevalence of overweight among children since most public health institution in Africa are tailored to handle mainly cases of stunting, wasting and underweight but not overweight. The policies that are in place to screen and manage under-nutrition must be reviewed to include screening and management of overweight among children. 


\section{References}

1. UNDP. Africa Human Development Report 2012. Towards a Food Secure Future [Internet]. 2012 2nd February 2013. Available from: http://www.afhdr.org/AfHDR/documents/summary_EN.pdf.

2. Wolfe WS, Frongillo EA. Building household food-security measuremnt tools from the ground up. Food and Nutrition Bulletin 2001;22 (1).

3. Crawford PB, Webb KL. Unravelling the paradox of concurrent food insecurity and obesity American Journal of Preventive Medicine. 2011;40(2):274-5.

4. Larson NI, Story MT. Food insecurity and weight status among US children and families: a review of the literature. American Journal of Preventive Medicine 2011 Feb;40(2):163-73.

5. FAO. Fighting hunger and obesity 2006. Available from: http://www.fao.org/ag/magazine/0602sp1.htm.

6. Nordin SM, Boyle Marie, \& Kemmer Terresa M. Position of the Academy of Nutrition and Dietetics: Nutrition Security in Developing Nations: Sustainable Food, Water, and Health. Journal of the Academy of Nutrition and Dietetics 2013 April 2013;113(4):581-95.

7. de Onis M, Blossner, Monika \& Borghi, Elaine. Global prevalence and trends of overweight and obesity among preschool children American Journal of Clinical Nutrition 2010 August 2010;92:1257-64.

8. Kenya National Bureau of Statistics (KNSB) ICF, Macro. Kenya Demographic Health Survey 2008092010 June 2010. Available from: http://www.measuredhs.com/pubs/pdf/FR229/FR229.pdf.

9. Gewa C. Childhood overweight and obesity among Kenyan pre-school children: an association with maternal and early child nutritional factors Public Health Nutrition 2009 November 2009;13(4):496503.

10. World Bank. Prevalence of Overweight (\% of children under 5) data 2008 25th April 2013. Available from: http://data.worldbank.org/indicator/SH.STA.OWGH.ZS.

11. Pawloski LR, Curtin K M, Gewa C, Attaway D. Maternal-child overweight/obesity and undernutrition in Kenya: a geographic analysis. Public Health Nutrition. 2012;15(11).

12. Masibo $P$, Makoka D. Trends and determinants of undernutrition among young Kenyan children: Kenya Demographic and Health Survey; 1993,1998,2003 and 2008-2009. Public Health Nutrition. 2012;15(9):1715-27. Epub June 2012.

13. Baker JL, Olsen LW, Sorensen TI. Childhood body mass index and the risk of coronary heart diseases in adulthood New England Journal of Medicine. 2007;357:2329-37.

14. Abubakar A, Holding P, Van de Vijver Fons J.R., Newton C, Van Baar A. Children at risk for developmental delay can be recognised by stunting, being underweight, ill, health, little maternal schooling or high gravidity Journal of Child Psychology and Psychiatry 2010;51(6):652-9.

15. Kabubo-Mariara J, Ndenge GK, Mwabu DK. Determinants of Children's Nutritional Status in Kenya: Evidence from Demographic and Health Surveys. Journal of African Economies. Journal of African Economies. 2008;18(3):363-87.

16. Caulfield LE, de Onis M, Blossner M, Borghi E. Undernutrition as an underlying cause of child deaths associated with dirrhoea, pneumonia, malaria and measles American Journal of Clinical Nutrition. 2004;80:193-8.

17. Lartey A, Manu A, Brown KH, Peerson JM, Dewey KG, . Predictors of growth from 1 to 18 months among breast-fed Ghanaian infants. European Journal of Clinical Nutrition. 2000;54(1):41-9.

18. Wamani H, Astrøm AN, Peterson S, K TJ, Tylleska T. Predictors of poor anthropometric status among children under 2 years of age in rural uganda. Public Health Nutrition. 2006;9(3):320-6.

19. USAID. Kenyan Fact SheetAccessed on 28th May 2013. Available from: http://kenya.usaid.gov/sites/default/files/profiles/Narok\%20County\%2023\%20Jan\%202012.pdf.

20. Westerterp KR, Wouters L, van Marken-Lichtenbelt WD. The Maastricht protocol for the measurement of body composition adn energy expenditure with labelled water. Obesity Research 1995;3:49-57.

21. Keino S, Plasqui G, Van den Borne B. Body composition, water turnover and physical activity among Kenyan women Unpublised work

22. Coates J, Swindale Anne, Bilinsky Paula,. Household Food Insecurity Access Scale (HFIAS) for Measurement of Food Access: Indicator Guide. Food and Nutrition Technical Assistant Project (FANTA) [Internet]. 2007 August 2007; Version 3. Available from: http://www.fantaproject.org/downloads/pdfs/HFIAS_v3_Aug07.pdf. 
23. Swindale Anne \& Bilinsky Paula. Household Dietary Diversity Score (HDDS) for Measurement of Household Food Access: Indicator Guide. Food and Nutrition Technical Assistant Project (FANTA) [Internet]. 2006; Version 2 Available from: http://www.fantaproject.org/downloads/pdfs/HDDS_v2_Sep06.pdf.

24. WHO, UNICEF. Children growth standards and identification of severe acute malnutrition in infants and children: A joint statement by World Health Organization and United Nations Children's Fund.2009. Available from: http://www.who.int/nutrition/publications/severemalnutrition/9789241598163_eng.pdf.

25. WHO. Global Database on Body Mass Index25th May 2013. Available from: http://apps.who.int/bmi/index.jsp?introPage=intro_3.html.

26. Semproli S, Gualdi-Russo E. Children malnutrition and growth in a rural area of western Kenya. American Journal of physiology Anthropology. 2007;132:463-9.

27. Dietz WH. Health conseqences of obesity in youth: childhood predictors of adult disease Pediatrics 1998;101(3 Pt2):518-25.

28. Wamani H, Astrøm AN, Peterson S, K TJ, Tylleska T. Boys are more stunted than girls in sub-saharan Africa: meta-analysis of 16 demographic and health surveys. BMC Pediatrics. 2007;7(17).

29. Ngare DK, Muttunga JN. Prevalence of malnutrition in Kenya East African Medical Journal. 1999;76(7):376-80.

30. Zere E, McIntyre D. Inequlities in under-five children in South Africa. International Journal of Equity in Health 2003;2(7).

31. Svedberg P. Undernutrition in sub-Saharan Africa: is there a gender bias? Journal of Development Studies 1990;26(3):469-86.

32. Kimani-Murage EW, Kahn K, Pettifor JM, Tollman SM, Dunge DB, Gomez-Olive XF, et al. The prevalence of stunting, overweight and obesity, and metabolic disease risk in rural South African children BMC Public Health. 2010;10(158).

33. Senbanjo IO, Oshikoya KA, Olutekunbi OA, OF. N. Body fat distribution of children and adolescents in Abeokuta, Southwest Nigeria American Journal of Physiology Anthropology. 2013;150(4):647-54. Epub Feb 28th 2013.

34. WHO. Women's Health Factsheet No 334 [Internet]. 2009 17th June 2013. Available from: http://www.who.int/mediacentre/factsheets/fs334/en/.

35. Norgan NG. The beneficial effects of body fat and adipose tissue in humans International Journal of obesity Related Metabolic Disorders 1997;21(9):738-46.

36. Taleb S, Oulamara H, Agli AN. Prevalence of overweight and obesity in schoolchildren in Tebessa (Algeria) between 1998-2005. Eastern Mediterranean Health Journal 2010;16(7):746-51.

37. Browman BA, Russel RM, editors. Present Knowledge in Nutrition 8ed: International Life Sciences Institute Press; 2001.

38. Black RE, Allen LH, Bhutta ZA, Caulfield LE, de Onis M, Ezatti M, et al. Maternal and child undernutrition 1. Lancet. 2008;371:243-60.

39. Jayatissa R. Determinants of and intervention for malnutrition Ceylon Medical Journal 2012;57:51-7.

40. Sharma S, Kolahdooz F, Butler L, Budd N, Rushovich B, Mukhina GL. Assessing dietary intake among infants and toddlers 0-24 months of age in Baltimore, Maryland, USA. . Nutrition Journa. 2013;12.(52).

41. Monasta L, Batty GD, Cattaneo A, Lutje V, Ronfani L, van Lenthe FJ, et al. Early-life determinants of overweight and obesity: a review of systematic reviews. Obesity Reviews. 2010;11:695-708.

42. Daniels SR, Jacobson MS, McCrindle BW, Eckel RH, Sanner BM. American Heart Association Childhoon Obesity Research Summit Repor. Circulation 2009;119:489-517.

43. The Lancet. The Lancet's series on maternal and child undernutrition The Lancet [Internet]. Accessed on 28th May 2013; (The Executive Summary ). Available from: http://www.imagine.in/Sem6ExeSum.pdf.

44. Barker DJP, Bergmann RL, Ogra PL. The Window of Opportunity: Pre-Pregnancy to 24 Months of Age2008; 61. Available from: https://www.karger.com/Book/Toc/233695.

45. Garcia V. Children malnutrition and horizontal inequalities in sub-Saharan Africa: A focus on contrasting domesic trajectories. Working Paper [Internet]. 2012; (WP 2012-019). Available from: http://web.undp.org/africa/knowledge/WP-2012-019-garcia-working-afhdr-malnutritioninequalities.pdf.

46. Carter MA, Dubois L, Tremblay MS. Place and food insecurity: A critical review and analysis of the literature Public Health Nutrition. 2013;April 8:1-19. 
47. Eisenmann JC, Gundersen C, Lohman BJ, Garasky S, Stewart SD. Is food insecurity related to overweight and obesity in children and adolescents? A summary of studies, 1995-2009. Obesity Reviews 2011;12:e73-e83.

48. Cheng JJ, Schuster-Wallace CJ, Watt S, Newbold BK, Mente A. An ecological quantification of the relationships between water, sanitation and infant, child, and maternal mortality. Environmental Health 2012;11(4).

49. WHO. Millennium Development Goals 2013 3rd April 2014. Available from: http://www.who.int/mediacentre/factsheets/fs290/en/.

50. Abuya BA, Ciera J, EW K-M. Effects of mother's education on child's nutritional status in the slums of Nairobi BMC Pediatrics. 2012;12(80).

51. Weisz A, Meuli G, Thakwalakwa C, Trehan I, Maleta K, Manary M. The duration of diarrhea and fever is associated with growth faltering in rural Malawian children aged 6-18 months. Nutrition Journa. 2011;10(25).

52. Sherry B, Zuguo M, Scanlon KS, Mokdad AH, Grummer-Strawn LM. Trends in state-specific prevalence of overweight and underweight in 2-through 4- year old children from low-income families from 1989 through 2000. Achieves of Pediatric \& Adolescent Medicine 2004;158(12):1116-24.

53. Lee JM, Subrahmanyam P, Gebremariam A, Keirns CC, Davis MM, Sandeep V, et al. Getting heavier, younger: Trajectories of obesity over the life course International Journal of obesity (London). 2010;34(4):614-23.

54. FAO. Food Security. Policy Brief [Internet]. 2006 [cited 2013 29th May ]; (Issue 2). Available from: ftp://ftp.fao.org/es/ESA/policybriefs/pb_02.pdf. 


\section{CHAPTER 5 \\ Body Composition, Water turnover and Physical activity among women in Narok County, Kenya}

Susan Keino, Bart van den Borne and Guy Plasqui Submitted for publication 


\begin{abstract}
Introduction: In developing countries where access to water and food is not guaranteed, women may have to travel long distance or engage in physical activities to gather food. This may compromise their water requirements and overall nutritional status. The aim of the study was to determine water turnover, physical activity and body composition among women in Kenya and to describe the differences between rural and urban Kenyan women.
\end{abstract}

Methods: We randomly selected 30 women in Narok County, who were not pregnant at the time of the study. Body mass index (BMI) was calculated from anthropometric measurements to assess nutritional status of the women. Deuterium dilution was used to determine total body water (TBW) and water turnover was measured from deuterium elimination. Fat-free mass (FFM) was calculated by assuming a constant hydration fraction of $73.2 \%$. Accelerometers (Actigraph GT3X) were used to assess physical activity and expressed as magnitude counts per day. Simple and multiple linear regressions were used to define the determinants of water turnover.

Results: Mean BMI was $23.4 \pm 4.1$ and $21.5 \pm 3.8(n=28)$ among rural and urban women respectively. The prevalence of overweight $\left(\mathrm{BMI}>25 \mathrm{~kg} / \mathrm{m}^{2}\right)$ was $24.1 \%$ and of underweight $\left(\mathrm{BMI}<18.4 \mathrm{~kg} / \mathrm{m}^{2}\right)$ was $25 \%$. The mean total body water (TBW) was $29.3 \pm$ 4.2 liters and water turnover was $3.2 \pm 0.8$ liters per day (L/day). Water loss was significantly related to $\mathrm{BMI}\left(\mathrm{R}^{2}=.45, p<0.001\right)$ and Fat mass index (FMI) $\left(\mathrm{R}^{2}=.41, p<0.001\right)$. Water loss was also significantly related to physical activity $(P A)\left(R^{2}=.25, p<0.05\right)$. Multiple regression analysis showed that $\mathrm{BMI}$ and physical activity together $(n=22)$ explained 68\% variation in water loss $\left(r^{2}=.38, p<0.005 ; \Delta R^{2}=.15, p<0.05\right)$.

Conclusion: Water loss is related to body composition and physical activity and $\mathrm{BMI}$ was the strongest predictor of water loss.

Key Words: Nutritional status, sub-Saharan Africa, water turnover, deuterium dilution, accelerometry 


\section{Introduction}

Physical activity in most sub-Saharan Africa is part and parcel of the daily routine of searching for water and gathering food unlike in the developed countries where it is emphasized for health purposes. During increased physical activity, there is increased sweating and breathing which contributes to body water loss. Water is an essential nutrient in all known forms of life [1] and it is the principal chemical constituent of the human body [2]. Variability in total body water in free living humans is primarily due to differences in body composition [2]. However the impact of physical activity on water loss among individuals living in the warm climatic conditions of Africa is not well understood and there is limited data of studies done in Africa. A study in the Netherlands found mean water loss among women to be $3.1 \mathrm{~L} / \mathrm{d}$ during summer and $3.0 \mathrm{~L} / \mathrm{d}$ in winter and the reason for the high water loss during summer was a result of sweating and increased physical activity during this season [3]. In that study, no relation was found between water loss and physical activity among women. Another study showed that the average water loss at high altitude was found to be $3.3 \pm 0.6 \mathrm{~L} / \mathrm{d}$ [4] and $3.0 \pm$ $0.6 \mathrm{~L} / \mathrm{d}$ in sedentary subjects at over $6000 \mathrm{~m}$ above sea level [5]. The impact of physical activity (PA) on water loss in Kenyan women is crucial since women are the primary caregivers within homes resulting in high workloads and energetic demands. Thus fluid loss can compromise their nutritional status and lead to reduced work performance due to dehydration and general apathy.

Body composition could affect physical activity levels (PAL) in that individuals with a higher fat deposition have been found to be less physically active than normalweight individuals [6]. The relationship between body composition and water turnover has been studied in different populations. A study on women in New Zealand found water turnover to be strongly correlated with body weight and fat free mass (FFM) [7]. Another study found that lean body mass (LBM) and fat mass (FM) influenced water turnover in females and not in males [8]. However, the use of body mass index (BMI) to assess body composition is faced with shortcomings as described by Schutz et al. [9] and Lu et al. [10]. To make up for this shortcoming, there is need to measure FM and FFM and adjusting it for height ${ }^{2}$ to get fat mass index (FMI) and fat free mass index (FFMI), since these measures may have advantages in assessing adiposity. Studies in Kenya that used deuterium dilution to assess body composition among women are limited and one study on lactating mothers found the average percentage FM to be $26.1 \pm 5.4$ and FFM as $41.3 \pm 5.1 \mathrm{~kg}$ [11]. However, data on the relationship between water turnover and FMI and FFMI among black race is not available to our knowledge making it difficult to make any recommendations regarding water requirements for people living in communities in warm climates like Kenya. Therefore the aim of this study was to assess water loss, and to determine the effect of body composition and 
physical activity on water loss in Kenyan women. Another aim was to describe the difference in body composition and physical activity among rural and urban Kenyan women.

\section{Subjects and methods}

\section{Subjects}

A total of 30 women aged (15-45 y) were randomly selected to participate in this study. The group included 10 women from the rural and 20 from the urban Narok North Country in Kenya. Subject characteristics are provided in Table 1. One subject declined to participate after recruitment and another subject was left out of the analysis because of violation of the protocol resulting in invalid numbers for total body water and water turnover. After the accelerometer data was downloaded and validated, only 22 women met the cut-off point which was set at a minimum wear time of 2 days. Prospective participants received verbal information about the nature and purpose of the study and those who agreed to participate signed or thumb-printed on the consent form. The procedures for this study were approved by the Institute for Research and Ethics Committee (IREC) of the Moi Teaching and Referral Hospital (MTRH) and Moi University.

\section{Anthropometry}

Body mass (BM) was measured to the nearest $0.1 \mathrm{~kg}$ with a mechanical scale (SECA 762) Height was measured to the nearest $0.1 \mathrm{~cm}$ with a stadiometer (SECA 214). Body mass index (BMI) was calculated using weight in kilograms divided by height in meters square $\left(\mathrm{BMI}=\mathrm{kg} / \mathrm{m}^{2}\right)$. The classifications for $\mathrm{BMI}$ according to $\mathrm{WHO}$ are $\mathrm{BMI}<18.5 \mathrm{~kg} / \mathrm{m}^{2}$ is underweight; $\mathrm{BMI}=18.5-24.9 \mathrm{~kg} / \mathrm{m}^{2}$ is normal and overweight is $\mathrm{BMI}>25 \mathrm{~kg} / \mathrm{m}^{2}$.

\section{Body composition and water loss}

TBW was measured using the deuterium dilution method where a dose of labelled water was given to the subjects and urine samples were collected according to a modified Maastricht protocol [12]. Water turnover was measured from deuterium elimination over a 3-day period instead of the 7-day period that was described by Goris et al [13]. Subjects drank a deuterium $\left({ }^{2} \mathrm{H}_{2} \mathrm{O}\right)$ dose of $70 \mathrm{ml}$ water with an enrichment of $5 \mathrm{~g}$ atom $\%$ excess ${ }^{2} \mathrm{H}$. Subsequently, two urine samples were collected 6 hours after dosing and one sample after the third day. Water loss was calculated from ${ }^{2} \mathrm{H}$ elimination with the equation of Fjeld et al. [14], while body composition was calculated from TBW 
assuming a constant hydration fraction of FFM of 73.2\%. FFM and FM indices (FMI and FFMI) were calculated, which are equivalent concepts to the BMI as shown in the following definition by Schutz et $a$ l [9], FFM=FFM/height $(m)^{2}$ and FMI $=F M /$ height $(m)^{2}$. Thus, BMI=FFMI+FMI.

\section{Physical Activity}

Actigraph GTX3 accelerometers (Actigraph, Pensacola, FL, USA) were used to determine physical activity. The tri-axial accelerometer measures $4.6 \mathrm{~cm} \times 3.3 \mathrm{~cm} \times 1.5 \mathrm{~cm}$ and weighs $19 \mathrm{~g}$ and is a validated tool that has shown to be reliable for the assessment of PA. It was attached to the lower back by means of an elastic belt and worn all the time except during sleep and while taking a bath or shower for a period of 2-4 days. The GT3X measures accelerations of the trunk (counts) in the antero-posterior, mediolateral and longitudinal axes, otherwise referred to as $X, Y \& Z$ axes. The GT3X actigraph records accelerations ranging from $0.5-2.5 \mathrm{G}$ 's and the output are digitized at a rate of $30 x$ per second ( 30 Hertz). The GT3X is designed to enable data storage for 30 days (with fully charged battery) and for optimal wearing comfort in order not to interfere with daily activities. The data was downloaded using the Actilife software and Vector magnitude counts per day were obtained from the output and intensity of physical activity was obtained using Troiano et al. cut-off points [15].

\section{Data analyses}

Microsoft@ Excel 2010 for windows was used to enter the data and SPSS version 19 was used to analyze the data. Excel was also used to generate the scatter plots. Descriptive measures were calculated to describe the sample and the measurements of body composition and physical activity using percentages, means and standard deviations. Simple linear regression and multiple regression analyses were used to assess the relationship between water turnover $(\mathrm{L} / \mathrm{d})$ as the dependent variable and values obtained from body composition (FFMI, FMI, BMI, BM and TBW) and those obtained from physical activity (VM/d) as the independent variables.

\section{Results}

A total of 28 women were included in the study and the mean age was $25 \pm 6.0$ (Table 1). Mean BM was $58.4 \pm 11.0$ and $56.2 \pm 11.4$ among rural and urban women respectively, while mean BMI was $23.4 \pm 4.1$ among rural women and $21.5 \pm 3.8$ among urban women. Of the total women, $24.1 \%$ were overweight and $25 \%$ were underweight. The average TBW was $29.3 \pm 4.2 \mathrm{~L}$, while average water turnover was $3.2 \pm 0.8 \mathrm{~L} /$ day (Table 
2). The mean VM/day was $859733 \pm 319404$ for rural and $740356 \pm 222551$ for urban women and the difference in physical activity among urban and rural women was not significant $(p=0.31)$. The intensity of activity using Troiano cut-off points indicated that $44.5 \%$ of the activity was sedentary, $48.7 \%$ of the activity was light, $8 \%$ of the activity was moderate and $0.02 \%$ was vigorous (Table 3 ).

Table 1: Anthropometric measurements of rural and urban women in Narok County

\begin{tabular}{llll}
\hline & $\begin{array}{l}\text { Population } \\
\text { Mean SD }\end{array}$ & $\begin{array}{l}\text { Rural } \\
\text { Mean }\end{array}$ & $\begin{array}{l}\text { Urban } \\
\text { Mean } \\
\end{array}$ \\
& $n(28)$ & $n(10)$ & $n(18)$ \\
\hline Age & $25 \pm 6.1$ & $26.7 \pm 7.6$ & $24.1 \pm 5.2$ \\
Height $(\mathrm{m})$ & $1.60 \pm 0.1$ & $1.58 \pm 0.0$ & $1.61 \pm 0.1$ \\
$\mathrm{BM}(\mathrm{kg})$ & $57.0 \pm 11.1$ & $58.4 \pm 11.0$ & $56.2 \pm 11.4$ \\
$\left.\mathrm{BMI} \mathrm{kg} / \mathrm{m}^{2}\right)$ & $22.2 \pm 3.9$ & $23.4 \pm 4.1$ & $21.5 \pm 3.8$ \\
\hline
\end{tabular}

Abbreviations: m-meters, kg- kilograms BM-body mass, BMI-body mass index, SD-standard deviation

Table 2: Body composition and water turnover of rural and urban women in Narok County

\begin{tabular}{llll}
\hline & $\begin{array}{l}\text { Population } \\
\text { Mean (SD) } \\
n(28)\end{array}$ & $\begin{array}{l}\text { Rural } \\
\text { Mean (SD) } \\
n(10)\end{array}$ & $\begin{array}{l}\text { Urban } \\
\text { Mean (SD) }\end{array}$ \\
& $29.3 \pm 4.2$ & $29.4 \pm 3.5$ & $29.2 \pm 4.6$ \\
\hline TBW(L) & $3.2 \pm 0.8$ & $3.3 \pm 1.2$ & $3.1 \pm 0.6$ \\
Water turnover (L/day) & $18.2 \pm 7.4$ & $19.5 \pm 7.8$ & $17.5 \pm 7.3$ \\
Fat Mass $^{\text {a }}$ & $38.9 \pm 5.6$ & $39.0 \pm 4.6$ & $38.8 \pm 6.2$ \\
Fat Free Mass $^{\text {a }}$ & $7.0 \pm 2.8$ & $7.8 \pm 3.1$ & $6.6 \pm 2.7$ \\
Fat Mass Index $^{\text {b }}$ & $15.1 \pm 1.9$ & $15.6 \pm 1.6$ & $14.9 \pm 2.0$ \\
Fat Free Mass Index $^{b}$ & & &
\end{tabular}

Abbreviations: SD—standard deviation TBW-total body water, L-litres, ${ }^{a} \mathrm{~kg},{ }^{b} \mathrm{~kg} / \mathrm{m}^{2}$

Linear regression results showed a positive significant relationship between water turnover and $\mathrm{BM}\left(\mathrm{r}^{2}=.38, p<0.001\right)$ and $\mathrm{BMI}\left(\mathrm{r}^{2}=.45, p<0.001\right)$. With regard to body composition, water turnover was significantly related to FMI $\left(r^{2}=.41, p<0.001\right)$ and FFMI $\left(r^{2}=.18, p<0.05\right)$. Water turnover was also related to physical activity $\left(r^{2}=.25\right.$ $p<0.05)$. 
Table 3: Physical activity among rural and urban women in Narok County, Kenya

\begin{tabular}{llll}
\hline PA & $\begin{array}{l}\text { Population } \\
\text { Mean SD } \\
n(22)\end{array}$ & $\begin{array}{l}\text { Rural } \\
n(8)\end{array}$ & $\begin{array}{l}\text { Urban } \\
n(14)\end{array}$ \\
\hline VM counts/day $^{\infty}$ & $783766 \pm 261001$ & $859733 \pm 319404$ & $740356 \pm 222551$ \\
Sedentary $^{\infty}$ & $359 \pm 120$ & $352 \pm 89.5$ & $364 \pm 137.3$ \\
Light $^{\infty}$ & $388 \pm 87$ & $377 \pm 78.6$ & $394 \pm 92.9$ \\
Moderate $^{\infty}$ & $71 \pm 45$ & $80 \pm 50.2$ & $65.6 \pm 42.6$ \\
Vigorous $^{\infty}$ & $0.18 \pm 0.34$ & $0.32 \pm 0.48$ & $0.10 \pm 0.20$ \\
Total wear time $^{\infty}$ & $802 \pm 118$ & $800 \pm 93.1$ & $803.4 \pm 133.9$ \\
\hline Activity levels $^{\infty}$ & Population (\%) & Rural (\%) & Urban (\%) \\
Sedentary $^{\infty}$ & 44.5 & 42.5 & 44.3 \\
Light $^{\infty}$ & 48.7 & 46.9 & 47.7 \\
Moderate $^{\infty}$ & 8.8 & 10.5 & 7.9 \\
Vigorous $^{\infty}$ & 0.02 & .03 & .02 \\
\hline
\end{tabular}

VM- vector magnitude, ${ }^{\infty}$ time in minutes based on cut-off points by Troiano et al [15]

Multiple regression analysis showed physical activity on top of BMI resulted in an additional $15 \%$ variation in water turnover $\left(r^{2}=.38, p<0.005 ; \Delta r^{2}=.15, p<0.05\right)$ resulting in a total explained variation of $53 \%$. The standardized beta values for BMI and physical activity were 0.544 and 0.393 respectively indicating that BMI was a strong predictor of water loss in this model (Table 4).

Table 4: Multiple regression results of water turnover (L/day) as dependent variable and BMI and VM/day as independent variables

\begin{tabular}{lllll}
\hline L/day & $\mathrm{B}$ & $\mathrm{SE}$ & $\beta$ & $\mathrm{P}$ \\
\hline Step 1 & .437 & .797 & & \\
Constant & .122 & .034 & .62 & $<0.005$ \\
BMI & $\mathrm{R}^{2}$ & & $\mathrm{SEE}$ & $<0.005$ \\
\hline Model & .38 & .65 & \\
\hline 1 & & & & \\
\hline Step 2 & & & & \\
Constant & .181 & .755 & .54 & $<0.005$ \\
BMI & .107 & .031 & .39 & $<0.05$ \\
VM & $1.219 \mathrm{E}-006$ & .000 & & \\
\hline Model & & & $\mathrm{SEE}$ & \\
\hline 2 & $\mathrm{R}^{2}$ & .15 & .58 & $<0.05$ \\
\hline
\end{tabular}


Whereas physical activity on top of FMI resulted in explaining additional variation in $\left(r^{2}=.37, p<0.005 ; \Delta r^{2}=.12, p<0.05\right)$ and the beta values were .509 for FMI and .359 for physical activity, indicating that FMI was stronger predictor in this model. And physical activity on top of FMI resulted in an additional $12 \%$ explanation of variation in water loss. Physical activity on top of FFMI showed an additional variation of $26 \%$ in water loss $\left(r^{2}=.14, p>0.05, \Delta r^{2}=.26 p<0.05\right)$. Each one unit increase of BMI brings about 0.11 $\mathrm{L} / \mathrm{d}$ increase in water loss holding physical activity constant, whereas a unit increase in FFMI brings about $0.17 \mathrm{~L} / \mathrm{d}$ increase in water loss holding physical activity constant.

\section{Discussion}

Our study objective was to assess water loss and its relationship with physical activity and body composition among women in rural and urban dwellings in Narok County, Kenya and to the best of our knowledge this study is the first among native black women. We found a positive relationship between body composition (BMI, FFMI, and TBW) and water turnover. Physical activity was also a positive predictor of water loss and physical activity together with BMI explained a 53\% variation in water loss. Water loss in our study was comparable to the findings in other studies done in varied climatological conditions [3-5].

Water is an important nutrient in maintenance of life and a major constituent of the human body. Water loss in itself is obligatory for elimination of wastes such as urea and excess salts via the kidney and carbon dioxide from the lungs and thermoregulation by way of sweat [16]. Water needs and requirements are a challenge to meet in sub-Saharan Africa, where food and water can be scarce and some communities in arid and semi-arid lands have to travel for several miles in search of both. Numerous factors, such as high temperature, humidity levels, physical activity and exercise, and heat stress in particular influence water needs [16]. The average temperatures in our study area are between $9{ }^{\circ} \mathrm{C}$ and $30{ }^{\circ} \mathrm{C}$ for cold and hot seasons respectively, whereas the average relative humidity levels are between $40 \%$ and $98 \%$ for the lowest to highest respectively. High humidity in a hot climate makes it hard for the body's natural cooling mechanism of sweating to take place and the body compensates by working harder to cool off and overheating or heat exhaustion can occur [17]. This may lead to dehydration and chemical imbalance within the body [17].

Thus, for women in most Kenyan communities who have the responsibilities of being key providers for their families and especially children, if water needs are not met, their nutritional status may be compromised since water is an essential nutrient [18] and their ability to provide for the household will be limited due to dehydration which causes impaired physiological and performance response [18]. In a Dutch study, 
it was found that water turnover among women was similar to our study and was not related to physical activity [3]. The magnitude of water loss through sweat during exercise in a warm environment is reported to be dependent primarily on exercise intensity and duration [19]. Adequate total water intakes for sedentary adults under temperate climatic condition on average are between 2 and $2.5 \mathrm{~L} /$ day for women and men respectively and water loss for a sedentary adult is between 2-3 L/day [16], whereas for those in hot environments this need increases variably depending on prevailing conditions, some studies indicate up to $6 \mathrm{~L} /$ day $[2,20]$. However, studies have shown that human water requirements should not be based on one meeting the minimal intake for age and gender because this can lead to deficit and possible adverse performance and health consequences [2]. The women in our study group participated mainly in sedentary and light activities, however, due to the mostly high temperatures the activity levels may be intense for a short period of time and during the rest of the day the activity intensity levels may slow down and remain low throughout. However, physical activity in most sub-Saharan African communities like most developing countries comes as part of the daily activities of searching for water and food [21, 22]. Rarely do adults exercise particularly in the rural areas unless for professional athletes and sports personalities. In comparison to a study by our group done on young adults (18-28yrs) in the Netherlands ( $n=40$; unpublished data)-on average the Dutch subjects spent $66.9 \%$ of their waking time per day engaged in sedentary behavior compared to the Kenyans who spent $44.5 \%$. The Kenyan subjects spent twice as much of their time on moderate intensity PA (8.8\%) compared to the Dutch $(4.4 \%)$. The average vector magnitude counts per day for the Kenyan subjects were 783766 while the average for the Dutch subjects was 524206 vector magnitudes per day.

Interesting to note however, was the high overweight levels among women in the study area and although our sample size was small to give us estimated prevalence, the trends of increasing overweight cases in African is worrying and previous studies have shown that overweight impedes physical activity and movement [23]. In our study, we found the percentage of FM to be higher and FFM to be lower compared to that reported in a study done in another part of Kenya [11]. The study found the percentage body fat among lactating women to be $26.1 \%$ compared to our study which was $30.7 \%$ and FFM was $41.3 \mathrm{~kg}$ while in our study it was $38.9 \mathrm{~kg}$. Another study among women in Kenya also found the mean TBW to be $24.0 \mathrm{~L}$ [24], while in our study the mean was 29.3.L. The TBW in our study was comparable to that found in studies in the US [25] and Kenya [11]. FMI and FFMI correlated significantly with water turnover. LBM is about $73 \%$ water and fat body mass is $10 \%$ water $[2,26]$ and TBW and LBM have been reported to strongly correlate with body surface area in normal and obese subjects [27], therefore presumably individuals with higher BMI would have higher water requirements and therefore water turnover is expected to be higher as BMI 
increases, as it was in our study and these findings concur with a study among adolescents [8].

Despite varying water needs brought about by differences in climatic conditions, physical activity levels, metabolic rate, body surface area and body weight and body composition, healthy humans regulate their water balance with precision. Meeting water requirements among women in Africa is essential for proper normal body function in order for them to accomplish cultural responsibilities of caring for household members. Acclimation may play a role in minimizing water loss among individuals in arid areas in order for the body to utilize water well since water loss was more or less similar to those of women in other climatic regions. Studies have indicated that well acclimatized humans in extremely warm/hot climates can sustain a perspiration rate of 2 L/hour for long duration activity [28] and another study indicates that for short time periods a sweating rate of $4 \mathrm{~L} /$ hour has been reported [29]. However humans have limited rehydration capacity which allows about $1 \mathrm{~L}$ at a time such that even if water is readily available, those working in warm climates will drink less than that lost through perspiration concluding that activity levels were not directly tied to and limited by water availability [30]. Our recommendation for future research is that it would focus more on coping mechanism adopted by people living in warm climates to cope with water loss. Our study is not without limitation, and this is due to the small sample size and care must be exercised while making generalizations. However, the strength of our study is in the methodology; we used deuterium dilution to assess body composition and water turnover, whereas accelerometers were used to assess physical activity; methods that have been validated in previous studies and have been found to be reliable.

In conclusion, water turnover among women was related to physical activity and body composition and BMI was the strongest predictor of water loss among our study group. 


\section{References}

1. Grandjean AC Water requirements, impinging factors, and recommendations. http://www.who.int/water_sanitation_health/dwq/nutrientschap3.pdf.

2. Sawka MN, Cheuvront SN, and Carter R, Human water needs Nutrition Reviews, 2005. 63(6): p. S30S39.

3. Westerterp KR, Plasqui G, and Goris AHC, Water Loss as a function of energy intake, physical activity and season. British Journal of Nutrition 2005. 93: p. 199-203.

4. Westerterp KR, et al., Energy expenditure climbing Mt Everest Journal of Applied Physiology 1992. 73 : p. 1815-1819.

5. Westerterp KR, et al., Energy balance at high altitude 6,542. Journal of Applied Physiology, 1994. 77(862-866).

6. Park J, et al., Relation of body composition to daily physical activity in free-living Japanese adult women British Journal of Nutrition, 2011. 106: p. 1117-1127.

7. Rush EC, et al., Water turnover in children and young adults. European Journal of Applied Physiology, 2010. 110: p. 1209-1214.

8. O'connell BN, et al., Water turnover assessment in overweight adolescents Obesity Journal 2011. 19(2): p. 292-297.

9. Schutz Y, Kyle UUG, and Pichard C, Fat-free mass index and fat mass index percentiles in Caucasians aged 18-98y International Journal of Obesity, 2002. 26: p. 953-960.

10. Lu Y, et al., Comparison of fat-free mass index adn fat mass index in Chinese adults European Journal of Clinical Nutrition, 2012. 66: p. 1004-1007.

11. Ettyang GA, et al., Serum retinol, iron status and body composition of lactating women in Nandi, Kenya Annals of Nutrition Metabolism, 2003. 47: p. 276-283.

12. Westerterp KR, Wouters L, and v.M.L. WD, The Maastricht protocol for the measurement of body composition and energy expenditure with labelled water obesity Research, 1995. Supp 1: p. 49-57.

13. Goris AHC and Westerterp KR, Underreporting of habitual food intake is explained by undereating in highly motivated lean women. American Society for Nutritional Sciences 1999. 129(4): p. 878-82.

14. Fjeld $\mathrm{CR}$, Brown $\mathrm{KH}$, and Schoeller DA, Validation of the deuterium oxide method for measuring average daily milk intake in infants American Journal Clinical Nutrition 1988. 48(3): p. 671-679.

15. Troiano RP, et al. Physical activity in the United States measured by accelerometer. Medicine \& Science in Sports \& Exercise, 2007. http://www.researchgate.net/publication/5757920_Physical_activityin_the_United_States_measured_by_accelerometer, 181-188 DOI: 10.1249/mss.0b013e3181a51b3.

16. Jequier E and Constant F, Water as an essential nutrient: the physiological basis of hydration. European Journal of Clinical Nutrition 2010. 64: p. 115-123.

17. Ahrens DC, Meteorology today: An introduction to weather, climate and the environment 10th ed. http://www.amazon.com/Meteorology-Today-Introduction-Weather-

Environment/dp/08400549982012, Stamford, Connecticut USA: Cengage Learning

18. Kleiner SM, Water: an essential but overlooked nutrient. Journal of the Academy of Nutrition \& Dietetics 1999. 99(2): p. 200-206.

19. Sawka MN, Wenger $\mathrm{C}$, and Pandolf $\mathrm{K}$, Thermoregulatory responses to acute exercise-heat stress and heat acclimation in Handbook of Physiology, Fregly M and B. C., Editors. 1996, Oxford University Press: New York. p. 157-185.

20. Welch B, Burkirk E, and lampietro $\mathrm{P}$, Relation of climate and temperature to food and water intake in man. Metabolism, 1958. 7: p. 141-148.

21. Rao S, et al., Maternal activity in relation to birth size in rural India. The Pune maternal nutrition study European Journal of Clinical Nutrition, 2003. 57: p. 531-542.

22. Steyn K and Damasceno A, Lifestyle \& related risk factors for chronic disease 2 nd ed. Disease \& Mortality in sub-Saharan Africa ed. Jamison DT, et al. http://www.researchgate.net/publication/49807212_Lifestyle_and_Related_Risk_Factors_for_Chronic_Diseases2006, Washington DC: World Bank

23. Wearing SC, et al., The biomechanics of restricted movement in adult obesity. Obesity Reviews 2006. 7(1): p. 13-24. 
24. Ettyang GA, van Marken Lichtenbelt WD, and S.W. Esamai F, Assessment of body composition and breast milk volume in lactating mothers in pastoral communities in Pokot, Kenya, using deuterium oxide. Nutrition \& Metabolism, 2005. 49: p. 110-117.

25. Bossingham MJ, Carnel NS, and Campbell WW, Water balance, hydration status, and fat-free mass hydration in younger and older adults The American Journal of Clinical Nutrition 2005. 81(6): p. 134250.

26. Van Loan M and Boileu R, Age, gender, and fluid balance Body Fluid Balance: Excercise and Sport. http://www.crcpress.com/product/isbn/97808493791851996, Boca Raton Fl: CRC Press.

27. Hume, R. and Weyers E, Relationship between total body water and surface area in normal and obese subjects. Journal of Clinical Pathology 1971. 24: p. 234-238.

28. Kerslake DM, The Stress of hot environment in The Monographs of the Physiological Society 1972, Cambridge University Press: Cambridge.

29. Eichana LW, et al., Thermal regulation during acclimatization to a hot dry environment. American Journal of Physiology, 1950. 163(3): p. 585-587.

30. Hanna JM and Brown DE, Human heat toleranace Annual Review of Anthropology 1993. 12: p. 259284. 


\section{CHAPTER 6 \\ Impact of Physical activity and Household food security on pregnancy outcomes among women in Narok County, Kenya}

By Susan Keino, Guy Plasqui and Bart van den Borne

Submitted for publication 


\begin{abstract}
Introduction:Pregnancy is a period characterized by various physical, emotional, hormonal and psychological changes. Gaining recommended weight during pregnancy minimizes the incidences of adverse outcomes, including gestational hypertension, birth weight ( $<2.5 \mathrm{~kg}$ or $\geq 4 \mathrm{~kg}$ ) and caesarian section. This period may also be characterized by decreased physical activity, although for some women in Africa, being the key food providers, activity levels may not decrease since they need to provide for their families.
\end{abstract}

Objectives: The objectives of this study were to: i) assess physical activity among pregnant women ii) assess food security status among pregnant women and iii) assess the impact of physical activity and food security on pregnancy outcomes.

Methods: Pregnant women in their second $(n=22)$ and third trimester $(n=28)$ were recruited for this study in Narok District Hospital, Narok County, Kenya. Structured questionnaires were used to collect data on socio-demographic characteristics. Twenty four hour-recall was used to collect data to assess dietary diversity and the Household food security Access scale was used to measure food security. GT3X accelerometers were used to measure physical activity. Pregnancy outcomes, birth weight and delivery method were noted.

Results: The pregnant women's mean weight and height were $66 \mathrm{~kg}$ and $1.63 \mathrm{~m}$ respectively. Mean BMI among urban and rural women was $25.2 \pm 3.4$ and $24.2 \pm 4.1$. Of the household, $28 \%$ were food secure and severely food insecure were $45.1 \%$. Physical activity was 616,447 vector magnitudes per day among women in their second trimesters and 475,002 vector magnitudes per day for women in their third trimester pregnancy. Multiple regression indicated after correction for gestational age at the time of measurement that only height was a significant predictor of birth weight $(p<0.05)$. Physical activity and food security were not significant predictors when added to the model.

Conclusion: Height is important in predicting infant birth weight and not physical activity and food security. 


\section{Introduction}

Pregnancy is a period characterized by various physical, emotional, hormonal and psychological changes. These changes may bring about a feeling of tiredness, depression and may result in changes in eating habits and reduced physical activity. Pregnancy is a critical period of body weight regulation (1). Although weight gain is recommended for proper fetal development before pregnancy and during pregnancy, studies have indicated that nearly one-third of women gain more than the recommended weight during pregnancy $(2,3)$. Gaining recommended weight during pregnancy minimizes the incidences of adverse outcomes, including gestational hypertension, birth weight $(<2.5 \mathrm{~kg}$ or $\geq 4 \mathrm{~kg}$ ) and caesarian section. In Africa, some cultures promote special foods and rest for women during pregnancy, while other do not and women continue to work hard (4) and since they are key food providers in homes, they need to provide for their families. Thus physical activity levels may or may not decrease for some women or remain too high during pregnancy, consequently being unable to match energy expenditure with sufficient energy intake. Dietary intake is also important during pregnancy although the food security situation in the home may affect women's access to food during this period. Although many cultures promote special foods for pregnant women, other cultures deprive women of the essential nutrients through food taboos (4).

The objectives of this study were to: i) assess physical activity among pregnant women ii) assess food security status among pregnant women and iii) assess the impact of physical activity and food security on pregnancy outcomes.

\section{Methods}

\section{Study, setting, design and sampling}

This was a longitudinal study that took place in Narok County, Kenya. The Narok County is made up of an agricultural and agro-pastrolists community in the South Rift Valley. The study was carried out in the Narok District Hospital where we purposively selected women who were in their $1^{\text {st }}$ and $2^{\text {nd }}$ trimester of pregnancy to participate in the study. The reason for identifying them early was that at least they needed to complete the study protocol in their $2^{\text {nd }}$ and $3^{\text {rd }}$ trimester. The women were randomly selected from the Antenatal clinic (ANC) where they were visiting for consultation. The women were approached and asked to participate in the study. A total of 132 women from rural and urban areas accepted, however after reading or being read to the study protocol only 50 women gave informed consent. During follow-up, some women either did not turn up or did not deliver at the district hospital and for the pregnancy 
outcomes only 36 women were included in total $(n=16$ second trimester; $n=20$ third trimester). The inclusion criterion was that the women had to be pregnant and this we confirmed by checking their name in the ANC register.

All study procedures were approved by the Institute for Research and Ethics Committee (IREC) of Moi Teaching and Referral Hospital, Eldoret, Kenya. The subjects gave written and verbal consent to both study procedure and participation. The data were collected by the first author and two trained research assistants in September and February 2012.

\section{Measurements}

Data were collected through interviews, anthropometric measurements and measuring physical activity. The interview consisted of a structured questionnaire and included questions on household socio-economic and demographic characteristics, 24 hour dietary recall, and a Household Food Insecurity measurement. After the interview, the participants presented themselves for the anthropometric and physical activity measurements.

\section{Interview schedule}

The interview schedule collected information on socio-demographic factors that included but were not limited to, age, area of residence, marital status, occupation and number of children of the participant.

Food Insecurity was measured by the Household Food Insecurity Access Scale (HFIAS) which is a nine-items scale consisting of two types of questions; an occurrence question followed by a frequency of occurrence question, which asked the participant how often the condition reported in the previous occurrences question happened during the previous month (5). The occurrence questions asked whether the respondent or other household members either felt a certain way or performed a particular behavior over the previous one month. Before inclusion in the questionnaire, the questions were reviewed with Key Informants as suggested in the protocol. A standard scoring procedure was used with 1 point for occurrence and 0 for non-occurrence. The frequency scores ranged from 0 to 3 , where 0 was the score for non-occurrence, 1 for rarely (once or twice in the past four weeks), 2 for sometimes (three to ten times in the past four weeks) and 3 for often (more than ten times in the past four weeks). For the purpose of this paper we used the total score (9-items based on the frequency score). A total score of 27 represents the most food insecure household whereas a lower score represents a more food secure household.

Data on household dietary diversity were collected using a 24 hour recall method and data entered into the Household Dietary Diversity Score sheet (HDDS) (6). The 
HDDS captures dietary diversity in a normal 24 hour period by the household as a whole and not a single member. Food consumed outside the home that was not prepared in the home was not included. A set of 12 food groups was used to guide the scoring as per the food items consumed, with 1 being the minimum score and 12 as the maximum (6).

\section{Anthropometric Measurements}

Anthropometric measurements of weight and height were taken from the woman that was interviewed. Weight was measured to the nearest $0.5 \mathrm{~kg}$ using a mechanical scale (SECA 762). Height was measure to the nearest millimeter also using a transportable stadiometer (SECA 214). The scales were calibrated after each session of measurements. Waist and hip measurements were measured using a tape. The waist was measured around the narrowest point between the navel and the ribcage. The hip was measured around the widest part of the hip to the nearest $\mathrm{cm}$. All measurements were taken with light clothing on and without shoes. A total of two measurements were taken and the average was calculated.

\section{Physical activity}

Actigraph GTX3 accelerometers (Actigraph, Pensacola, FL, USA) were used to determine physical activity (PA). The tri-axial accelerometer measures $4.6 \mathrm{~cm} \times 3.3 \mathrm{~cm} \times 1.5$ $\mathrm{cm}$ and weighs $19 \mathrm{~g}$ and is a validated tool that has shown to be reliable for the assessment of PA (7). It was attached to the lower back by means of an elastic belt and worn all the time for a period of 2-4 days except during sleep and while taking a bath or shower. The GT3X measures accelerations of the trunk (counts) in the anteroposterior, medio-lateral and longitudinal axes, otherwise referred to as $X, Y \& Z$ axes. The GT3X actigraph records accelerations ranging from $0.5-2.5 \mathrm{G}$ 's and the output is digitized at a rate of $30 x$ per second ( 30 Hertz). The GT3X is designed to enable data storage for 30 days (with fully charged battery) and for optimal wearing comfort in order not to interfere with daily activities. The data was downloaded using the Actilife software and Vector magnitude (VM) counts per day were obtained from the output and intensity of physical activity was obtained using Troiano et al. cut-off points (8).

\section{Birth outcomes}

After delivery the birth weight of the child and the delivery method were noted, whether it was a normal delivery or delivered by caesarian section. 


\section{Data analysis}

Data was entered using SPSS version 20 and Microsoft ${ }^{\circledR}$ Excel 2010. The data was presented using tables in percentages, means and standard deviation. Data was analyzed using Pearson's correlations and multiple regression analysis.

\section{Results}

In Table 1, the mean BMI among pregnant women in the urban area was $25.2 \pm 3.4$ while that of women in the rural area was $24.2 \pm 4.1$. Of the total population, $88.7 \%$ were married. Dietary diversity scores did not differ between rural and urban women (6.3), however women in their $2^{\text {nd }}$ and $3^{\text {rd }}$ trimester, women had $6.1 \pm 0.89$ and $6.6 \pm$ 0.80 dietary diversity scores respectively. Food insecurity access score among urban and rural women was $5.0 \pm 5.0$ and $7.4 \pm 5.4$ respectively (Table 1 ).

Table 1: General characteristics and food security status of pregnant women in Narok Country

\begin{tabular}{|c|c|c|c|}
\hline & $\begin{array}{l}\text { Population } \\
\mathrm{N}=132 \\
\text { Mean (SD) }\end{array}$ & $\begin{array}{l}\text { Urban } \\
\mathrm{N}=101 \\
\text { Mean (SD) }\end{array}$ & $\begin{array}{l}\text { Rural } \\
\mathrm{N}=31 \\
\text { Mean (SD) }\end{array}$ \\
\hline Weight & $66.0(11.2$ & $67.0(11.1)$ & $63(11.3)$ \\
\hline Height & $1.63(0.07)$ & $1.6(0.07)$ & $1.6(0.06)$ \\
\hline BMI & $26.0(3.6)$ & $25.2(3.4)$ & $24.2(4.1)$ \\
\hline Food security & Mean (SD) & Mean (SD) & Mean (SD) \\
\hline Dietary diversity score $(n=60)$ & $6.3(0.8)$ & $6.3(0.9)$ & $6.3(0.6)$ \\
\hline HFIAS_score $(n=132)$ & $4.1(3.0)$ & $5.0(5.01)$ & $7.4(5.41)$ \\
\hline Food secure (\%) & 28.6 & 33.7 & 13.3 \\
\hline Mildly food insecure (\%) & 11.3 & 13.9 & 3.3 \\
\hline Moderately food insecure (\%) & 15.0 & 9.9 & 30 \\
\hline Severely food insecure (\%) & 45.1 & 42.6 & 53.3 \\
\hline
\end{tabular}

Abbreviations: BMI-body mass index; HFIAS-household food security score

Whereas between trimesters food insecurity access score, $2^{\text {nd }}$ trimesters was $5.0 \pm 2.7$ and $3^{\text {rd }}$ trimesters was $3.7 \pm 3.4$. Food secure households were $28.7 \%$ while $45.1 \%$ were severely food insecure. While in the $2^{\text {nd }}$ trimester severe food insecurity was reported by $61.9 \%$ of households and in the $3^{\text {rd }}$ trimester it was $42.9 \%$. Physical activity among women in their $2^{\text {nd }}$ trimester of pregnancy was $616,447 \mathrm{VM}$ per day, while women in their $3^{\text {rd }}$ trimester reported 475, 002 VM per day (Table 2). Using Troiano (8) cut-off points, the time spent on sedentary activities among women in $2^{\text {nd }}$ trimester and $3^{\text {rd }}$ trimester were $51 \%$ and $56 \%$ respectively (Table 2 ). The mean birth weight was 
$3.04 \pm 0.53$ and $82.9 \%$ of the pregnant women had normal delivery, while $17.1 \%$ delivered via caesarian section (Table 3). Low birth weight (LBW) children were $12.2 \%$.

Table 2: Physical activity and Time spent on physical activity intensity levels in minutes per day among pregnant women in Narok County, Kenya

\begin{tabular}{|c|c|c|c|c|c|c|}
\hline \multirow[b]{2}{*}{ Vector magnitude } & \multicolumn{3}{|c|}{2 trimester $(n=22)$} & \multicolumn{3}{|c|}{$3^{\text {rd }}$ trimester $(n=28)$} \\
\hline & Mean & SD & & Mean & SD & \\
\hline VM daily & 616447 & 244812 & & 475002 & 212540 & \\
\hline VM CPM & 780 & 266 & & 630 & 246 & \\
\hline Calender days & 3.27 & .88 & & 3.21 & .69 & \\
\hline Time spent ${ }^{\#}$ & Mean & SD & $\%$ & Mean & SD & $\%$ \\
\hline Sedentary & 311 & 182 & 51 & 340 & 190 & 56 \\
\hline light & 272 & 159 & 44 & 249 & 161 & 41 \\
\hline moderate & 29 & 31 & 5 & 17 & 18 & 3 \\
\hline Vigorous & 1.0 & 0.11 & 0.02 & 0.02 & 0.11 & .003 \\
\hline Total wear time $\infty$ & 783 & 75 & & 748 & 87 & \\
\hline
\end{tabular}

Abbreviations: VM-vector magnitude CPM- counts per minute; "time spent in different intensities of physical activity in minutes per day based on Troiano cut-off points (8); $\infty$ total wear time in minutes per day.

Pearson correlations results showed a significant negative relationship between HFIAS and $\mathrm{BMI}(\mathrm{r}=-.25, \mathrm{p} \leq 0.01)$, and also a significant negative relationship between place of residence (rural or urban) and $\mathrm{BMI}(\mathrm{r}=-.12, \mathrm{p} \leq 0.05)$. There was a significant positive relationship between HFIAS and residence $(r=.28, p \leq 0.05)$, while a significant negative relationship was reported between weight and HFIAS ( $r=-.29, p \leq 0.01)$.

Table 3: Birth weight and delivery of infants born to women in their $2^{\text {nd }}$ and $3^{\text {rd }}$ whose physical activity and food security was assessed in Narok County

\begin{tabular}{llll}
\hline & $2^{\text {nd }}$ trimester & $3^{\text {rd }}$ trimester & Population \\
& $\mathrm{M}(\mathrm{SD})$ & $\mathrm{M}(\mathrm{SD})$ & \\
\hline Birth weight $(\mathrm{kg})$ & $2.84(0.49)$ & $3.15(0.36)$ & \\
Normal delivery & $87.5 \%$ & $78.9 \%$ & $82.9 \%$ \\
Caesarian section & $12.5 \%$ & $21.1 \%$ & $17.1 \%$ \\
\hline
\end{tabular}

Multiple regression results in Table 4 indicated that mother's height and weight corrected for gestational age was significant predictors of birth weight $\left(r^{2}=.22, p \leq 0.05\right)$. Physical activity on top of height and weight corrected for gestational age was a nonsignificant predictor of birth weight (Table 4). HFIAS on top of height and weight corrected for gestational age was non-significant predictor of birth weight (Table 5). 
Table 4: Multiple regression table of birth weight as the dependent variable and mothers Height, Weight, Gestational week and Physical activity as independent variables

\begin{tabular}{|c|c|c|c|c|}
\hline Birth weight & B & SE B & $\beta$ & $P$ value \\
\hline \multicolumn{5}{|l|}{ Step 1} \\
\hline Constant & -1.44 & 1.76 & & \\
\hline Height & .024 & .011 & $.379 *$ & $\leq 0.05$ \\
\hline Weight & -.004 & .007 & -.107 & NS \\
\hline Gestational age & .028 & .013 & $.365^{*}$ & $\leq 0.05$ \\
\hline Model & $\mathrm{R}^{2}$ & SE & Adjusted $\mathrm{R}^{2}$ & \\
\hline 1 & .220 & & .141 & $\leq 0.05$ \\
\hline \multicolumn{5}{|l|}{ Step 2} \\
\hline Constant & -1.44 & 1.79 & & \\
\hline Height & .024 & .012 & .381 & $\leq 0.05$ \\
\hline Weight & -.004 & .007 & -.116 & NS \\
\hline Gestational age & .028 & .013 & .367 & $\leq 0.05$ \\
\hline VMC_day & $-9.296 \mathrm{E}-008$ & .000 & -.039 & NS \\
\hline Model & $\mathrm{R}^{2}$ & Adjusted $\mathrm{R}^{2}$ & $\Delta \mathrm{R}^{2}$ & \\
\hline 2 & .221 & .121 & .001 & NS \\
\hline
\end{tabular}

Height, Weight, Gestational week and food security as independent variables

Table 5: Multiple regression table of birth weight as the dependent variable and mothers

\begin{tabular}{|c|c|c|c|c|}
\hline Birth weight & B & SE B & $\beta$ & $P$ value \\
\hline \multicolumn{5}{|l|}{ Step 1} \\
\hline Constant & -1.43 & 1.791 & & \\
\hline Height & .024 & .012 & $.373^{*}$ & $\leq 0.05$ \\
\hline Weight & -.004 & .007 & -.108 & NS \\
\hline Gestational age & .028 & .014 & $.361^{*}$ & $\leq 0.05$ \\
\hline Model & $\mathrm{R}^{2}$ & SEE & Adjusted $\mathrm{R}^{2}$ & \\
\hline 1 & .220 & .417 & .144 & $\leq 0.05$ \\
\hline \multicolumn{5}{|l|}{ Step 2} \\
\hline Constant & -1.90 & 1.736 & & \\
\hline Height & .029 & .011 & .442 & $\leq 0.05$ \\
\hline Weight & -.008 & .007 & -.212 & NS \\
\hline Gestational age & .033 & .013 & .424 & $\leq 0.05$ \\
\hline HFIAS & -.028 & .014 & -.306 & NS \\
\hline Model & $\mathrm{R}^{2}$ & Adjusted $\mathrm{R}^{2}$ & $\Delta \mathrm{R}^{2}$ & \\
\hline 2 & .305 & .212 & .085 & NS \\
\hline
\end{tabular}

Height, Weight, Gestational week and food security as independent variables 


\section{Discussion}

The main finding of this study is that height was found to be a significant predictor of birth weight and not physical activity and food security. Other results in this study indicate that urban women weighed more $(67 \pm 11.1 \mathrm{~kg})$ than their rural counterparts $(63 \pm 11.3 \mathrm{~kg}), 88.7 \%$ were married and the food secure households were $28.6 \%$, whereas $45.1 \%$ were severely food insecure. Women in their second trimesters who reported severe food insecurity were $61.9 \%$, while those in their third trimester were $42.9 \%$.

Weight gain during pregnancy among women is encouraged for proper growth and development of the fetus. However, several factors are coming into play to determine gestational weight gain. Some of these factors that include societal/institutional, environmental and community determinants have been highlighted by Rasmussen et al (2). Cultural norms and beliefs, as societal determinants show that some cultures encourages the avoidance of certain foods because of the belief that they make the fetus not to grow too big and therefore making delivery easier for the mother. It is also indicated that community amenities such as parks in the neighborhood encourage pregnant women to make regular walks. Gestational weight gain if not checked can be excessive and may result in gestational diabetes and hypertension and the excess weight gain is particularly high among already overweight women prior to being pregnant (9).

Most communities in Kenya ensure that pregnant women get special attention especially when it comes to food provision and more so after delivery. However, the food insecurity situation in many parts of the country makes it impossible for women to get the nutrients they want during pregnancy. The food insecurity was more severe for women in their second trimester compared to the women in their third trimester. The reason for this is not very clear although as pregnancy progresses and the woman is taken care of by members of the family, in some cases the food is brought to the woman by the extended family members. Dietary diversity (HDDS) also differed slightly between the two groups ( $p=0.08)$, the $2^{\text {nd }}$ trimester women had HDDS of 6.1 and $3^{\text {rd }}$ trimester group had a HDDS of 6.5. The more diverse diet means that one gets more nutrients from it than less diverse diets. The maximum score on dietary diversity scale was 12 . The pregnant women consumed more of carbohydrates than fruits and vegetables. Although in our study we did not find a relationship been food insecurity and birth outcomes, what is coming out clearly is that the pregnancy nutrition is important in determining birth outcomes as seen in the fact the height was a clear predictor of birth weight of the child. Height does not change during pregnancy, but it is attained during childhood and adolescents, therefore nutrition during childhood and during young adulthood will influence birth outcomes as also reported in other studies (10, 
11). A study by Branca et al. indicated that intrauterine growth retardation (IUGR) is higher in stunted girls (12).

LBW $(<2.5 \mathrm{~kg})$ in our study was higher $(12.2 \%)$ compared to that reported in a study in 2004 which indicated that in most sub-Saharan African countries LBW was $10 \%$ (13). The United Nations Children Educational Fund (UNICEF) estimated that in 2004 low birth weight in developing countries was 16\%, in Eastern Africa it was $13.5 \%$ (14).

Our study like many other studies found no relationship between physical activity of the mother and birth weight $(2,15,16)$. In our study we found the average vector magnitude per day was 616447 in the $2^{\text {nd }}$ trimester and 475002 in the $3^{\text {rd }}$ trimester and the mean was 537238 compared to the mean of 783766 among the non-pregnant women reported in a yet unpublished study (17). Physical activity such as exercise by African women for health reasons is low and more so among pregnant women. The reason for the low physical activity among pregnant women is as a result of the potential risk both to the unborn baby and to the mother (2). In Kenya, there are no guidelines on how much physical activity is required for a healthy pregnancy; however a common belief among older women is that walking during the last trimester may quicken labour and heavy manual work should be avoided during the early stages of pregnancy to avoid complications. There is also a high energy demand during pregnancy to meet the requirements brought about by pregnancy. Some physical activity is important for pregnant women if the pregnancy is not at risk, therefore proper policies and guidelines must be put in place to encourage women to take up exercise during and after pregnancy.

While physical activity may or may not decrease during pregnancy, some cultures in Africa promote special foods and rest during this period. However, others continue to work hard throughout their pregnancy because they are the key food providers for their families (4) and thereby with the increased physical activity and the need for extra energy demands during the gestational period, a mismatch between energy expenditure and energy intake may occur.

The time spent on sedentary activities among pregnant women was $53.8 \%$, while in our other unpublished data on non-pregnant women (17), we found the time spent on sedentary activities to be $44.5 \%$, thus pregnant women spent more time on sedentary activities than non-pregnant women. In comparison with non-pregnant subjects in another unpublished study on healthy young Dutch subjects $18-28$ years of age, time spent on sedentary activities was $66.9 \%$ indicating that women in Kenya, pregnant or not partake in more moderate to vigorous activities as opposed to sedentary activities by the Dutch subjects which included young men and women. Another possible reason for the difference is that the Dutch subjects were younger and school going, whereas 
of the Kenyan subjects with a mean age of 24 years, most were married $(88.7 \%)$ and not attending school.

Our study has some limitations. Our study sample was small and the results from this study may not be accurate to enable us to make generalized statements, thus there is need for a study to be done on a larger sample before conclusive statements can be made. Data on physical activity of pregnant women in Kenya is also limited; our study has contributed to this knowledge by using objective and reliable instruments like the GT3X accelerometer. The other limitation was that our data on PA was not longitudinal therefore we were not able to determine the PA for an individual pregnant women at different stages of pregnancy and this is also our recommendation for future research.

Although our study did not find a relationship between physical activity and birth outcomes, there is need for a policy regarding physical activity for pregnant women to guide the recommendations on how much physical activity is safe for the different stages of pregnancy in Kenya. This is in consideration to the consequences of lots of daily work which leads to higher energy expenditure which may not be met with the high food insecurity in the region. There is also a need for intervention to be designed which will address the food insufficiency suffered by pregnant women. Height of the mother was significant in predicting birth weight, indicating that proper nutrition during childhood and early adulthood will influence birth outcomes, and the more reason why under-nutrition among young girls such as stunting, wasting and underweight can be prevented in order to safeguard their future pregnancies. Thus intervention programs aimed at improving birth weights of the children should target school children and more so girls. 


\section{References}

1. Ferraro ZM, Gaudet L, Adamo KB. The potential impact of physical activity during pregnancy on maternal and neonatal outcomes Obstetrical and Gynecological Survey 2012;67(2):99-110.

2. Rasmussen KM, Yaktine AL. Weight gain during pregnancy: Reexamining the guidelines Institute of Medicine of National Academies. 2009.

3. Mamun AA, O'Callaghan M, Callaway L, Williams G, Najman L, Lawlor DA. Associations of gestational weight gain with offspring body mass index and blood pressure at 21 years of age: evidence from a birth cohort study Circulation 2009 119:1720-7. Epub 2009 March 23.

4. Lincetto O, Mothebesoane-Anoh S, Gomez P, Munjanja S. Antenatal Care. Opportunities for Africa's Newborns [Internet]. 6th June 2013. Available from: http://www.who.int/pmnch/media/publications/oanfullreport.pdf.

5. Coates J SA, \& Bilinsky P.,. Household Food Insecurity Access Scale (HFIAS) for Measurement of Food Access: Indicator Guide v. 3. Food and Nutrition Technical Assistance Project, Academy for Educational Development. 2007.

6. Swindale A B, P.,. Household Dietary Diversity Score (HDDS) for Measurement of Household Food Access: Indicator Guide v. 2. Food and Nutrition Technical Assistance Project, Academy for Educational Development. 2006.

7. Davis EE, Byun W, Ozemek C, Kaminsky LA. Inter-instrument reliablity of GT3X accelerometers in a free-living condition2013. Available from: http://www.actigraphcorp.com/research-database/interinstrument-reliability-of-gt3x-accelerometers-in-a-free-living-condition/.

8. Troiano R, Berrigan D, Dodd KW, Masse LC, Tilert T, McDowell M. Physical activity in the United States measured by accelerometer. Medicine \& Science in Sports \& Exercise 2008;40(1):181-8.

9. Carvalhaes MA, Gomes Cdes B, Malta MB, Papini SJ, Parada CM. Pregnancy overweight is associated with excessive weight gain during pregnancy Revista Brasileira de Ginecologia e Obstericia. 2013 Nov;35(11):523-9.

10. Graff M, Yount KM, Ramakrishnan U, Martorell R, Stein AD. Chilhood nutrition and later fertility: Pathways through education and pre-pregnancy nutritional status Demography 2010 February 47(1):125-44.

11. Martorell R, Habicht JP. Growth in early childhood in developing countries. Human Growth [Internet]. 1986 13th December 2013; 3. Available from: http://www.popline.org/node/344869.

12. Branca F, Ferrari M. Impact of micronutrient deficiencies on growth: The stunting syndrome. Annals of Nutrition Metabolism. 2002;46 (Suppl 1):8-17.

13. Ramakrishnan U. Nutrition and low brith weight: from research to practice American Society for Clinical Nutrition 2004;70(1):17-21.

14. UNICEF, WHO. Low Birthweight Country, Regional and Global Estimates [Internet]. 2004. Available from: http://www.unicef.org/publications/files/low_birthweight_from_EY.pdf.

15. Sternfeld B. Physical activity and pregnany outcome. Review and recommendations Sports Medicine 1997 Jan;23(1):33-47.

16. Currie LM, Woolcott CG, Fell DB, Armson BA, Dodds L. The association between physical activity and maternal and neonatal outcomes: A prospective cohort Maternal Child Health [Internet]. 2013. Available from: http://www.ncbi.nlm.nih.gov/pubmed/24347091.

17. Keino S, van den Borne B, Plasqui G. Body Composition, Water turnover and Physical activity among women in Narok County, Kenya Unpublished Manuscript 2013. 


\section{CHAPTER 7}

Measuring adiposity among women in Narok County, Kenya:

Comparison between body mass index, waist-hip ratio, waist circumference, fat mass index and percentage fat mass

Susan Keino, Guy Plasqui, and Bart van den Borne Submitted for publication 


\section{Abstract}

Introduction: There is an increase in the prevalence of overweight among women in sub-Saharan Africa and although it has not received much attention among researchers and policy makers, its impact is being felt with the increasing cases of overweight-related diseases.

Objective: The aims of this study were to assess overweight using different measures of adiposity, and secondly, to compare the relationships between different measures of adiposity and \% fat mass (FM) from deuterium dilution, as the reference method. Thirdly, the aim was to assess overweight in relation to socio-demographic factors.

Setting: The study was carried out in Narok County, Kenya.

Design: Our study sample was selected randomly among women aged 15-49 years. Anthropometric measurements were taken to assess body mass index (BMI), waist circumference (WC), and waist-hip ratio (WHR). Deuterium dilution was used to assess total body water from which fat mass (FM) and fat free mass (FFM) were calculated assuming a constant hydration of FFM of $73.2 \%$.

Results: Using WC as a measure of adiposity, the number of overweight women was higher (46.4\%) compared to when BMI (21.4\%), WHR (28.6\%) or FMI (28.6\%) were used. WC correlated significantly with all the other measures (WHR, $r=.74, B M I, r=.77$ $\% \mathrm{FM}, \mathrm{r}=.64$ and FMI, $r=.76$; all $p<0.001)$. The \% FM correlated significantly with all measures but not with WHR (WC, $r=.64, p<0.001$; WHR, $r=.25, p=.197$; BMI, $r=.61$, $p<0.01 ; \mathrm{FMI}, \mathrm{r}=.94, p<0.001)$.

Conclusion: $\mathrm{BMI}$ and $\mathrm{WC}$ are adequate measures to assess adiposity as well as FM and FMI. With the clear difference in the outcome of the different measures to assess overweight among women in Africa, more research is needed to identify cut-off point's for the different measures of adiposity specific to the African population.

Key words: Body mass index, fat mass, measures of adiposity, sub-Saharan Africa, women 


\section{Introduction}

Overweight is a known contributor to chronic diseases such as cancer, type 2 diabetes, cardiovascular diseases and hypertension (1-4). The rising prevalence of overweight and obesity in developing countries is of major concern in that it compromises public health gains (5) and diverts resources that would otherwise benefit other sectors of growing economies. The major causes of the rising overweight are attributed to poor quality diets high in sugar and unsaturated fats, lack of physical activity and in some cases underlying medical conditions and genetic factors. There is a lack of attention given to the rising cases of overweight in Africa by policy makers and researchers (6, 7).

There is no ideal measurement of adiposity that is accurate, precise and accessible, although acceptable superior indirect measures available such as densitometry are expensive and time consuming (8). Anthropometric methods are cheap and simple to use for routine clinical and epidemiological field studies (9) and they are needed for screening and diagnosis of individuals at risk of metabolic disorders and also for selective interventions. Body mass index (BMI) is used in most epidemiological studies to classify the degree of obesity and overweight (10-12) although it cannot distinguish between fat and fat-free components (13) and its universal cut-off points have been challenged (14). The World Health Organization (WHO) cut-off points for overweight is $\geq 25 \mathrm{~kg} / \mathrm{m}^{2}$ (15), while the National Health and Nutrition Examination (NHANES III) uses $27.3 \mathrm{~kg} / \mathrm{m}^{2}$ for women (16). There is a discrepancy between average BMI and average relative body fat in certain ethnic groups as demonstrated by Deurenberg-Yap et al.(17). Africans have been shown to have a lower BMI compared to Caucasians at the level of body fat and age (18). In addition, BMI, has been known to underestimate the number of females and overestimate the number of males that are obese (19), thus making it a poor screening tool for females with regard to BMI defined obesity (20). $\mathrm{BMI}$ does not take into consideration the actual composition of body weight, in that excess body weight may be made up of fat or muscle, hence the need to partition BMI into fat-free mass index (FFMI) and fat mass index (FMI) (10). FFMI and FMI are equivalent concepts to the $\mathrm{BMI}$ and in our study we use deuterium dilution to estimate body composition, which is FFM and FM. However, a study by Vanltallie et.al indicates that expressing FFM and FM as percentages of body weight or by weight is unsatisfactory (21) and thus the need to use height-normalized indices (FFMI=FFM $(\mathrm{kg} / \mathrm{m})^{2}, \mathrm{FMI}=\mathrm{FM}$ $(\mathrm{kg} / \mathrm{m})^{2}$. The reason for this is that tall patients with protein-energy malnutrition (PEM) can exhibit values for FFM and FM similar to those of shorter well-nourished individuals (21). Unlike in their study, where FFM and FM were used to diagnose PEM, in our study we use it to measure overweight. 
Waist circumference (WC) and Waist-hip ratio (WHR) according to WHO are additional measures of body fat distribution to BMI (15). Some potential uses of the cut-off points for WC and WHR include surveillance, screening, diagnosis and assessing the value of intervention in the community and the cut-off points for women for risk of metabolic complications include:- WC $>80 \mathrm{~cm}$ for increased risk, WC $>88 \mathrm{~cm}$ or WHR $\geq 0.85$ for substantially increased risk (15). However, there are no specific cut-off points for Africans. The cut-off point of $80 \mathrm{~cm}$ that has been used in many studies was found to be inappropriate as it was obtained from studies in European populations (22). However, reference values for WC and WHR are scarce particularly for Africans and thus hinder their use in screening and identification of at risk individuals for selective intervention and preventive measures (23). In addition, the use of the present cut-off points may not be appropriate for Africans since some studies have demonstrated that whites and blacks have a number of differences in body composition, such as fat distribution and patterning (24). In addition, to use BMI as a measure of body composition, one needs to take into account sex, age, shape and ethnicity (25). In this pilot we compared the different methods of measuring overweight among African women. The aims of this study were to assess overweight using different measures of adiposity, and secondly, to compare relationships between other measures of adiposity and \% fat mass (FM) from deuterium dilution, the reference method and thirdly, to assess the association between overweight as measure by the different methods and socio-demographic factors.

\section{Methods}

\section{Study setting, participants and sampling}

The participants in our study were women of ages $15-45$ years randomly selected in Narok County, Kenya. The inclusion criteria were that the women had a child below five years of age and were not pregnant at the time of data collection. A total of 30 women enrolled in this study, 1 participant failed to report for assessment after recruitment and 1 was left out due to failure to comply with the protocol, resulting in a total of 28 participants with valid data. The ethical committee of Moi Teaching and Referral Hospital and Moi University granted approval and clearance for this study. Informed consent was obtained from each participant.

\section{Measurements}

Weight was measured using the SECA mechanical weighing scale to the nearest $0.1 \mathrm{~kg}$. Standing height was measured to the nearest $0.5 \mathrm{~cm}$ against a wall mounted (SECA) 
stadiometer. Both measurements were taken with the participants having minimal clothing on and without shoes. BMI was calculated as weight in kilograms divided by height in meters squared $\left(\mathrm{kg} /(\mathrm{m})^{2}\right)$. WC and Hip circumference $(\mathrm{HC})$ were measured with the participant standing following the WHO protocol (15) and both measurements were rounded to the nearest $0.5 \mathrm{~cm}$. The cut off points for overweight and obesity were classified according to $\mathrm{WHO}$ and participants with $\mathrm{BMI}<18.5$ were classified as underweight, BMI 18.5-24.9 as ideal, BMI 25-29.9 as overweight and BMI $\geq 30$ as obese. For WC the cut off points $>80 \mathrm{~cm}$ and WHR $\geq 0.85$ were used.

The total body water (TBW) was measured using the deuterium dilution method where a dose of labelled water was given to the participants and urine samples were collected according to a modified Maastricht protocol for assessing body composition(26). After collection of a baseline urine sample, participants drank a deuterium $\left({ }^{2} \mathrm{H}_{2} \mathrm{O}\right)$ dilution $\left(70 \mathrm{ml}\right.$ water with an enrichment of $5 \mathrm{~g}$ atom $\%$ excess ${ }^{2} \mathrm{H}$ ). Six hours after dosing, two urine samples were collected, of which the first urine sample was discarded and the second urine sample was used for analysis. Body composition was calculated from TBW assuming a constant hydration fraction of FFM of $73.2 \%$. FFM and $\mathrm{FM}$ indices (FMI and FFMI) were calculated, which are equivalent concepts to the BMI as shown in the following definition by Schutz et $a l$, FFMI=FFM/height $(m)^{2}$ and $F M I=$ FM/height $(m)^{2}$. Thus, BMI=FFMI+FMI. There are no acceptable cut-off points for percentage body fat (27), therefore for this study we used percentage fat mass of $33.2 \%$ in women (28). There being no cut-off points for FMI and FFMI for Africans, we used those recommended for Caucasians, where $\mathrm{FMI}=8.2$ and $\mathrm{FFMI}=16.8$ which corresponds with $\mathrm{BMI}=25 \mathrm{~kg} / \mathrm{m}^{2}(28)$

\section{Statistical analysis}

Data were entered into Microsoft Excel 2010 for Windows. All statistical analyses were completed using SPSS version 19. Means and standard deviations were calculated for all variables. Bivariate correlation analysis was used to compute Pearson's correlation coefficients to ascertain associations between variables.

\section{Results}

The mean age of the women was 25 , while $35.7 \%$ and $64.3 \%$ were rural and urban residents respectively. Those with post primary level of education were $42.9 \%$ whereas $57.1 \%$ had no formal education or had (some) primary level of education. Married participants were $85.7 \%$ and the mean size of households was 4 persons while the mean number of children per household was 2 children. The mean height and weight 
(M, SD) of the participants was $160.1 \pm 6.3 \mathrm{~cm}$ and $57.0 \pm 11.2 \mathrm{~kg}$ respectively (Table 1).

Table 1: Anthropometric characteristics of women in Narok County, Kenya

\begin{tabular}{llll}
\hline Variables & $\begin{array}{l}\text { Population } \\
\text { Mean } \pm \text { SD }\end{array}$ & Minimum & Maximum \\
& $n(28)$ & & \\
\hline Age (years) & $25.0 \pm 6.1$ & 15 & 45 \\
Height $(\mathrm{cm})$ & $160.1 \pm 6.3$ & 148 & 172 \\
BM(kg) & $57.0 \pm 11.2$ & 39 & 75 \\
BMI kg/m ${ }^{2}$ ) & $22.2 \pm 3.9$ & 16.3 & 31.7 \\
Hip circumference $(\mathrm{cm})$ & $96.3 \pm 8.6$ & 83 & 111 \\
Waist Circumference $(\mathrm{cm})$ & $79.9 \pm 10.4$ & 64 & 103 \\
WHR & $0.83 \pm 0.07$ & 0.71 & 0.95 \\
Fat Mass (kg) & $18.2 \pm 7.4$ & 4.5 & 32.9 \\
Fat Free Mass $(\mathrm{kg})$ & $38.9 \pm 5.6$ & 29.6 & 49.5 \\
Fat\% & $30.8 \pm 8.1$ & 11.3 & 45.0 \\
Fat Free Mass\% & $69.2 \pm 8.1$ & 55.0 & 88.7 \\
Fat Mass Index & $7.04 \pm 2.81$ & 1.87 & 14.0 \\
Fat Free Mass Index & $15.13 \pm 1.87$ & 11.6 & 18.7 \\
\hline
\end{tabular}

Abbreviations: BM-body mass; BMI- body mass index, WHR- waist-hip ratio

Mean FM was $18.2 \mathrm{~kg}$, with a mean percentage fat mass of $30.8 \%$ while mean FFM was $38.9 \mathrm{~kg}$ and mean percentage FFM of $69.2 \%$. Using $\mathrm{BMI}\left(<18.5 \mathrm{~kg} / \mathrm{m}^{2}\right)$ underweight among the participants was $25 \%$, normal BMI $\left(18.5-25 \mathrm{~kg} / \mathrm{m}^{2}\right)$ was $53.6 \%$ and overweight (BMI>25 kg/m ${ }^{2}$ ) was $21.4 \%$, while overweight according to WHR (>0.85) was $28.6 \%$, and using WC (>80) was $46.6 \%$. Using body fat percentage ( $>32 \%)$, overweight were $39.3 \%$, whereas using FMI with $8.1 \mathrm{~kg} / \mathrm{m}^{2}$ as the cut off, overweight was $28.6 \%$.

The prevalence of overweight among women increased with age using all the measurements (Table 2) and correlations were significant ( $p \leq 0.05$ ) except for BMI. However, urban residents were more overweight than rural for all the measurements except for BMI which showed overweight among rural women to be similar to the urban women. Women with post primary education and those who were married had higher overweight than those with primary or lower levels of education and the single, divorced or separated. Comparison between the different measures is shown in Table 3, WC correlated significantly with all the other measures (WHR $r=.74, \mathrm{BMI} r=.77 \% \mathrm{FM}$ $r=.64$ and FMI $r=.76 ; p \leq 0.001$ ), while WHR correlated significantly with only BMI ( $r=$ $.43, p \leq 0.05)$. \% FM correlated significantly with all measures except WHR. 
Table 2: Relationship between different measures of adiposity and socio-demographic variables and Pearson correlation results among women in Narok County, Kenya

\begin{tabular}{|c|c|c|c|c|c|c|c|c|c|c|}
\hline & \multicolumn{2}{|c|}{ WHR } & \multicolumn{2}{|c|}{ WC } & \multicolumn{2}{|c|}{ BMI } & \multicolumn{2}{|c|}{$\% \mathrm{FM}$} & \multicolumn{2}{|c|}{ FMI } \\
\hline & $\%$ & $r$ value & $\%$ & $r$ value & $\%$ & r value & $\%$ & r value & $\%$ & r value \\
\hline $\begin{array}{l}\text { Sample population } \\
(n=28)\end{array}$ & 28.6 & & 46.4 & & 21.4 & & 32.1 & & 28.6 & \\
\hline Age & & $.41 *$ & & $.47 *$ & & .35 & & $.46^{*}$ & & $.44^{*}$ \\
\hline $15-24$ & 37.5 & & 46.2 & & 50.0 & & 44.4 & & 37.5 & . \\
\hline $25-50$ & 62.5 & & 53.8 & & 50.0 & & 55.6 & & 62.5 & \\
\hline Residence & & .10 & & -.03 & & .20 & & .03 & & .08 \\
\hline Urban & 50.0 & & 69.2 & & 83.3 & & 66.7 & & 75.0 & \\
\hline Rural & 50.0 & & 30.8 & & 16.7 & & 33.3 & & 25.0 & \\
\hline Education & & -.10 & & .05 & & .03 & & $.43^{*}$ & & .32 \\
\hline Post primary & 62.5 & & 53.8 & & 83.3 & & 88.9 & & 87.5 & . \\
\hline$<$ Primary lower & 37.5 & & 46.2 & & 16.7 & & 11.1 & & 12.5 & \\
\hline Marital status & & -.27 & & -.22 & & -.27 & & -.10 & & -.14 \\
\hline Married & 87.5 & & 84.6 & & 83.3 & & 100. & & 100. & \\
\hline Single/separated & 15.5 & & 15.4 & & 16.7 & & 0 & & 0 & \\
\hline No of children & & $.40^{*}$ & & $.39 *$ & & $.40^{*}$ & & .28 & & .36 \\
\hline $1-2$ & 50.0 & & 61.5 & & 83.3 & & 77.8 & & 60.0 & \\
\hline$>3$ & 50.0 & & 38.5 & & 16.7 & & 22.2 & & 40.0 & \\
\hline
\end{tabular}

Abbreviations: WHR- waist-hip ratio; WC- waist circumference, BMI- body mass index; FM-fat mass; FMI- fat mass index. ${ }^{*} p<0.05$,

Table 3: Pearson's coefficient correlation $r$ of the different measures of overweight among women in Narok $(n=28)$

\begin{tabular}{llllll}
\hline & WC & WHR & BMI & \%FM & FMI \\
\hline WC & - & & & & \\
WHR & $.74^{* * *}$ & & & & \\
BMI & $.77^{* * *}$ & $.43^{*}$ & & & \\
$\% \mathrm{FM}$ & $.64^{* * *}$ & .25 & $.61^{* *}$ & & \\
FMI & $.76^{* * *}$ & .32 & $.79^{* * *}$ & $.94^{* * *}$ & - \\
\hline
\end{tabular}

Abbreviations: WC-waist circumference; WHR- wait-hip ratio; BMI-body mass index, \%FM- percentage body fat mass, and FMI- fat mass index. ${ }^{* * *} p<0.001,{ }^{* *} p<.01 * p<.05$

\section{Discussion}

Overweight is a nutritional problem that cannot be ignored anymore in sub-Saharan Africa, and for it to be recognized as a disease of public health importance, its measurement has to give an accurate estimation of the problem and its magnitude. This study found that WHR and FMI were similar in terms of measurements of overweight 
(28.6\%), while WC using the WHO cut-off points found overweight to be $46 \%$. Using $\mathrm{BMI}$ and \%FM, the percentage of overweight women were $21.4 \%$ and $32.1 \%$ respectively. When using \%FM as our reference for body composition, as it was determined using the deuterium dilution technique, it correlated with all other measures except WHR.

Research suggests that body composition tends to vary among different populations in terms of age, sex, ethnicity or race (29) and the general health status of the individual (30). Age also plays a role in that percentage of body fat may remain constant or increase with age but there is a substantial redistribution of fat tissue in the subcutaneous, adipose and visceral depots (29). With age there is also a loss of lean body mass and accumulation of fat outside adipose tissue. Studies on body composition and race/ethnicity found groups to differ from each other (30). Research has shown blacks to have a greater mineral bone density and body protein content than whites which results in a higher density of $\operatorname{FFM}(16,31)$. Disease states or malnutrition may cause wasting or reduced FFM in individuals who may be characterized as having a normal \% fat (30). Thus there is a need to have specific cut-off points for the different age, sex and ethnic groups. In our study, we used different available measures of adiposity to ascertain the problem of overweight among women and with the different measures there were different outcomes. BMI is the most widely used diagnostic tool to identify weight problems and although there are cut-off points for Chinese where overweight is $\mathrm{BMI} \geq 24 \mathrm{~kg} / \mathrm{m}^{2}(10)$ there are no clear cut-off points for Africans. Our study, like other studies used the WHO cut-off points whereby overweight was $\mathrm{BMI} \geq 25 \mathrm{~kg} / \mathrm{m}^{2}$. All the measures of adiposity we used yielded different numbers with WC giving us the highest and BMI the lowest level of adiposity. For WC and WHR we relied on WHO-cited cut-off points and although there are cut-off points for different ethnic groups (Asians, Chinese, Caucasian) provided by the International Diabetes Federation (IDF), there are none for black Africans, IDF suggests that cut-off points for Europeans be used until cut-offs for Africans are available (32).

Although FMI is said to be a more reliable measure of nutritional status as opposed to BMI $(21,33)$, our study did not find standard cut-off points for FMI among African women and different cut points exist for different races except for native Africans. For example, one study indicated that the mean FMI for Caucasian women aged $18-34$ was $5.8 \mathrm{~kg} / \mathrm{m}^{2}$ and was $6.2 \mathrm{~kg} / \mathrm{m}^{2}$ for women aged $35-54(33)$ and $8.16 \mathrm{~kg} / \mathrm{m}^{2}$ for Chinese (10). Another study found mean FMI values of 3.9 to $8.2 \mathrm{~kg} / \mathrm{m}^{2}$ and FFMI values of 14.6 to $16.8 \mathrm{~kg} / \mathrm{m}^{2}$ for white women of normal BMI ranges (28). A study on African American women that used a prediction equation found the mean FMI to be $10.9 \pm 4.4$ (30), while in our study the mean was $7.04 \pm 2.8$. We used the cut-off $8.2 \mathrm{~kg} / \mathrm{m}^{2}$ to designate overweight among women in Africa, which is the cut-off point 
for Caucasians, and may not be reliable when used for Africans. It is the lack of cut-off points for Africans that makes FMI unreliable as a screening method for adiposity.

All the measures indicated that overweight was common among the married, a finding that is consistent with other studies. However, we found overweight to be higher among those with fewer children, a finding that is not in agreement with other studies. Many studies report that overweight increases with increasing number of children among women (34-37). It is argued that parity without much spacing between children does not allow a mother to regain her body shape. However, in our study, fewer children could also mean more food to go round and this may explain overweight among Kenyan women with fewer children. Also in our study we did not measure the impact of spacing between the children, which may be a contributor to overweight among women. Overweight also increased with age, a finding that was consistent with other studies $(37,38)$. Although many studies indicate that overweight is high among the educated, our study found mixed results with the different measures. All measures except WC, showed overweight to be high among women with post primary education. In our study, women, regardless of their economic status or job opportunities that come with secondary level of education and beyond which would mean higher purchasing power were prone to abdominal adiposity all the same just because they were women. Wagner reiterates that women tend to have a greater fat mass rather lean body mass and this may contribute to higher bone density and that black women have the smallest waist-hip ratio and a greater abdominal skinfold compared to white women (16). However, in terms of predicting risk of metabolic syndrome, studies have shown WC to predict high density lipoproteins and WHR to predict triglycerides $(39,40)$. BMI on the other hand is said to misclassify persons who carry more weight as fat-free mass while \% fat can mislead in cases of diseases that cause wasting of lean tissue thus the need to use FFMI as proposed in a study by Hull et al. (30). The partitioning of BMI can show whether an increase or decrease in body weight can be determined in changes in either FFM or FM or changes in both.

The strength of our paper is the use of labeled water to measure body composition and the studies that have used the same technique to assess overweight among Kenyan women are very limited. The use of deuterium dilution is considered a gold standard to measure body composition, and has been validated in several studies. The limitation of this study is the small sample size. Due to this the results of this study cannot be generalized to other populations. Our recommendation for future studies is the need to have studies with a large number of participants to compare the different measures of overweight to be able to come up with more representative data which may offer better opportunities for interpretation of data.

In conclusion, different measures of overweight present a different prevalence of adiposity among women and therefore, not knowing the magnitude of the problem, 
proper action in terms of intervention cannot be taken. It is our recommendation that for future research on overweight among women in Africa one should aim at identifying suitable cut-off points to ensure proper screening and identification of at risk populations to overweight. This will enable proper interventions to be put in place to curb the occurrence of diseases related to overweight. This is important in cases where proper cut-off points are not provided. Regardless of the limitations, BMI and WC are still the cheap and acceptable methods to be used when a measure of FM is not possible. However, proper cut-off points for WC and FMI need to be identified to offer reliable and cheap measures in screening for overweight among women in Africa through further research in order to make more valid and reliable diagnoses of adiposity. 


\section{References}

1. Adeboye B, Bermano G, Rolland C. Obesity and its health impact in Africa: a systematic review. Cardiovascular Journal of Africa. 2012 october 23(9):515-21.

2. Must A, Spadano J, Coakley EH, Field AE, Colditz G, Dietz WH. The disease burden associated with overweight and obesity. Journal of America Medical Association. 1999;282(1523).

3. Asfaw A. The effects of obesity on doctor-diagnosed chronic diseases in Africa: empirical results from Senegal and South Africa. Journal of Public Health Policy. 2006;27:250-64.

4. Capuccio FP, Kerry SM, Adeyemo A, Luke A, Amoah AGB, Bovet P. Body size and blood pressure: an analysis of Africans and the African diaspora Epidemiology 2008;19(38).

5. Hawkes C, Eckhardt C, Ruel M, Minot N. Diet quality, poverty and food policy: A new research agenda for obesity prevention in developing countries SCN News: A prediodic Review of Developments in International Nutrition. 2005;29(Late 2004-Early 2005).

6. Kruger HS, Puone T, Senekal M, Van der Merwe MT. Obesity in South Africa: Challenges for government and health professionals Public Health Nutrition. 2005;8:201-11.

7. Van der Merwe MT, Pepper MS. National Prevalence of obesity in South Africa Obesity Reviews 2006; 7:315-22.

8. Burniat W, Cole TJ, Lissau I, Poskitt E. Child and Adolescent Obesity Cambridge Cambridge University Press; 2002.

9. Lohman TG, Roche AF, Martorell R. Anthropometric Standardization Reference Manual 1988 8th August 2013. Available from: http://books.google.co.ke/books/about/Anthropometric_Standardization_Reference.html?id=jjGAAAAAMAAJ\&redir_esc=y.

10. Lu Y, Shu H, Zheng Y, Li C, Liu M, Chen M, et al. Comparison of fat-free mass index and fat mass index in Chinese adults. European Journal of Clinical Nutrition 2012;66:1004-7.

11. Snijder MB, van Dam RM, Visser M, Seidell JC. What aspects of body fat are particularly hazardous and how do we measure them? International Journal of Epidemiology 2006;35:83-92.

12. Stein CJ, Colditz GA. The epidemic of obesity Journal of Clinical Endocrinology and Metabolism [Internet]. 2004 4th May 2013. Available from: http://www.ncbi.nlm.nih.gov/pubmed/15181019.

13. Cole TJ, Bellizzi MC, Flega KM, Dietz WH. Establishing a standard definition for child overweight and obesity worldwide: international survey. British Medical Journal 2000;320:1240-3.

14. Deurenberg P. Universal cut-off BMI points for obesity are not appropriate. British Journal of Nutrition. 2001;85:135-6.

15. WHO. Waist circumference and waist-Hip ratio. Report of a WHO Expert consultation [Internet]. 2008 8-11 December 2008.

16. Wagner DR, Heyward VH. Measures of body composition in blacks and whites: a comparative review American Journal of Clinical Nutrition 2000;71:1392-402.

17. Deurenberg-Yap M, Schmidt G, van Staveren WA, Deurenberg P. The paradox of low body mass index adn high body fat percentage among chinese, malays and indians in Singapore. International Journal of Obesity Related Metabolic Disorders. 2000;26:1011-7.

18. Deurenberg $P$, Yap M, van Staveren WA. Body mass index and percent body fat: a meta-analysis among different ethnic groups International Journal of Obesity Related Metabolic Disorders. 1998;22:1164-71.

19. Goonasegaran AR, Mat Nawi FN, Abdul Wahab NS. Comparison of the effectiveness of body mass index and body fat percentage in defining body composition. Singapore Medical Journal 2012;53(6):403-8.

20. Romero-Corral A, Somers VK, Sierra-Johnson J, Thomas RJ, Bailey KR, Collazo-Clavell ML, et al. Accuracy of body mass index to diagnose obesity in the general population International Journal of obesity (London). 2008;32:959-66.

21. Vanltallie TB, Yang M, Heymsfield SB, Funk RC, Boileau RA. Height-normalized indices of the body's fatfree mass and fat mass: potentially useful indicators of nutritional status American Journal of Clinical Nutrition. 1990;52:953-9.

22. Crowther NJ, Norris SA. The current waist circumference cut point used for the diagnosis of metabolic syndrome in sub-Saharan African women is not appropriate. Plos One. 2012;7(11).

23. Neovius M, Linne $Y$, Rossner S. BMI, waist-circumference and waist-hip-ratio as diagnostic tests for fatness in adolescents. International Journal of Obesity. 2005;29:163-9. 
24. Zillikens MC, Conways JM. Anthropometry in blacks: applicability of generalized skinfold equations and differences in fat patterning between blacks and whites. American Journal of Clinical Nutrition. 1990;52:45-51.

25. Norgan NG. Population differences in body composition in relation to the body mass index European Journal of Clinical Nutrition. 1994;48(Supp 3):S10-25.

26. Westerterp KR, Wouters L, van Marken-Lichtenbelt WD. The Maastricht protocol for the measurement of body composition adn energy expenditure with labelled water. Obesity Research 1995;3:49-57.

27. Flegal KM, Shepherd JA, Looker AC, Graubard BI, Borrud LG, Ogden CL, et al. Comparisons of percentage body fat, body mass index, waist circumference, and waist-stature ratio in adults. American Journal of Clinical Nutrition. 2009;89(2):500-8.

28. Kyle UG, Schutz Y, Dupertuis YM, Pichard C. Body composition interpretation: Contributes of the fatfree mass index and the body fat mass index. Nutrition. 2003;19:597-604.

29. WHO. Waist circumference and waist-hip ratio Report of a WHO Expert Consultation [Internet]. 2008. Available from: http://www.who.int/nutrition/publications/obesity/WHO_report_waistcircumference_and_waisthip_ratio/en/.

30. Hull HR, Thornton J, Wang J, Pierson RN Jr, Kaleem Z, Pi-Sunyer X, et al. Fat-free mass index: changes and race/ethnic differences in adulthood International Journal of Obesity (London). 2011;35(1):121-7.

31. Dioum A, Gartner A, Marie B, Delpeuch F, Wade S. Body composition predicted from skinfolds in African women: a cross-validation study using air-displacement plethysmography and a black-specific equation. British Journal of Nutrition 2005;93(6):973-9.

32. International Diabetes Federation. The IDF consensus worldwide definition of the metabolic syndrome 2006 20th June 2013. Available from: http://www.idf.org/webdata/docs/IDF_Meta_def_final.pdf.

33. Schutz Y, Kyle UG, Pichard C. Fat-free mass index and fat mass index percentiles in Caucassians aged 18-98 y. International Journal of Obesity 2002;26:953-60.

34. Kim SA, Yount KM, Ramakrishnan U, Martorell R. The relationship between parity and overweight varies with household wealth \& national development International Journal of Epidemiology. 2006 December 2006;36:93-101.

35. Gunderson EP, Abrams SB. Epidemiology of gestational weight gain and body changes after pregnancy Epidemiology Review. 1998;21:261-75.

36. Rooney BL, Schauberger CW. Excess weight gain and long-term obesity: one decade later Journal of Obstretric and Gynaecology 2002;100:245-52.

37. Mbochi RW, Kuria E, Kimiywe J, Ochola S, Steyn NP. Predictors of overweight and obesity in adult women in Nairobi Province, Kenya. BMC Public Health 2012;12(823).

38. Christensen DL, Eis J, Hansen AW, Larsson MW, Mwaniki DL, Kilonzo B, et al. Obesity and Regional fat distribution in Kenyan population: Impact of ethnicity and urbanization. Annals of Human Biology 2008;35(2):232-49.

39. Rheeder P, Stolk RP, Veenhouwer JF, Grobbee DE. The metabolic syndrome in black hypertensive women- waist circumference more strongly related than body mass index. South African Medical Journal 2002;92:637-41.

40. Janssen I, Katzmarzyk PT, Ross R. Waist circumference and not body mass index explains obesityrelated health risk American Journal of Clincal Nutrition 2004;79:379-84. 
CHAPTER 8

General Discussion 
The motivation to carry out this study is based on the ever increasing cases of food insecurity within our country Kenya. Personally, I have experienced hunger due to drought when I was growing up. It was the first time for us to eat yellow maize, a donation from western countries. I have seen children go move from house to house begging for food or looking to offer some form of labour in exchange for food. Hunger seasons are the worst times when food deficits are experienced by not only the poor. It is the period after planting and before harvest season when the crops are not mature enough to harvest. In this context of hunger and deficit, there is also the other side of the coin. With improved access to food and inactivity, overweight is also going up. Personally, I have witnessed a growing number of overweight not only among the adults, but also among children. Growing up we had no television, no computers and cars were few. We walked everywhere. We played outside the whole day when we were not in school. And when in school, we had the opportunity to play outside during break, physical education (PE) lesson and during games time after school. We walked to school. Nowadays, children sit in front of the television, when not in school. And when in school, they have a tight curriculum that does not allow much time for play. People use cars to go everywhere. Children, within the urban centers get a car ride to and from school. Or if they walk, it is for a short distance. Physical education is no longer important in school. Adults have access to fast foods in the urban centers. In the rural areas, the farms are now small and there is very little farm work. Heavy mechanization is employed in bigger farms. My grandmother boiled most of her food and she used locally processed ghee sometimes. Overweight therefore is now a challenge to our country together with food insecurity.

In the onset of the study, we had intended to carry out 3 phases of the project; a prevalence study, a longitudinal study and finally an intervention study. The prevalence study was to determine the levels of malnutrition among women and children in Narok County. The longitudinal study was to follow up pregnant women in their first and second trimester until delivery to be able to assess their physical activity and food security and how this impacted on the birth weight and delivery method of the child. During the intervention study, which was to start after delivery we intended to followed up the women, while we offered nutrition education on infant feeding and care and follow them up for 2 years. Then, after 2 years we intended to determine the impact of nutrition education and care on the nutritional status of the child. However due to circumstances beyond us, we only managed to accomplish phase $\mathrm{i}$ and ii and we modified phase iii. The study was financed by The Netherlands Organization for International Cooperation in Higher Education (NUFFIC) and supervised by promoters from Maastricht University. The study aimed at influencing policy in that by pointing out the increasing overweight among the food insecure, proper interventions for example surveillance to monitor the numbers would be set up. 
The objectives of our study were i) to determine the prevalence and risk factors of malnutrition (overweight, stunting, wasting and underweight) among children ii) to assess food security and its effects on maternal and child malnutrition iii) to assess physical activity, water turnover and body composition and their impact on maternal nutrition iv) to assess physical activity among pregnant women and food insecurity and their impact on pregnancy outcomes and lastly v) to assess overweight among women using different measures of adiposity. We focused on the persisting food insecurity and consequent under nutrition as well as the emerging trend of overweight among women and children in Kenya and the role of physical activity and body composition among women. In this thesis, chapter 2, 3 and 4 are discussed together since they address objectives i) and ii) and lastly we discuss chapters 5 and 6 together as they address objectives iii) and iv). Chapter 7 is on the methodology of assessing overweight and is discussed at the end.

As we discuss the results in this study, care must be taken in making generalizations; first and foremost, our studies on physical activity, body composition and measures of adiposity are limited in terms of sample size. The sampling size was determined by the limited deuterium samples and the number of accelerometers. There in our recommendation, we propose that in the future a similar study be conducted among a representative sample size in order to generalize conclusions.

Our study was guided by two conceptual frameworks: i) the United Nations Children's Education Fund (UNICEF) conceptual framework on causes of malnutrition among children and women and ii) Scott's conceptual framework on etiology of overweight and obesity in Africa. Both frameworks are explained in detail in Chapter 1 . The UNICEF conceptual framework is quite detailed in illustrating the causes of both undernutrition and over-nutrition; however we brought in the Scott's framework because of physical inactivity which is included in this framework as one of three proximate factors that cause overweight and obesity as it was one of the objectives of our research. However, in as much as several studies have found a relationship between household food insecurity and overweight, our study did not find an association among children below five years of age. The studies that found an association between food insecurity and overweight were mainly in the developed countries and we noted that the foods consumed by the lower and middle income household were high in saturated fats and sugars and notably their diets were not diverse and these factors and physical inactivity may have contributed to overweight. Dietary diversity needs to be incorporated in the conceptual framework as it is important in ensuring an adequate diet in terms of nutrient content. However, the issue of eating the right amounts also comes into play whereby an individual may over-consume certain food items and thus may contribute to overweight. 
In addition to the conceptual frameworks on causes of malnutrition and etiology of overweight and obesity, although in our study we did not look at it, it is important to mention the importance of health promotion theories of reasoned action/ planned behavior, health belief model and self-efficacy theory in predicting health behaviors (1). The social cognitive theories argue that a positive attitude towards physical activity, balanced diet as well as intentions to pursue health promoting behavior are confounding factors in determining an individual's overall health. Therefore one has to make a decision to eat healthy and to exercise in order to avoid being overweight or obese. In addition, when women choose to eat healthy and exercise they minimize obstetric risk such as having a low birth weight child or undergoing a caesarian section during birth.

The main findings in chapter 2, 3 and 4 are that Kenya like other countries in the developing world is experiencing a nutrition transition leading to increased numbers of overweight. There has been a gap in studies done in Kenya on overweight since most studies concentrated on issues related to under nutrition, which has been and still is a problem in most sub-Saharan countries. With the improving economies and many people moving into the urban areas, economic and nutrition transitions were inevitable. The nutrition transition is defined as the changes in dietary patterns and nutrient intake when a population adopts a modern lifestyle during economic and social development, urbanization and acculturation (2). These changes in dietary patterns include consumption of foods that have refined carbohydrates, are low in fiber, have high a fat content (3) and together with an increased sedentary lifestyle and reduced physical activity, have contributed to pushing the numbers of people with overweight and obesity up in the developing countries. The prevalence of overweight and obesity combined among women in our study was $35.6 \%$, which is comparable to results found in a study by Ziraba who found overweight in Kenya to be $38 \%$ (4). The World Health Organization (WHO), indicated that in all its regions, women were more overweight compared to men (5), a fact that is also noted in a study by Mandez et al (6). In our study, the overweight prevalence of children under 5 years in Kenya was 6.9\%, and the World Bank had estimated the prevalence in 2010 to be $5 \%$. Although other studies found the prevalence of overweight to be higher among children in Kenya compared to our study $(7,8)$. The geographical locations of these studies could be the main reason for these differences, in that different parts of the country have varied climatological conditions and also vary in socio-economic status, a factor that was brought out in a study by Pawloski et al (9) and Kandala et al (10). Narok County is one of the richest counties in the republic of Kenya; however, poverty is still high among the local communities. According the county report more than $12 \%$ of the population live below the poverty line (11). 
Although the prevalence of overweight is on the increase among both women and children, stunting, underweight and wasting were reducing among children until 2009 according to a study by Masibo (12) after which there was again a slight increase in the prevalence of wasting in 2010 (13). Levels of under nutrition were lower in our study compared to other studies in Kenya $(8,12)$ which may be attributed to the geographical locations as cited earlier. Different tribes tend to occupy distinct geographical areas, and therefore with varied sociocultural factors among the tribes may influence their nutritional status due to dietary factors (9). The Maasai are the majority tribe in Narok County, and they are known pastoralists who travel long distance in search of pasture and water (14). The Maasai's diet consists of curdled milk, blood, meat and sometimes herbs and recently they have added maize meal porridge to their diet (15) and are settled mainly in the rural areas (16). The rural areas report lower overweight compared to the urban areas $(4,6,17)$. Underweight among women in our study group was comparable to that of women in other parts of Kenya (18), although our sample consisted of largely women from the urban setting, our findings are comparable with those of other developing countries (6).

The determinants of under nutrition and overweight in Kenya have been highlighted at length in the studies by Gewa (8) and Masibo (12) and their findings indicate that among children in Kenya overweight $(18 \%)$ is co-existing together with stunting (30\%) and underweight (16\%). According to the study by Gewa (8), being an older child and living in a larger size of household were associated with lower odds of being overweight. However, our review study in Chapter 2 indicates that the major predictors of stunting and overweight in 18 studies across sub-Saharan African include a combination of demographic, socio-economic and environmental factors. Lifestyle and nutritional factors, although important, were not found to be significant in the reviewed studies. However, other studies have found that dietary patterns and nutrient intake played a role in both under nutrition (19) and over nutrition (20). Early introduction of solid foods may increase the risk of overweight among young children (21), while breastfeeding exclusively for six months may be protective against overweight (22-24). While among teenagers, a study by Friedman et al (25) indicated that teenagers who are stunted and continue to remain in the same environment continue to deviate from the National Centre for Health Statistics (NCHS) standards, accruing greater height deficits with age and no catch-up growth is experienced. In addition, teenagers in urban and rural areas vary in lifestyles in that rural children tend to eat their meals at home compared to their urban counterparts who have more access to money and tend to eat meals away from home particularly in social places like movie theatres and shopping arcades (26). With access to fast foods and snacks, overweight among teenagers in the urban areas is higher compared to that of their rural counterparts. Life- 
style factors like low physical activity also push the numbers of overweight and obesity among teenagers $(27,28)$.

In chapter 4 we address the issues of food insecurity. Food insecurity, hunger and under-nutrition have been the challenges in sub-Saharan Africa in the $21^{\text {st }}$ Century, however, despite the persisting stunting and underweight particularly among children under five years of age, overweight is an emerging pandemic. In our study, overweight was a major nutritional problem among women in the study area although food insecurity was also a problem confirming the paradox of over-nutrition occurring where food insecurity exists. This coexistence of overweight among food insecure has been confirmed in other studies in developed countries but not in the developing countries (29-32). In our study the food secure household had higher odds of being overweight and not underweight. Which is expected because the more food secures the household is, the easier it is for individuals to access food of high quality and a large quantity which may contribute to overweight. For adolescent children, studies have found no associations between overweight and food insecurity (33). Other predictors of overweight included being in an urban settlement, high standard of living (SOL), increasing parity and age. In our study, we also found dietary diversity to reduce with increasing household food insecurity. As food security improves within a home, access to quality and quantity food can be achieved, however, when one is not educated on how to make the right choices, then overweight and stunting as well as underweight can be found within food secure homes. However, in a situation whereby food insecurity persists, a household may not be able to access a wider variety of foods to meet their nutrient requirements.

If not reversed, the increasing rates of overweight among children will have enormous implications not only for future health care expenditures but also for the overall development of the nation $(34,35)$. There is urgency in reversing the trends of increasing overweight and obesity in developing countries which are still battling with effects of under-nutrition, food insecurity and hunger. This is because both extreme forms of malnutrition have far reaching consequences on health, economic resources and can cause disability or death in the long run.

In chapter 5, we sought to find out the relationship between water turnover, physical activity and body composition. Our main findings were that water loss was significantly related to physical activity and body composition, and that BMI was the strongest predictor of water loss. Water is an essential nutrient (36) and it is the largest constituent of the human body $(37,38)$. In this chapter we sought to find out how women cope with the day to day physical activities in search for food and water in terms of regulating body water. Meeting water requirements among women in Africa is essential for proper normal functioning of the body in order for them to accomplish cultural responsibilities of caring for household members. However, due to hot tem- 
perate climatic conditions, varied metabolism, food security status and other factors, water requirements within this community may not have been adequately met. Comparing physical activity, our study found Kenyan women to be more active compared to a Dutch study group and water loss was similar among the Dutch and Africans in another study (39). In another study on obese and lean women, overweight women were less active and tended to sweat more profusely $(40,41)$. What is important to note in this study is the role of acclimatization in regulating water loss, since we found water loss to be similar among our subjects and those from other regions.

The implication of this study is that physical activity and body composition play a role in water turnover. However, other studies have shown that acclimatization and body's thermoregulation processes also play a role in enabling one to utilize the available water in the body. The Kenyan food policy does not have information on required water recommendations for consumption particularly in the different climatic conditions. Therefore, this is important to policy makers who need to offer recommendations on daily water requirements for the arid and semi-arid regions. Therefore giving water the attention it deserves as an essential nutrient. In addition, adverse climatic conditions and increased physical activity affects the performance of women as key food providers within a home. In addition to adequate food access and sufficient health services and healthy environment, women time to adequately care for their children. As a result of the semi-arid conditions, women have to travel long distance to fetch for food and water. Therefore, women need to be provided with conducive environments within the homes and health services need to be easily accessible and sufficient to avoid the long distance they travel.

In chapter 6, our main findings were that there was no relationship between physical activity, food security and pregnancy outcomes. However, using height and weight and correcting for gestational age we found a significant relationship with birth weight. Height of the mother was a strong predictor of birth weight of the child, which brings about the importance of pre-pregnancy nutrition of the mother. In our study we found pregnant women to have low physical activity although women in low-income countries are generally known to have high physical activity which is sustained through pregnancy (42-45). And the reason for the low physical activity among pregnant women is because of the assumed potential risk to the unborn baby, thus pregnant women may take up less work within the home. However several studies have disputed this claim and physical activity should be encouraged among pregnant women. Physical activity is important in regulating gestational weight gain $(46,47)$. Excess weight gain during pregnancy may lead to hypertension, gestational diabetes as well as delivery complications (48). Dietary diversity among pregnant women differed slightly between $2^{\text {nd }}(6.1)$ and $3^{\text {rd }}(6.5)$ trimester groups. However, when we compared rural and urban groups there was no difference in dietary diversity. Pregnant women are regarded as a 
special needs group of people by many communities in Kenya and therefore they are provided with special diets in some cases, although in food insecure communities this may not be the case. After delivery it is common to find among the Maasai communities a goat being slaughtered for the new mother. Thus, there is need for nutritional interventions particularly among young girls to eradicate all forms of malnutrition to prevent complications during their adulthood more so as it affects pregnancy outcomes. Physical activity ought to be promoted among pregnant women as it prevents excessive weight gain and it also improves cardiovascular functions.

In chapter 7, we looked at measures of adiposity and we found out that there are various measures that have been used over time to assess overweight and at present there is a lack of data on the best measures to use for the black African population. We used the gold standard measure of using deuterium dilution to determine body fat mass (\%FM) which we used to compare with the other measures including BMI, waist circumference (WC), waist hip ration (WHR) and fat mass index (FMI). It is interesting to note that all these measures yielded different results. WHR and FMI yielded the same $(28.6 \%)$ percentage when used as a measure of adiposity whereas with WC the percentage was the highest (46.4\%). In this study we did not find clear cut-off points for black Africans in the assessment of overweight. BMI has been widely used to assess overweight in populations, however it is not the most accurate methods to use because it can be influenced by age, gender, and ethnicity (49). This study indicates that the deficits of $\mathrm{BMI}$ are in that it can estimate the relative risk of the disease in most people but it is not an accurate predictor of body fat or fat distribution particularly in muscular individuals, because of difference in body-fat proportions and distribution. WC is similar with BMI in that it is influenced by age and ethnicity in both men and women $(50,51)$, however they differ in that WC is independent of height (52). Some studies indicate that WHR is an accurate measure of adiposity (53).

With the different outcomes with the different measures of adiposity, it is difficult to get a clear picture of the magnitude of the problem of overweight and obesity. And considering the consequences of the problem for example chronic ailments (coronary heart diseases, hypertension and diabetes) overweight and obesity must be given a priority in research to come up with proper cut-off points. Otherwise, the recommendation for the black African population is to combine measures, since there is no one measure which is accurate and no cut-off points to guide health practitioners. Thus the implication of this study to policy makers is that there is need for more research to be conducted among black people in order to reach an agreement on suitable cut-off points. 


\section{Limitations and strengths}

The strength of our research is that we were able to analyze the nutritional status of children and determine overweight cases as well as under-nutrition together with food insecurity which has not been reported in many studies in Kenya. The limitation of the study is that the household food insecurity access was assessed based on how the participant answered the questions. Hunger and anxiety of not having sufficient food is perceived differently by different people. Some people consider hunger as not being able to access staple food although other foods may be available. According to the FAO, food security has three dimensions, access, availability, and stability and utilization (54). In our study, we assessed food access using the HFIAS food access tool and utilization was measured using anthropometric measurement, while dimensions of stability and availability were not covered. It is a suggestion for future research that all the dimensions of food security be studied in this area to provide an opportunity for a more holistic analysis. Our study relied on recall to assess dietary diversity and relying on recall can lead to misreporting on the actual events that took place. The participants may not have recalled actual intake due to poor memory or by false reporting.

\section{Recommendations}

Future research is needed to look at food security's dimensions of stability and availability as well as psychosocial factors surrounding food intake, and how these factors impact on overweight and stunting among children. Further, more studies on dietary intake of the children may highlight the importance of feeding patterns on nutritional status, particularly feeding schedules and weighing the child's food in a situation

where the child is not breastfeeding and also the technique of force feeding needs to be studied further to understand its underlying nutritional effects on children. In addition, an intervention is recommended to curb the raising prevalence of overweight among children since most public health institutions in Africa are tailored to handle mainly cases of stunting, wasting and underweight but not overweight. The policies that are in place to screen and manage under-nutrition must be reviewed to include screening and management of overweight among children. In other word, there is so much information available to healthcare providers on how to manage under nutrition cases such as marasmus, kwashiorkor among others, and less or no information is available on overweight and obesity. Therefore there is need for nutrition information packages need to be developed on screening and management of overweight.

On importance of physical activity, although we did not find a significant association between physical activity and birth outcomes in our study, we found caesarian 
sections and time spent on sedentary activities to be high; there is need for a policy to guide on recommendations for pregnant women in terms of quantity and quality of information, since it is not clear how much physical activity is ideal for the different stages of pregnancy.

On methodology, there is need for further research to come up with clear cut-off points for assessing adiposity among women in Africa to enable proper screening of overweight cases for early intervention.

\section{Conclusion}

Our study concludes that food insecurity is still rampant in Kenya in spite of the progress made in economic developments, food production and infrastructure. As a result of food insecurity, under-nutrition has continued to persist especially among children under five years old. In addition, overweight is emerging as a threat to progress made in the area of food access resulting in a double burden of malnutrition. Overweight combined with under-nutrition poses a challenge both to researchers and policy makers as they exist within the same community, among individuals and in the same households. Women and children are the most affected by the double burden of malnutrition. The consequences of the double burden of malnutrition are far-reaching and the end result may be disability or death. Interventions need to be put in place urgently to curb the rising overweight and the persisting under-nutrition. 


\section{References}

1. Culos SN, Gyurcsik NC, Brawley LR. Using theories of motivated behavior to understand physical activity: Perspectives on their influence. Singer RN, HA H, Janelle CM, editors. New York Wiley 2001.

2. Popkin BM. An overview on the nutrition transition and its health implications: the Bellagio meeting. Public Health Nutrition 2002;5(1A):93-103.

3. Popkin BM. The nutrition transition and its health implications in lower-income countries. Public Health Nutrition. 1997;1(1):5-21.

4. Ziraba AK, Fotso JC, Ochako R. Overweight and obesity in urban Africa: A problem of the rich or the poor? BMC Public Health 2009;9(465).

5. WHO. Obesity Global Health Observatory [Internet]. Available from: http://www.who.int/gho/ncd/risk_factors/obesity_text/en/.

6. Mendez MA, Monteiro CA, Popkin BM. Overweight exceeds underweight among women in most developing countries American Journal of Clinical Nutrition. 2005;81:714-21.

7. Kamau JW, Wanderi MP, Njororai WWS, EK W. Prevalence of overweight and obesity among primary school children in Nairobi Province, Kenya African Journal for Physical, Health Education, Recreation and Dance. 2011;17(2).

8. Gewa C. Childhood overweight and obesity among Kenyan pre-school children: association with maternal and early child nutritional factors Public Health Nutrition. 2009;13(4):496-503.

9. Pawloski LR, Curtin KM, Gewa C, Attaway D. Maternal-child overweight/obesity and undernutrition in Kenya: a geographical analysis. Public Health Nutrition. 2011;15(11):2140-7.

10. Kandala NB, Madungu TP, Emina JBO, Nzita KPD, Cappuccio FP. Malnutrition among children under the age of five in the Democratic Republic of Congo (DRC): does geographic location matters? BMC Public Health. 2011;11(261).

11. Kenya Mpya. Narok County 2012 April 2014. Available from: http://www.kenyampya.com/index.php?county=Narok.

12. Masibo PK, Makoka D. Trends and determinants of undernutrition among young Kenyan children: Kenya Demographic and Health Survey; 1993, 1998, 2003 and 2008-2009. Public Health Nutrition. 2012;15(9):1715-27.

13. UNICEF. Statistics-Basic Indicators Available from: http://www.unicef.org/infobycountry/kenya_statistics.html\#100.

14. FAO. The utilization of indegenous knowledge in range management and forage plants April 2014. Available from: http://www.fao.org/docrep/009/a0182e/A0182E06.htm.

15. Luxwolda MF, Kuiperst RS, Kema IP, Dijck-Brouwer DAJ, Muskiet FAJ. Traditionally living populations in East Africa have a mean serum 25-hydroxyvitamin D concentration of $115 \mathrm{nmol} / \mathrm{l}$. British Journal of Nutrition. 2012;108(9):1557-61.

16. Christensen DL, Eis J, Hansen AW, Larsson MW, Mwaniki DL, Kilonzo B, et al. Obesity and regional fat distribution in Kenyan populations: Impact of ethnicity and urbanization. Annals of Human Biology 2008;35(2):232-49.

17. Mbochi RW, Kuria E, Kimiywe J, Ochola S, Steyn NP. Predictors of overweight and obesity in adult women in Nairobi Province, Kenya. BMC Public Health. 2012;12.

18. Jayne J, Scrimgeour AG, Polhemus ME, Otieno L, Bovil ME. Dietary and socio-economic correlates of nutritional status in a rural adult Kenyan population African Journal of Food, Agriculture, Nutrition and Development 2011;11(4).

19. Bloss E, Wainaina F, Bailey RC. Prevalence and predictors of underweight, stunting and wasting among children aged 5 and under in Western Kenya Journal of Tropical Pediatrics 2004;50(5):260-70. Epub October 2004.

20. Swinburn BA, Caterson I, Seidell JC, James WPT. Diet, nutrition and the prevention of excess weight gain and obesity Public Health Nutrition. 2004;7(1A):123-46.

21. Pearce J, Taylor MA, Langley-Evans SC. Timing of the introduction of complementary feeding and risk of childhood obesity: a systematic review. International Journal of Obesity 2013;37:1295-306.

22. von Kries R, Koletzko B, Sauerwald T, von Mutius E, Barnert D, Grunert V, et al. Breastfeeding and obesity: cross sectional study BMJ. 1999;319:147-50.

23. Simon VGN, de Souza JMP, de Souza SB. Breastfeeding, complementary feeding, overweight and obesity in pre-school children Revista de Saúde Pública. 2009;43(1). 
24. Dewey KG. Is breastfeeding protective against child obesity? Journal of Human Lactation. 2003;19(1):9-18. Epub February 2003.

25. Friedman JF, Philips-Howard PA, Mirel LB, Terlouw DJ, Okello N, Vuvule JM, et al. Progression of stunting and its predictors among school-aged children in western Kenya. European Journal of Clinical Nutrition 2005;59:914-22. Epub 1st June 2005.

26. Ginsbert PE. Globalization: Adolescent experience in Kenya Global Studies Review [Internet]. 17th December 2013. Available from: http://www.globality-gmu.net/archives/962.

27. Stankov I, Olds T, Cargo M. Overweight and obese adolescents: what turns them off physical activity International Journal of Behaviourial Nutritrion and Physical Activity 2012;9.

28. Maples JM, Fitshugh EC, Costello CA, Moustaid-Moussa N, Bassset DR, Spence ML, et al. Physical activity, screen time, and prevalence of overweight/obesity among adolescents in a Creative, problem-solving Program Food and Nutrition Sciences 2012;3(4):568-78.

29. Dinour LM, Bergen D, Yeh MC. The food insecurity-obesity paradox: A review of the literature and the role food stamps may play. Journal of the American Dietetic Association. 2007;107(11):1952-61.

30. Bhattacharya J, Currie J, Haider S. Poverty, food insecurity, and nutritional outcomes in children and adults. Journal of Health Economics. 2004;23:839-62.

31. Rutten LF, Yaroch AL, Patrick H, Story M. Obesity prevention and National food security: A food system approach. ISRN Public Health 2012;2012.

32. Townsend MS, Peerson J, Love B, Achterberg C, Murphy SP. Food insecurity is positively related to overweight in women Journal of Nutrition. 2001;131:1738-45.

33. Gundersen C, Lohman BJ, Eisenmann JC, Garasky S, SD S. Child-specific food insecurity and overweight are not associated in a sample of 10 - to 15- year old low-income youth Journal of Nutrition 2008;138(2):371-8.

34. Sherry B, Zuguo M, Scanlon KS, Mokdad AH, Grummer-Strawn LM. Trends in state-specific prevalence of overweight and underweight in 2-through 4- year old children from low-income families from 1989 through 2000. Achieves of Pediatric \& Adolescent Medicine 2004;158(12):1116-24.

35. Lee JM, Subrahmanyam P, Gebremariam A, Keirns CC, Davis MM, Sandeep V, et al. Getting heavier, younger: Trajectories of obesity over the life course International Journal of obesity (London). 2010;34(4):614-23.

36. Kleiner SM. Water: an essential but overlooked nutrient. . Journal of the Academy of Nutrition and Dietetics Associaion 1999;99(2):200-6.

37. O'Connell BN, Weinheimer EM, Martin BR, Weaver CM, WC C. Water turnover assessment in overweight adolescents Obesity. 2012;19(2):292-7.

38. Institute of Medicine Dietary Reference Intake for Water, Potassium, Sodium, Chloride and Sulfate 2004 18th May 2013. Available from: http://books.nap.edu/openbook.php?record_id=10925.

39. Westerterp KR, Plasqui G, Goris AHC. Water loss as a function of energy intake, physical activity and season. British Journal of Nutrition. 2005;93:199-203.

40. Bar-Or O, Lundergren HM, Buskirk ER. Heat tolerance in exercising and obese women. Journal of Applied Physiology 1969;26(4):403-9.

41. Hanna JM, Brown DE. Human heat tolerance: An anthropological perspective Annual Reviews $1983 ; 12: 259-84$.

42. Benefice E, Cames C. Physical activity patterns of rural Senegalese adolescent girls during the dry and rainy seasons measured by movement registration and direct observation methods. . European Journal of Clinical Nutrition. 1999 August;53(8):636-43.

43. Lawrence M, Whitehead RG. Physical activity and total energy expenditure of child-bearing Gambian village women. . European Journal of Clinical Nutrition. 1988;42(2):145-60.

44. Spurr GB, Dafour DL, Reina JC. Energy expenditure of urban Colombian women: a comparison of patterns and total daily expenditure by the heart rate and factorial methods. . American Journal of Clinical Nutrition. 1996;63(6):870-8.

45. Hjorth MF, Kloster S, Girma T, Faurholt-Jepsen D, Andersen G, Kaestel P, et al. Level and intensity of objectively assessed physical activity among pregnant women from urban Ethiopia. BMC Pregnancy and Childbirth 2012;12:154.

46. Morgan KL, Rahman MA, Hill RA, Zhou SM, Bijlsma G. Physical activity and excess weight in pregnancy have independent and unique effects on delivery and perinatal outcomes. Plos One 2014 April 10.

47. Haakstad LA, Voldner N, Henriksen T, K B. Physical activity level and weight gain in a cohort of pregnant Norwegian women. Acta Obstetricia et Gynecologica Scandinavica. 2007;86(5):559-64. 
48. Rasmussen KM, Yaktine AL. Consequences of gestational weight gain for the mother. Washington DC: National Academies Press (US); 2009.

49. Frankenfield DC, Rowe WA, Coonery RN, JS S, Becker D. Limits of body mass index to detect obesity and predict body composition Nutrition 2001;17(1):26-30.

50. Lemieux S, Prud'homme D, Bouchard C, Tremblay A, Despres' J. A single threshold value of waist girth identifies normal-weight and overweight subjects with excess viceral adipose tissue. American Journal of Clinical Nutrition. 1996;64(5):685-93.

51. Molarius A, Seidell JC, Visscher TL, Hofman A. Misclassification of high-risk older subjects using waist action levels established for young and middle-aged adults- results from the Rotterdam Study Journal of American Geriatric Society. 2000;48(12):1638-45. Epub Dec 2000.

52. Han TS, Seidell JC, Currall JE, Morrison CE, Deurenbert P, Lean ME. The influence of height and age on waist circumference as an index of adiposity in adults. International Journal of Obesity and Related Metabolic Disorders 1997;21(1):83-9. Epub Jan

53. Barreto Silva MI, Lemos CC, Torres MR, R B. Waist-to-hip ratio: An accurate anthropometric index of abdominal adiposity and a predictor of high HOMA-IR values in nondialyzed chronic kidney disease patients 2013;S(13).

54. FAO. Food Security. Policy Brief 2006. 

Appendix 

Summary 
There is a growing concern over the increasing number of overweight people in developing countries particularly in Africa. The increase in the prevalence of overweight and obesity in developing countries is largely attributed to lifestyle changes that are consistent with countries in transition. With the changes in dietary patterns and reduced physical activity, there is an increase in numbers of overweight and obesity particularly among the poor and the urban and rural populations. Physical inactivity has been reported in many developing countries, particularly in Africa among the urban populations. The nutritional status is changing in many developing countries from persistent underweight, stunting and wasting to overweight and obesity among children and adults and now frequently a combination of under-nutrition and over-nutrition is observed resulting in a situation that is now commonly referred to as the 'double burden of malnutrition.' Under-nutrition, particularly stunting, has also been known to result in overweight later in life.

The aims of this thesis therefore were to determine the prevalence and risk factors of malnutrition (overweight, stunting, wasting and underweight) among children, to assess food insecurity and its effects on maternal and child malnutrition, to assess physical activity, water turnover and body composition and their impact on maternal nutrition and to assess physical activity and food insecurity among pregnant women and their impact on pregnancy outcomes.

During the literature review also a systematic review was carried out to assess determinants and prevalence as well as risk factors for overweight, stunting, wasting and underweight among young children in sub-Saharan Africa. We carried out a study to assess the prevalence of overweight as well as stunting, underweight and wasting among children and also to assess overweight and underweight among women in Narok County in Kenya, located in Rift Valley Province. In addition, we carried out a longitudinal study to determine body composition, physical activity and water turnover among women and also to determine the impact of physical activity and food security on pregnancy outcomes among pregnant women in their second and third trimesters in Narok County.

The main findings from our review study were that demographic, socio-economic and environmental factors are the major players in determining stunting, underweight and overweight among young children and adolescents. Although nutritional and lifestyle factors are important as mentioned in other studies, they were not significant in the studies sampled. Stunting is a risk factor in early childhood that may result in overweight later in adolescence and adulthood. Promoting exclusive breastfeeding is important in preventing both stunting and overweight among children.

In the prevalence study among our population of children under five in Kenya, mild, moderate and severe stunting were $12.3 \%, 4.8 \%$ and $2.6 \%$ respectively, $15.7 \%$, 
$6.0 \%$ and $2.2 \%$ for mild, moderate and severe underweight and $16.6 \%, 5.2 \%$ and $4.3 \%$ for mild, moderate and severe wasting. Overweight among children was $6.9 \%$. While among women, the prevalence of underweight was $5.6 \%$, overweight was $26.5 \%$ and obesity was $9.1 \%$. The food security status among households was varied: Of all households involved $70.1 \%$ were categorized as severely food insecure, $21.9 \%$ were moderately food insecure, $3.7 \%$ were mildly food insecure whereas $4.3 \%$ were food secure.

In our study on of body composition and physical activity on water loss among women we found the mean total body water (TBW) as $29.3 \pm 4.2$ liters and water turnover was found to be $3.2 \pm 0.8$ liters per day (L/day). Water loss was significantly related to BMI, Fat mass index (FMI) and physical activity. BMI was the strongest predictor of water loss. Water loss increase with increased physical activity and increased BMI. Meeting water requirements among women in Africa is essential for proper normal body functioning in order for them to accomplish cultural responsibilities of caring for household members. Acclimation may play a role in minimizing water loss among individuals in arid areas in order for the body to utilize water well since water loss was more or less similar to those of women in other climatic regions.

In our study on effects of physical activity and food security on pregnancy outcomes, we found food security and physical activity not to be significant predictors of birth outcomes; however, height of the mother was an important predictor of birth weight. Food insecurity was $45.1 \%$ among the pregnant women, however those in their $2^{\text {nd }}$ trimester reported severe food insecurity as high as $61.9 \%$ compared to the $3^{\text {rd }}$ trimester women whose severe food insecurity was $42.9 \%$. Vector magnitude counts indicated that physical activity reduced in the third trimesters and that all the pregnant women spent more time on sedentary activities as indicated by $51 \%$ in the $2^{\text {nd }}$ trimester and $56 \%$ in the $3^{\text {rd }}$ trimester.

The results from our prevalence study showed that in Kenya overweight is on the increase. The prevalence of overweight among children under five years of age according to our study was $6.9 \%$, and this is consistent with data reported by the World Bank which estimated the prevalence by 2010 to stand at 5\%. Among women in our study population who had a child below 5 years of age, overweight and obesity combined was $35 \%$. Other studies indicate that the prevalence of overweight in the different regions in Kenya varied as a result of varied socio-economic status and climatological conditions that affect the food availability and accessibility. Food insecurity was persistent among the study population confirming the paradox of over-nutrition occurring among the food insecure. Physical activity was low among women in our study confirming the reduced physical activity in countries in transition. The reduced physical activity and change in dietary patterns has contributed to the prevalence of overweight. Although there was no impact of physical activity and food insecurity on preg- 
nancy outcome, however, height of the mother was associated with birth weight. This reaffirms the importance of pre-pregnancy nutrition in determining outcomes such as birth weight and height of the infant. Nutritional status of the young women, more so girls is important in predicting future pregnancy outcomes. In terms of regulating water intake, among women living in arid and semi-arid lands, physical activity, body mass index (BMI) and body composition were predictors of water loss, however, BMI was the strongest predictor. Total body water (TBW) among the women in our study was comparable to that of women other studies done in Kenya. Meeting water requirement is crucial for women living in this region also more so because women are the key food providers within a home, thus if their water needs are not met then they can become dehydrated and therefore not able to provide for their families. Other than the body maintaining its water balance, it is important to note the role played by acclimatization by individuals that enables them to cope with the conditions of water shortage without increasing the intake.

In conclusion, food insecurity is still rampant in Kenya in spite of the progress made in economic developments, food production and infrastructure. As a result of food insecurity, under-nutrition has continued to persist especially among children under five years old. In addition, overweight is emerging as a threat to progress made in the area of food access resulting in a double burden of malnutrition. Overweight combined with under-nutrition poses a challenge both to researchers and policy makers as they exist within the same community, among individuals and in the same households. Women and children are the most affected by the double burden of malnutrition. The consequences of the double burden of malnutrition are far-reaching and the end result may be disability or death. Interventions need to be put in place urgently to curb the rising overweight and the persisting under-nutrition. 



\section{Valorization}


Increasing overweight among women and children has far reaching consequences in the developing countries. Together with persistent food insecurity and under nutrition, overweight pose a challenge to health workers and policy makers due to the fact that in can co-exist within the same household and community and thus the double burden of malnutrition. The relationship between nutrition and physical activity forms part of this study due to its direct link to overweight as indicated in one of the conceptual frameworks.

The results from this study are relevant to the public, the academia and the government as it reports on the prevalence of overweight, food insecurity and physical activity particularly among women and young children. We explored the importance of food security and physical activity in determining pregnancy outcomes. This knowledge is gainful to the health sector (policy) as it forms the basis for nutrition counselling during pregnancy and the need to highlight the importance of physical activity to prevent obstetric risks such as birth via caesarian section instead of normal birth.

The current study explored the use of deuterium dilution in assessing body composition as well as compare different measures of adiposity. We bring out the shortcoming of the different measure and how the measures differ in estimating overweight and the need for clear cut points for populations in Africa. This study makes recommendations towards adjusting some cut points may go a long way in surveillance by properly estimating the prevalence of overweight.

I work in a public teaching institution of higher learning in my country at the moment a school of public health and it is my moral duty to incorporate the key elements of this study in my day to day academic work. The new knowledge attained contributes immensely towards our new curriculum of sports nutrition. I have gained a lot of experience in assessment of physical activity and nutritional status and this study goes into building capacity in this area of nutrition that is not common in Kenya. I also come from a community that has fielded renowned athletes who have competed in the world marathons and my university is squarely located within the city where most of these renowned athletes call home. I work with these athletes to come up with proper nutrition plans to package and make it available to other aspiring individuals.

From a public health point of view, it is important to educate the public on the consequences of reduced physical activity in relation to health outcomes. With the results from this study and experience gained I am able to focus on the need to enhance physical activity at an early age in order to minimize the consequences associated with low or reduced physical activity. With the increasing lifestyle related ailments such as diabetes, hypertension, cancer and obstetric risks associated with overweight, nutrition education needs to be made top priority by policy makers. My role as an educator is in ensuring information is available that is relevant on importance of maintaining some form of physical activity and management of weight. In our study, alt- 
hough we did not look at nutrition education as a component we have evidence from our literature review that nutrition education is important in combating overweight by having the knowledge to make wise choices when it comes to food.

As a researcher, as I sought to have my research questions answered, instead I have arrived at more questions that are motivating me to go on in this field. From my study, there are some questions that were left unanswered and some answers have elicited more questions. There is need for an intervention to see how nutrition education and physical activity impacts on pregnancy outcomes and this is going to be the motivation for my next project.

In conclusion, this study highlights the increasing overweight and persistent undernutrition and the results hopefully will benefit the public, the academia and the government in the long-run. We propose in this study recommendation that will help in curbing the problem of overweight particularly the emphasis placed on physical activity. 


\section{Thank you!}

First and foremost I want to thank the almighty God for his grace that was sufficient and abundant for me throughout my PhD studies. I can declare that this far indeed the Lord has brought me from my humble village in Kapnyamisa, Mosoriot, Kenya to the prestigious Maastricht University in the Netherlands. I am grateful and I would not ask for a better university to do my PhD.

To my husband, my rock and the solid ground on which I stand, you are the most patient man I have ever met. You patiently watched me struggle and did not waver in your support. You made sure the children were taken care of in my absence; you also spared time to check on my extended family. Although the road was rocky and not always smooth, you never let go of my hand. We were together in all this.

Thank you to my son Calvin, for always reminding me that I was not only a PhD student, but his mother too. Nothing brought back senses into my head, than arriving home after weeks (sometimes months!!) of being away in Maastricht to hear him call out to me-Mum! Calvin, you are the reason why this PhD was accomplished!

To my daughter Nikki, you are my other PhD! You arrived in my second of PhD and I thought to myself, what I have gotten myself into!! You were definitely not a mistake! You are only two years now and you may not understand it but I will make sure you read this when you are older. Girl, you were sent to rescue me! (lyrics from Martina Mc bride's In my daughters eyes). I thank God for you. 
My promoters, DANK U WEL!!

Prof Bart van den Borne, I am grateful for your sound guidance and sound counsel. Amidst the tears and frustrations along the way, you guided me along, letting me learn from the process. You did not impose; you did not try to take over. You saw the potential in me and nurtured it. I count myself fortunate to have worked with you.

Guy Plasqui, I am forever in debt to you for your expertise, your knowledge and your willingness to share. You were the voice of reason, the reality check. You made me understand that I cannot accomplish something overnight. You taught me that life is a process and we take a day at a time. You brought in the fun side of being in school at the same time being serious.

I want to also thank my Dutch family! The Martens! Monique, Carrie, Jacqueline and Magritte, You guys are just the best! The first time I walked into Monique's house was during winter (January 2010!!!) I will never forget that day and the day after when I could not find my way home in the dark (at 5 pm!!!) Thank you for making me feel welcome in your homes, the many vlaai's we ate together, the many barbeques! Thank you Carrie for watching over Nikki and when she was here!! Thank you Davina, Louis, and Gwen for the many gifts to my children!

Thank you to my devoted friend Phyllis and your family. I say devoted because the things you did for me when I was here and away in Kenya, no words are sufficient to describe them. You were my sounding board. You listened, listened and listened more. You were the friend I needed here and the friend I will always need by my side. I treasure you and Peter, Suzie, Jim, Tess and Sly. God bless you my friend.

The entire department of Health Promotion I salute you for opening your door to International student. We came from various backgrounds and met in Maastricht to promote Health especially in the developing countries. The guys I shared an office with- Aziza, Mercy, Diep, Mutaz, Mohamed, Hans and others. Thank you for being there to distract me away from my laptop to learn more about your research, your countries and your families.

To Leon and Marja, Thank you for rooting us to Maastricht and providing us with the branches to help keep our balance. For showing us the ropes, and for making it all seem for easy. Leon, thank you for nagging me to take the bike, even when I did not feel like it especially when it was cold and windy! I tried for a couple of days but gave up. You did not only solve my computer problems, but saved my day when my hard 
drive crashed! The many times you encouraged me to take time off and just get to know Maastricht! I took your advice and I can now tell a bit of history of Maastricht. Marja, you are what every international students needs in a foreign country! You do not judge but take everyone as they are. Thank you for allowing us to walk into your office without appointment. You motivated me and will not forget the one time we had a talk in my office. Thank you for being there.

The Maastricht International Church, thank you for welcoming me with open arms into you church! To Hettie, Claire, Jenny, Jessica, Frank, Richard and all the others God bless you and let us keep the faith.

Last but not least, to my belated mum and dad, you are the two people who made my world go round! I dedicate this thesis to you both. Especially mum, you did not see it to completion but I am sure you were with me every step of the way. In memory of my Dad and mum, I don't have to say anything, you and only you understand-the unspoken words. Thank you and I love you! To my extended family, my sisters my brothers, nephews, nieces this is for you ...........

Asante sana!!!!!! 

List of Publications 


\section{Papers}

1. Keino S. Nutrition And the Millennium Development Goals A Kenyan Perspective on the Eradication of Extreme Poverty and Hunger.

SCN News March 2004

2. Keino S. Linking poverty to food insecurity and malnutrition in sub-Saharan Africa. In the book Fostering Subsistence Agriculture, Food Supplies and Health in subSaharan Africa 2007 published by Peter Lang International Academic Publishers

3. Keino S, Plasqui G \& van den Borne B. Household food insecurity access: A predictor of overweight and underweight among Kenyan women.

Published in Agriculture and Food Security 3:2 2014

4. Keino S, Plasqui G \& van den Borne B. Determinants of stunting and overweight among young children and adolescents in sub-Saharan Africa

Published in Food and Nutrition Bulletin June 32:2 2014

5. Keino S, Plasqui G \& van den Borne B. Is overweight found among the food insecure? A study of prevalence and risk factors of malnutrition among children in Narok County, Kenya.

Submitted.

6. Keino S, van den Borne B \& Plasqui G. Body composition, water turnover and physical activity in women in Narok County

Submitted.

7. Keino S, Plasqui G \& van den Borne B. Body composition, body mass index, waisthip-ratio, waist circumference and overweight among Kenyan women.

Submitted.

8. Keino S, Plasqui G \& van den Borne B. Impact of physical activity and food security on pregnancy outcomes among women in Narok County, Kenya

\section{Books}

Franz-Theo Gottwald, Susan Keino and Timothy Rotimi Fayey (eds.) 2007

Fostering Subsistence Agriculture, Food Supplies and Health in sub-Saharan Africa. 


\section{Curriculum Vitae}




\section{Curriculum Vitae}

Susan Keino was born on the $20^{\text {th }}$ October 1972 and raised in a small village in Nandi County, Kenya. She attended Aldai Girls Primary and A.I.C Girls Secondary Schools and got her high school certificate in 1991. She later joined Maseno University College, then a constituent college of Moi University and graduated with a Bachelor of Science (Home Science and Technology) degree in 1997. She was employed by Maseno University College as a graduate assistant in 1999 and she later enrolled for her master's degree (Community Nutrition and Development) at the same university and graduated in 2005. In 2007 she took up and appointment as an Assistant Lecturer at Moi University and was awarded the Nuffic Scholarship in 2010 to pursue her PhD at Maastricht University under the supervision of Prof Bart van den Borne and Guy Plasqui at the Department of Health Promotion. She completed her PhD in March 2014. She is married with two children. 